UNIVERSIDADE DE SÃO PAULO

FACULDADE DE ODONTOLOGIA DE RIBEIRAO PRETO

\begin{abstract}
AVALIAÇÃO DA INFLUÊNCIA DO ENVELHECIMENTO ARTIFICIAL ACELERADO E ARMAZENAMENTO EM FLUORFOSFATO ACIDULADO A 1,23\% NA RUGOSIDADE SUPERFICIAL E NA ALTERAÇÃO DE COR DE CERÂMICAS ODONTOLÓGICAS DE ULTRA-BAIXA FUSÃO PARA TITÂNIO COMERCIALMENTE PURO
\end{abstract}

Janisse Martinelli Borges de Oliveira 


\section{AVALIAÇÃO DA INFLUÊNCIA DO ENVELHECIMENTO ARTIFICIAL ACELERADO E ARMAZENAMENTO EM FLUORFOSFATO ACIDULADO A 1,23\% NA RUGOSIDADE SUPERFICIAL E NA ALTERAÇÃO DE COR DE CERÂMICAS ODONTOLÓGICAS DE ULTRA-BAIXA FUSÃO PARA TITÂNIO COMERCIALMENTE PURO}

\footnotetext{
Dissertação de Mestrado apresentada ao Curso de Pósgraduação da Faculdade de Odontologia de Ribeirão Preto USP para obtenção do Título de Mestre em Odontologia Área de Concentração: Reabilitação Oral.
}

Orientadora: Prof ${ }^{a}$. Dra . Maria da Glória Chiarello de Mattos 
Autorizo a reprodução e a divulgação total ou parcial deste trabalho, por qualquer meio convencional ou eletrônico para fins de estudo e pesquisa, desde que citada a fonte.

\section{FICHA CATALOGRÁFICA}

Martinelli, Janisse

Avaliação da influência do envelhecimento artificial acelerado e armazenamento em fluorfosfato acidulado a $1,23 \%$ na rugosidade superficial e na alteração de cor de cerâmicas odontológicas de ultra-baixa fusão para titânio comercialmente puro Ribeirão Preto, 2007.

90 p. : il.; $30 \mathrm{~cm}$

Dissertação de Mestrado, apresentada à Faculdade de Odontologia de Ribeirão Preto/ Universidade de São Paulo - USP. Área de concentração: Reabilitação Oral.

Orientadora: Mattos, Maria da Glória Chiarello de

1. Cerâmica Odontológica. 2. Titânio comercialmente puro. 3. Alteração de cor. 4. Envelhecimento artificial acelerado. 5. Fluorfosfato acidulado 


\section{FOLHA DE APROVAÇÃO}

\section{Janisse Martinelli Borges de Oliveira}

Avaliação da influência do envelhecimento artificial acelerado e armazenamento em fluorfosfato acidulado a 1,23\% na rugosidade superficial e na alteração de cor de cerâmicas odontológicas de ultra-baixa fusão para titânio comercialmente puro.

Tese apresentada à Comissão de Pós-Graduação da área de Reabilitação Oral da Faculdade de Odontologia de Ribeirão Preto da Universidade de São Paulo para obtenção de título de Mestre em Odontologia.

Ribeirão Preto,

\section{Banca Examinadora}

Prof (a). Dr (a).:

Instituição: Assinatura:

Prof (a). Dr (a).:

Instituição: Assinatura:

Prof (a). Dr (a).:

Instituição: Assinatura: 
“Tudo o que Jesus falou no Sermão da Montanha foi ao coração, ao sentimento. Não disse nada ao raciocínio, porque é pela inteligência que caímos. Ele não disse: Bem-aventurados os inteligentes. Chegou mesmo, certa vez, a dar graças ao Pai por ter ocultado os segredos do céu aos sábios e inteligentes. Quem cai pelo amor, o próprio motivo da queda faz com que se reerga, mas quem cai pela inteligência, não se sente caído." 


\section{DEDICO ESTE TRABALHO:}

\section{Aos meus pais Wildomar e Gislene,}

anjos celestes por quem tenho toda admiração, a quem meu amor e carinho serão eternos. Agradeço por terem despertado em mim a paixão por essa belíssima profissão. Agradeço pelo incentivo constante e exemplo que tive ao optar pela carreira acadêmica. Impossível expressar em palavras minha gratidão por terem me aceito como filha.

Aos meus irmãos Anelise e Lucius, por serem exemplos de caráter e retidão. Por sempre me incentivarem nessa carreira, pelos momentos inesquecíveis juntos, pelas lindas lembranças que o tempo jamais apagará.

\section{Ao meu querido Felipe,}

homem de alma iluminada.. Dedico a você todas minhas conquistas, toda minha vida e todo meu amor.. 


\section{AGRADECIMENTO ESPECIAL}

À Prof. ${ }^{a}$ Dr ${ }^{a}$. Maria da Glória Chiarello de Mattos, o meu sincero muito obrigada. Agradeço pelo exemplo de caráter e honestidade. Agradeço por ser sua orientada, pelo aprendizado, por sua generosidade e amizade. Agradeço pelos ótimos momentos juntas. 


\section{AGRADECIMENTOS}

À Faculdade de Odontologia de Ribeirão Preto da Universidade de São Paulo, pela acolhida durante os cursos de graduação e pós-graduação.

À Prof. ${ }^{a}$ Dr $^{a}$. Marisa Semprini, pelo apoio constante.

À Prof. ${ }^{a}{ }^{D r}$. Fernanda de Carvalho Panzeri Pires de Souza, por ter estado ao meu lado no início de minhas experiências científicas, me ensinando com exemplo e carinho os meandros da ciência estética odontológica.

Aos Prof. Dr. Ricardo Faria Ribeiro e Prof. ${ }^{a}$ Dr. $^{a}$ Renata Cristina Silveira Rodrigues Ferracioli pela presença e incentivo.

Ao coordenador da comissão de pós graduação da área de Reabilitação Oral Prof. Dr. Osvaldo Luiz Bezzon, pelo apoio científico.

À Prof. ${ }^{a}$ Dr $^{a}$. Regina Maura Fernandes, pela solicitude em compartilhar seu vasto conhecimento a respeito do assunto deste trabalho.

À Ana Paula Macedo pelos ensinamentos técnicos, científicos e estatísticos, sem os quais seria impossível o desenvolvimento deste trabalho. O meu muito obrigada.

Aos funcionários Ana Paula Xavier, Edson Volta, Luis Sérgio Soares, Paulo Sérgio Ferreira, Regiane de Cássia Tirado Damasceno, Ricardo de Souza Antunes, Odair Rosa Silva, pelo suporte técnico e auxílio na conclusão deste projeto.

Aos amigos da pós-graduação, Abílio Coppedê, Antônio Malheiros, Fabiano Gamero, Fabrício Mundim, Humberto Pinto, Ingrid Machado, Lâner Botrel, Marco Vasco, Natércia Soriani, Pâmela Mello, pelas experiências, pelo companheirismo e apoio constantes. 
Este trabalho foi realizado no Laboratório de Solda a Laser e Análise de Corrosão e no Laboratório Integrado de Pesquisa em Biocompatibilidade de Materiais (LIPEM) do Departamento de Materiais Dentários e Prótese da Faculdade de Odontologia de Ribeirão Preto da Universidade de São Paulo. 
Martinelli, J. Avaliação da influência do envelhecimento artificial acelerado $e$ armazenamento em fluorfosfato acidulado a 1,23\% na rugosidade superficial e na alteração de cor de cerâmicas odontológicas de ultra-baixa fusão para titânio comercialmente puro. 2007. 90 p. Dissertação (Mestrado) - Faculdade de Odontologia de Ribeirão Preto, Universidade de São Paulo, Ribeirão Preto.

\section{RESUMO}

O objetivo do trabalho foi avaliar a influência do envelhecimento artificial acelerado e do fluorfosfato acidulado a $1,23 \%$ sobre a rugosidade superficial e alteração de cor de duas cerâmicas odontológicas de ultra-baixa fusão para titânio (Triceram- Dentaurum, e Noritake Ti22- Noritake), livre de metal ou com subestrutura em titânio comercialmente puro (TritanDentaurum). A partir de uma matriz cilíndrica em teflon foram confeccionados, ao todo, 80 corpos-de-prova, com $15 \mathrm{~mm}$ de diâmetro e $2,5 \mathrm{~mm}$ de espessura, sendo 40 para cada cerâmica, 20 amostras livre de metal e 20 metalocerâmicas, que foram divididas em dois grupos de 10 amostras cada, sendo submetidas ao envelhecimento artificial acelerado (Sistema Acelerado de Envelhecimento para não-metálicos C-UV - Comexim Matérias Primas Ltda, São Paulo, Brasil) ou ao armazenamento em fluorfosfato acidulado a 1,23\%. A rugosidade superficial foi realizada em rugosímetro SJ - 201P (Mitutoyo, Tokyo, Japão) em dois momentos: inicial (R1) foi aquela mensurada logo após obtidos os corpos-de-prova e a rugosidade superficial final (R2) aquela obtida após o envelhecimento artificial acelerado ou armazenamento em fluorfosfato acidulado a 1,23\%. Para verificar as alterações de cor ocorridas nas cerâmicas odontológicas utilizou-se o Espectrofotômetro PCB 6807 BYK GARDNER (Columbia, Estados Unidos). Foram feitas leituras antes e após as etapas de envelhecimento artificial acelerado e armazenamento em fluorfosfato acidulado a $1,23 \%$. Os resultados médios e desvios padrão para os corpos-de-prova livre de metal com envelhecimento artificial acelerado foram: a) rugosidade superficial: Triceram antes $0,390 \pm$ 0,097, após 0,431 $\pm 0,100$; Noritake Ti 22 antes 0,299 $\pm 0,075$, após 0,312 $\pm 0,076$; b) alteração de cor: Triceram 0,28 $\pm 0,14$; Noritake Ti 22 0,33 $\pm 0,22$; e para os corpos-de-prova submetidos ao armazenamento em fluorfosfato acidulado a 1,23\% foram: a) rugosidade superficial: Triceram antes 0,325 $\pm 0,036$, após 2,199 $\pm 0,889$; Noritake Ti 22 antes 0,317 \pm 0,094 , após $2,760 \pm 0,833$; b) alteração de cor: Triceram 5,39 $\pm 1,61$; Noritake Ti 22 7,31 \pm 0,71. Para as amostras metalocerâmicas com envelhecimento artificial acelerado foram: a) rugosidade superficial: Triceram antes 0,282 $\pm 0,06$, após 0,315 $\pm 0,095$; Noritake Ti 22 antes $0,269 \pm 0,062$, após $0,290 \pm 0,075 ;$ b) alteração de cor: Triceram $0,57 \pm 0,11$; Noritake Ti 22 $0,41 \pm 0,08$; e para os corpos-de-prova submetidos ao armazenamento em fluorfosfato acidulado a $1,23 \%$ foram: a) rugosidade superficial: Triceram antes $0,137 \pm 0,026$, após 2,560 $\pm 0,377$; Noritake Ti 22 antes $0,125 \pm 0,34$, após 3,174 $\pm 0,565$; b) alteração de cor: Triceram $7,56 \pm 1,21$; Noritake Ti 22 7,69 $\pm 1,26$. Os resultados obtidos mostraram que o envelhecimento artificial acelerado simulando dez anos de uso clínico da restauração não afetou a rugosidade superficial de nenhuma das cerâmicas avaliadas, em nenhum grupo; que apenas o grupo da cerâmica Triceram com subestrutura em titânio comercialmente puro revelou valores de $\Delta \mathrm{E}$ estatisticamente maiores que os demais, revelando que $\mathrm{o}$ envelhecimento artificial acelerado influenciou a coloração desse grupo. Entretanto, a alteração de cor apresentou-se menor que um, sendo considerada clinicamente indetectável; que após o armazenamento em fluorfosfato acidulado foi observado aumento de rugosidade superficial semelhante estatisticamente para ambas as cerâmicas estudadas, tanto em amostras livres de metal quanto metalocerâmicas; que a alteração total de cor, após armazenamento em fluorfosfato acidulado, todos os grupos revelaram valores inaceitáveis clinicamente $(\Delta \mathrm{E}>$ $3,3)$. 
Martinelli, J. Evaluation of the influence of the accelerated artificial aging and storage in $1.23 \%$ acidulated phosphate fluoride over superficial roughness and color stability of two low-fusing dental ceramics to commercially pure titanium. 2007. 90 p. Dissertação (Mestrado) - Faculdade de Odontologia de Ribeirão Preto, Universidade de São Paulo, Ribeirão Preto.

\section{ABSTRACT}

The purpose of this study was to evaluate the influence of accelerated artificial aging and of $1.23 \%$ acidulated phosphate fluoride over superficial roughness and color stability of two low-fusing dental ceramics for titanium (Triceram- Dentaurum, and Noritake Ti22- Noritake), metal-free or metalceramics using commercially pure titanium (Tritan- Dentaurum). 80 cylindrical samples, with $15 \mathrm{~mm}$ of diameter and $2.5 \mathrm{~mm}$ of thickness, being 40 for each ceramic, 20 metal free and 20 metal-ceramics, which were divided into two groups of 10 samples, being submitted to the accelerated artificial aging (System Accelerated of Aging for not-metallic C-UV - Comexim Raw materials Ltda, São Paulo, Brazil) or storage in $1.23 \%$ acidulated phosphate fluoride. Superficial roughness was accomplished by roughness tester SJ - 201P (Mitutoyo, Tokyo, Japan) in two moments: initial measured after obtained the samples and final superficial roughness after the accelerated artificial aging or storage in $1.23 \%$ acidulated phosphate fluoride. Color changes were analyzed by a spectrophotometer PCB 6807 BYK GARDNER (Columbia, United States). The average results and standard deviations for the metal free over accelerated artificial aging were: a) superficial roughness: Triceram before $0.390 \pm 0.097$, after $0.431 \pm 0.100$; Noritake Ti22 before $0.299 \pm 0.075$, after $0.312 \pm 0.076$; b) color evaluation: Triceram $0.28 \pm 0.14$; Noritake Ti22 $0.33 \pm 0.22$; and for samples submitted to the storage in $1.23 \%$ acidulated phosphate fluoride were: a) superficial roughness: Triceram before $0.325 \pm 0.036$, after $2.199 \pm 0.889$; Noritake Ti22 before $0.317 \pm 0.094$, after $2.760 \pm 0.833$; b) Color evaluation: Triceram $5.39 \pm 0.61$; Noritake Ti22 $7.31 \pm 0.71$. The data were submitted to ANOVA and Duncan statistics analysis to $\mathrm{p} \leq$ .05 . The obtained results showed that the accelerated artificial aging simulating ten years of clinical use of the restoration did not affect the superficial roughness of none of the evaluated ceramics, in no group; which only the group of the Triceram with substructure in commercially pure titanium revealed values statistically greater than the rest, revealing that the accelerated artificial aging influenced the color of this group. However, the values of color alteration was smaller than 1, being considered clinically acceptable ; which after the storage in $1.23 \%$ acidulated phosphate fluoride was observed increased values of superficial roughness with significant difference between both studied ceramics, as in metal-free samples as in metal-ceramics; which the color alteration, after storage in $1.23 \%$ acidulated phosphate fluoride, revealed to all the groups evaluated unacceptable values clinically $(\Delta \mathrm{E}$ $>3.3)$. 


\section{SUMÁRIO}

\section{RESUMO}

ABSTRACT

1 INTRODUÇÃ

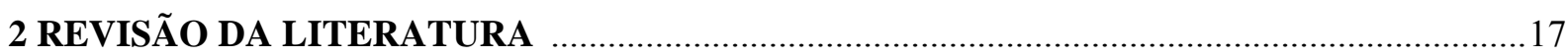

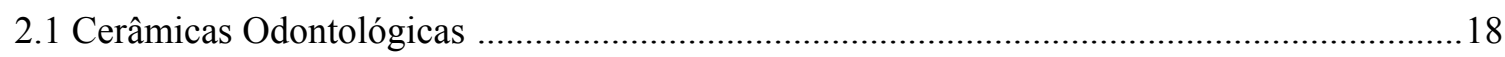

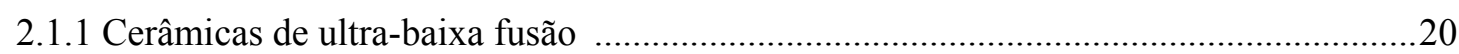

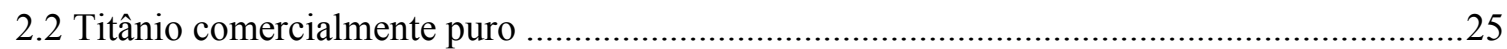

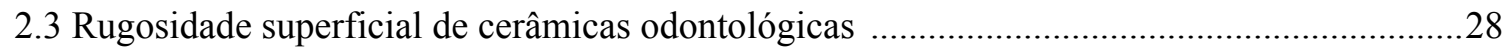

2.4 Alteração de cor em cerâmicas odontológicas .........................................................................

2.5 Envelhecimento artificial acelerado em cerâmicas odontológicas ..........................................37

2.6 Fluorfosfato acidulado e cerâmicas odontológicas ....................................................................38

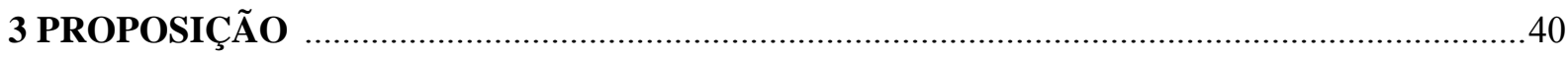

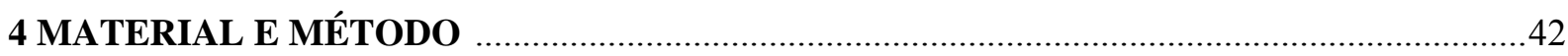

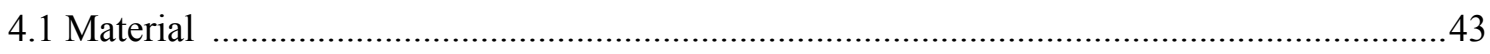

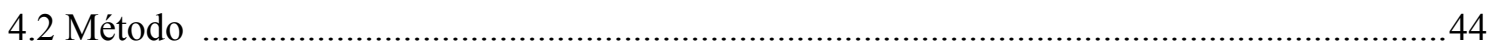

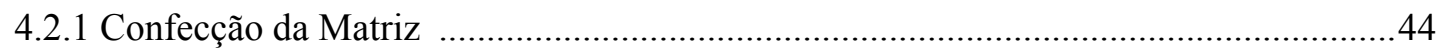

4.2.2 Confecção dos corpos-de-prova livres de metal ...........................................................45

4.2.3 Confecção das infra-estruturas metálicas .......................................................................47

4.2.4 Confecção dos corpos-de-prova metalocerâmicos .........................................................50

4.2.5 Acabamento dos corpos-de-prova …………...........................................................

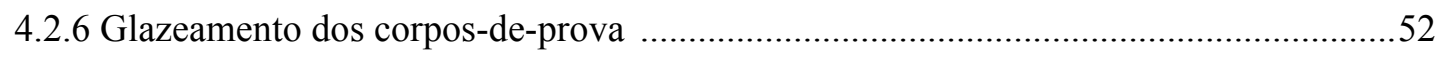

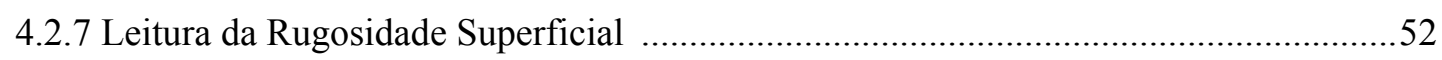

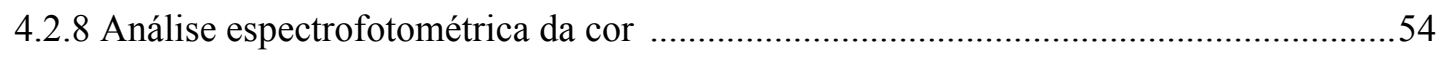

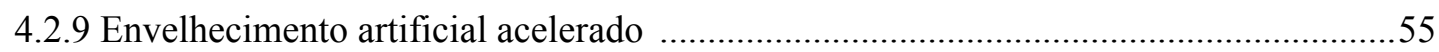

4.2.10 Armazenamento em fluorfosfato acidulado (1,23\%) ..............................................57

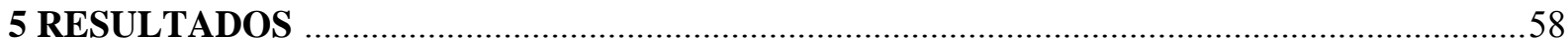

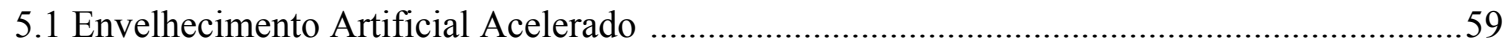

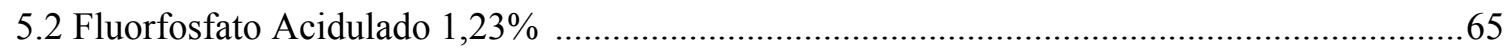

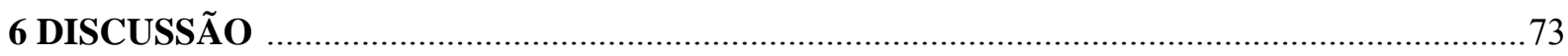

6.1 Envelhecimento Artificial Acelerado - Rugosidade Superficial e Alteração de Cor ................75

6. 2 Fluorfosfato Acidulado 1,23\% - Rugosidade Superficial e Alteração de Cor ........................79

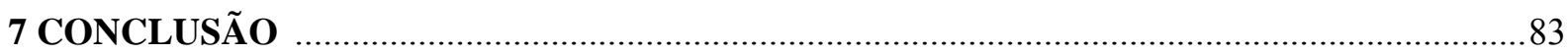

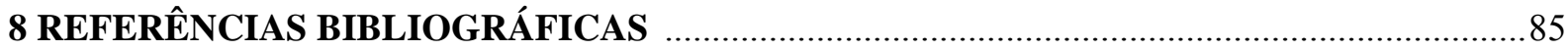


INTRODUÇÃO 


\section{INTRODUÇÃO}

A odontologia, desde seu princípio, teve como uma das principais preocupações a busca pelo material restaurador ideal, que reproduzisse e restabelecesse a função do elemento dental perdido, que fosse biocompatível, apresentasse boa adaptação marginal, adequada resistência à abrasão, e principalmente que reproduzisse a cor natural e as características ópticas e estruturais dos dentes naturais.

A percepção do fenômeno de opalescência, fluorescência e translucidez encontradas nos dentes naturais, e a busca por sua reprodutibilidade na cerâmica, deram uma nova visão estética em Odontologia restauradora, pela capacidade de reprodução das mesmas características encontradas nos dentes naturais no material restaurador (MEZZOMO; SUSUKI, 2006).

Com essa finalidade, novos materiais restauradores estéticos têm sido introduzidos no mercado odontológico, no entanto, a cerâmica ainda continua sendo o material estético de escolha. A opção por restaurações cerâmicas, em suas várias formas, é baseada em sua excelente biocompatibilidade, resistência, lisura superficial e excelente estética (CRAIG; POWERS, 2004). Restaurações metalocerâmicas são as mais efetivamente utilizadas na prática clínica, combinando a qualidade estética da cerâmica à resistência do metal, que proporciona o sucesso desse elemento protético na cavidade oral (RAPTIS et al., 2006; KOURTIS et al., 2004), comprovado por diversos estudos clínicos (FRADEANI, 1998; PEUMANS al., 2000). Contudo, a grande desvantagem desse tipo de restauração é o aumento da reflexão da luz atribuído à camada de cerâmica opaca que é aplicada para mascarar a subestrutura metálica. A luz sobre a dentição natural é refletida e dispersa por toda a superfície do elemento dental, enquanto que a restauração metalocerâmica não apresenta essas propriedades, apenas dispersando e refletindo a luz que incide sobre a cerâmica de corpo. 
Como resultado, restaurações metalocerâmicas frequentemente parecem mais brilhantes na cavidade oral (RAPTIS et al.; 2006).

O uso das cerâmicas odontológicas vem crescendo na clínica diária desde a década de 1960, quando houve grande desenvolvimento tecnológico a respeito desses materiais. Nessa época, as restaurações metalocerâmicas eram confeccionadas em ouro ou ligas de ouro, contudo, o significante aumento no preço desse metal na década de 1970 impulsionou o estudo e desenvolvimento científico de novas tecnologias para confecção de restaurações metalocerâmicas, introduzindo no mercado, metais alternativos para essas restaurações, como o paládio e outras ligas metálicas (ANUSAVICE,2003).

Além disso, vários foram os registros encontrados na literatura em relação às reações adversas de contato apresentadas por pacientes a componentes metálicos das ligas odontológicas (YANG et al., 1992; LANG, et al., 1985; BRUZE et al., 1994; BJÓRKNER, et al., 1994).

Com o advento do uso do titânio puro nos implantes osseointegrados, seu emprego na clínica odontológica teve um aumento considerável. Esse metal possui características bastante atrativas à odontologia, como elevada biocompatibilidade, menor custo quando comparado ao ouro e excelentes propriedades físicas e mecânicas (ZINELIS et al. 2003). O titânio é o quarto elemento metálico mais abundante da natureza, compondo aproximadamente $0,6 \%$ da crosta terrestre. Seu nome foi dado por um químico alemão chamado Klaproth em 1975, fazendo uma equivalência entre os atributos dos Titans da mitologia grega e às propriedades deste elemento metálico (BERGMAN, 1995). O titânio comercialmente puro e ligas de titânio apresentam excelentes características como: baixo peso específico e densidade, alta resistência à corrosão, baixo módulo de elasticidade, excelente biocompatibilidade, baixa condutibilidade térmica, boa soldagem elétrica e fácil acabamento por diferentes processos mecânicos e eletroquímicos. Assim, o material se tornou desejável 
para o uso em procedimentos dentais como implantes e restaurações fundidas (LAUTENSCHLAGER; MONAGHAN, 1993; BERGMAN, 1995). Além disso, o titânio em relação a outros metais e ligas odontológicas possui baixo grau de radiopacidade. Deste modo, é possível realizar radiografias para identificação de eventuais porosidades no interior de estruturas metálicas, para que peças defeituosas sejam descartadas; e em próteses parciais fixas, a identificação de cáries recorrentes em dentes pilares pode ser facilmente alcançada em exames radiográficos de rotina, dificultando a perda precoce dos elementos de suporte (WANG; BOYLE, 1993). Não obstante, o titânio possui alguns inconvenientes como alta reatividade com gases como o oxigênio e, devido à sua baixa densidade, problemas com a fundição e interação com o material de revestimento (LAUTENSCHLAGER; MONAGHAN, 1993; BERGMAN, 1995).

O titânio requer um sistema cerâmico especial, uma vez que sua exposição a temperaturas acima de $882^{\circ} \mathrm{C}$ induz a uma reação entre sua superfície e o oxigênio e o nitrogênio, ocorrendo alteração de suas propriedades, levando à formação de uma espessa camada de óxidos superficial e também de poros em sua estrutura. Durante a fundição, a superfície do titânio reage tanto com a atmosfera quanto com as paredes do revestimento, formando uma camada $\alpha$ heterogênea frágil, porosa, contendo tanto elementos do revestimento como do titânio, sendo incompatível com a cerâmica. Assim, fez-se necessário o desenvolvimento de cerâmicas apropriadas para o uso com titânio, sendo desenvolvidas as cerâmicas de ultra-baixa fusão.

As cerâmicas de ultra-baixa fusão apresentam temperatura máxima de sinterização inferior a $850^{\circ} \mathrm{C}$, prevenindo o excesso de formação de óxidos na superfície do titânio (KNABE; HOFFMEISTER, 1998). Essas cerâmicas possuem coeficiente de expansão térmico próximo ao do titânio (ATSÜ; BERKSUN, 2000) e apresentam menor resistência à abrasão que cerâmicas feldspáticas convencionais (DERAND; VEREBY, 1999). 
Diferentes produtos usados na cavidade oral possuem inúmeras substâncias que podem influenciar no estado natural do titânio, dentre elas, pode-se citar como produto muito comum encontrado no dia-a-dia, o flúor. Tais possíveis alterações podem ocasionar efeitos não previstos e desejáveis

O elemento flúor, podendo estar presente principalmente nos enxaguatórios bucais e dentifrícios, demonstra-se como importante elemento a ser considerado. Fatores como corrosão e desgaste da superfície do titânio e dos materiais usados na cavidade oral podem ser direta e indiretamente influenciados pelo uso de produtos contendo flúor em diferentes e variadas concentrações.

Soluções fluoretadas são rotineiramente utilizadas na odontologia, sendo indicadas para prevenção de cárie (BHASKAR, 1976), em tratamento de pacientes que apresentam diminuição do fluxo salivar por irradiação, medicação, síndrome de Sjogren ou cirurgia. Ainda, estudos demonstram que seu uso diário está relacionado à paralisação de lesões cariosas já existentes (DREIZEN, DALY, DRANE; 1977).

Devido à necessidade de maior documentação científica sobre as cerâmicas de ultra-baixa fusão, este estudo tem por objetivo avaliar a influência do envelhecimento artificial acelerado e do fluorfosfato acidulado a 1,23\% sobre a cor e a rugosidade superficial de cerâmicas de ultra-baixa fusão, empregadas em restaurações livres de metal e metalocerâmicas com subestrutura em titânio comercialmente puro. 
REVISÃO DA LITERATURA 


\section{REVISÃO DA LITERATURA}

\subsection{Cerâmicas Odontológicas}

A cerâmica dental é o material estético mais utilizado para repor ausências dentais. A primeira coroa totalmente estética foi confeccionada a partir de uma cerâmica feldspática sinterizada sobre uma lamina de platina, apresentado baixa resistência, com indicações clínicas limitadas (LAND, 1903). Entretanto, apesar destas limitações, foi durante décadas a restauração mais estética que a odontologia podia oferecer (PORTO, 2007).

A composição básica da porcelana feldspática (sílica, caulim e feldspato) foi descrita em 1932 por Felcher. O autor relatou também em seu estudo diversas dificuldades técnicas encontradas na manipulação de material como problemas de sinterização e excessiva formação de porosidades.

Antes de 1938 as cerâmicas dentais se apresentavam em colorações relativamente opacas e brancas. A partir de então, Elias Wildeman desenvolveu um material mais translúcido que se revelasse coloração mais próxima ao dos dentes naturais (CLARK, 1939).

Em 1956, Brecker afirmou que, apesar de satisfazerem os anseios estéticos dos pacientes até aquela época, as próteses metaloplásticas apresentavam importantes limitações como descoloração e mudanças de forma devido à abrasão. Essas características impulsionaram os pesquisadores a desenvolver novas técnicas e novos materiais. Ligas e cerâmicas foram então sendo estudadas no intuito de resolver os problemas causados pela fratura das restaurações em cerâmicas pura e a descoloração dos plásticos em coroas veneer, solucionando a exigência estética dos pacientes. Desta maneira, os sistemas cerâmicos assumiram seu lugar de direito na Odontologia Restauradora. Segundo o autor, a cerâmica 
poderia ser fundida sobre vários tipos de metais, como ligas de platina e irídio, ligas de paládio e ligas de ouro. As ligas de ouro para metalocerâmica foram consideradas como as melhores em termos de união metal/cerâmica, devido ao coeficiente de expansão térmica da liga ser compatível com o sistema cerâmico, não ocorrendo tensões que originariam trincas na cerâmica. Adicionalmente, a aplicação de um agente umectante e uma fina camada de cerâmica opaca produziria uma restauração esteticamente aceitável e com excelente adaptação marginal.

Ainda nos anos 50, uma nova técnica para sinterização de cerâmicas sob vácuo foi desenvolvida, marcando a historia quanto ao aprimoramento das cerâmicas, tanto em relação à estética quanto à resistência. Esse processo de sinterização reduz o número e o tamanho das bolhas de ar existentes entre as partículas de cerâmica (Vines e Semmelman em 1957).

Hodson, em 1959, estudando a respeito da fragilidade das cerâmicas usadas em odontologia, relatou que os materiais com boa resistência mecânica são geralmente cristalinos na sua estrutura e opacos. As cerâmicas dentais, que por sua vez são translúcidas o suficiente para simular o esmalte dental, são constituídas basicamente por vidro em sua estrutura e consequentemente possuem as propriedades físicas mais compatíveis com o vidro, explicando a dificuldade para encontrar uma formulação que apresente adequadas propriedades físicas e estéticas.

Em 1961, Bassman realizou avaliações de próteses metalocerâmicas por um período de três anos. Os resultados confirmaram que a cerâmica fundida sobre o ouro foi o maior desenvolvimento das restaurações dentais da época. O autor ressalva a necessidade de realização de testes laboratoriais para avaliar a resistência da união metalocerâmica, o que serviria para esclarecer qualquer dúvida sobre a utilização destes materiais em restaurações 
dentais. Ressalta ainda que deveria ser aplicada corretamente uma camada de cerâmica opaca para otimizar o desempenho mecânico e estético.

A estrutura subjacente das restaurações metalocerâmicas prejudicava a estética da peça, uma vez que diminuía a transmissão de luz através da porcelana. Buscando desenvolver uma cerâmica que fosse mais resistente sem prejudicar a estética, Mc Lean (1996) incluiu a alumina em sua composição. A cerâmica que foi obtida se mostrava $80 \%$ mais resistente, contudo, tinha o inconveniente de ser acentuadamente antiestética, sendo, portanto, empregada para a confecção de núcleo cerâmico, que posteriormente seria recoberto por uma cerâmica feldspática, melhorando a estética do trabalho.

Em 1975, Simonpaoli definiu cerâmicas odontológicas como vidros transparentes ou opacos que recobrem por fusão os metais com um propósito estético ou funcional. A cerâmica ideal deve reunir um conjunto de qualidades como adesão ao metal sobre o qual é fundida e conservação dessa aderência; resistência aos choques e às deformações das peças às quais está aplicada; resistência a agentes físicos e químicos; tolerância dos tecidos orais; capacidade de reprodução de detalhes anatômicos; técnicas de aplicação simples; estética aceitável e preço acessível.

Na década seguinte, Anusavice et al. (1985), relataram que diferenças acentuadas nos coeficientes de expansão térmica entre metal e cerâmica podem provocar distorção da estrutura durante a cocção da cerâmica.

\subsubsection{Cerâmicas de ultra-baixa fusão}

Segundo Togaya et al. (1983), o baixo coeficiente de expansão térmica do titânio $\left(9,4 \times 10^{-6}{ }^{\circ} \mathrm{C}\right)$ era o fator responsável por sua incompatibilidade com as cerâmicas convencionais que apresentavam coeficiente de expansão térmica muito maior. Esse fato 
causava diminuição na resistência de união devido ao acúmulo de tensões na interface metal/ cerâmica. Então, para que fosse possível obter adequada resistência de união era necessário reduzir o coeficiente de expansão térmica do titânio. O uso de temperaturas de queima mais baixas também mostrou prevenir o excesso de oxidação do substrato metálico de Ti cp, o que favoreceu a obtenção de adequada resistência de união e ainda limitava a deformação do coping durante a queima da cerâmica, já que o titânio possui temperatura de fusão de $1670{ }^{\circ} \mathrm{C}$.

Menis et al. (1986) realizaram um estudo em que tentaram promover a união de uma cerâmica de baixa fusão ao titânio puro fundido. Os autores utilizaram três cerâmicas experimentais, com temperatura de queima de $800^{\circ} \mathrm{C}$. A resistência de união foi comparável ao grupo controle ( $\mathrm{Ni}-\mathrm{Cr}$ e cerâmica convencional) e pôde ser observado que a fratura ocorreu na interface óxido-metal.

Analisando as propriedades das cerâmicas de baixa fusão, Esquivel et al., em 1995, compararam a cor de duas cerâmicas especialmente formuladas par titânio: Procera e Duceratin; e uma cerâmica feldspática convencional de baixa fusão Vita VMK 68. As amostras livres-de-metal possuindo $20 \mathrm{~mm}$ de diâmetro e $2 \mathrm{~mm}$ de espessura foram obtidas de acordo com as instruções de cada fabricante. Os autores dividiram os corpos-de-prova de maneira que havia amostras glazeadas e amostras que tiveram o glaze removido submetendoas ou à imersão em azul de metileno por 24 horas, ou à imersão em água destilada pelo mesmo período de tempo. Os pesquisadores realizaram a leitura da cor em espectrofotômetro, utilizando o $\Delta \mathrm{E}$ (diferença entre a cor das amostras armazenadas em azul de metileno e àquelas armazenadas em água destilada) para análise estatística. Ao final do trabalho foi possível concluir que, quando imersas em azul de metileno, as amostras das duas cerâmicas avaliadas que tiveram o glaze removido, exibiram alterações de cor, com manchamento visível. Já as amostras glazeadas, das duas cerâmicas, se mostraram resistentes ao azul de metileno. 
No ano seguinte, White et al. (1996), realizaram estudo em que investigaram a força de resistência da cerâmica Ti-Ceram fundida sobre titânio c.p. com o propósito de determinar o modo de falhas e analisar a interface titânio/cerâmica. Foram observados valores menores que $26 \mathrm{MPa}$ para a força de adesão entre a cerâmica e o titânio. Relataram que a força entre a camada cerâmica e o titânio foi limitada pela tensão coesiva ou compressiva da cerâmica e não pela adesividade interfacial entre o titânio e a cerâmica. As falhas ocorreram ao se atingirem valores menores do que os esperados para a resistência de união entre cerâmica e titânio. A microscopia eletrônica de varredura demonstrou que a adesividade foi dependente da espessura da camada de óxidos formada, sendo que as falhas sempre ocorreram entre a camada de óxido de titânio e o titânio.

Em 1999, Derand e Vereby avaliaram a resistência à abrasão, dureza e rugosidade superficial de cerâmicas odontológicas de diferentes pontos de fusão. Após a realização dos ensaios e análise estatística os autores concluíram que a cerâmica Finesse (ultra-baixa fusão, $760^{\circ} \mathrm{C}$ ) apresentou os maiores valores de perda de massa. Quanto à dureza superficial, as cerâmicas Finesse e Vita Alpha apresentaram os menores valores. Já para rugosidade superficial Finesse, Vita Omega e Procera apresentaram os valores mais baixos. Os autores concluíram que Finesse (cerâmica de ultra-baixa fusão) exibiu os menores valores de resistência à abrasão em relação às demais cerâmicas, sendo ressaltada pelos autores sua utilização em detrimento das demais cerâmicas analisadas, uma vantagem clínica.

Reyes et al., em 2001, estudando o efeito da modificação dos tratamentos superficiais na adesividade da cerâmica ao titânio afirmaram que em estudos prévios verificaram que o titânio era incompatível com cerâmicas dentais convencionais devido à fraca adesividade e alta reatividade do titânio e que a respeito do desenvolvimento de cerâmicas de baixa fusão para titânio, pesquisas anteriores demonstraram que o prétratamento com jateamento, previamente à aplicação da cerâmica leva ao enfraquecimento da 
força de adesão entre cerâmica e metal. Então, procuraram alternativas ao tratamento superficial do substrato de titânio antes da aplicação da cerâmica. Para tal, utilizaram ácido hidrofluorídrico ou jateamento e compararam com o grupo controle que não recebeu tratamento nenhum. Os autores concluíram que a força de adesão do sistema cerâmica-titânio com o tratamento superficial com acido hidrofluorídrico obteve resultados comparáveis ao do sistema liga metálica e cerâmica convencional.

Ainda em 2001, Cai et al. também estudaram os efeitos de tratamentos superficiais na adesividade da cerâmica ao titânio. Confeccionaram corpos-de-prova em que aplicaram jateamento com óxido de alumínio e imergiram as amostras em diferentes soluções, previamente à aplicação da cerâmica de ultra-baixa fusão (Vita- Titankeramik). As amostras foram então analisadas por difração de Rx e microscopia eletrônica de varredura e os perfis de dureza foram determinados. A adesão da cerâmica ao titânio foi determinada com auxílio do teste de flexão biaxial e a fração dessa área de aderência foi analisada pelo difrator de Rx. Baseados nos resultados encontrados, os autores concluíram que a adesividade da cerâmica ao titânio pode ser aumentada pelo uso de banhos ácidos precedidos por banhos cáusticos para tratamento de superfície.

Conti, em 2002, realizou estudo para caracterizar química e metalograficamente o titânio c.p. antes e após a fundição e analisou a interfaces entre este metal e as cerâmicas Vitatitankeramik, Triceram e Noritake Ti22, utilizando microscopia eletrônica de varredura (MEV), mapeamento elementar e dilatometria. Foram obtidas 35 placas de titânio c.p. medindo $25 \times 3 \times 1 \mathrm{~mm}$. Cinco amostras foram empregadas para análise química e metalográfica e as 30 restantes, utilizadas para aplicação das porcelanas, divididas em 3 grupos de 10 placas cada. Seguiu-se a recomendação do fabricante quanto ao tratamento do metal e aplicação e cocção das cerâmicas. As amostras foram lixadas até que houvesse a exposição da interface, preparadas para análise por MEV. Para o ensaio de dilatometria foram 
confeccionadas duas amostras de titânio cp. e 2 para cada sistema de porcelanas em forma de cilindro e soldadas a um termopar de cromel-alumel para medida da temperatura dos ensaios, verificando a curva de expansão térmica e a compatibilidade entre os conjuntos metalocerâmicos. Pelos resultados da análise química e das imagens obtidas por microscopia, o autor concluiu que o titânio comercialmente puro após fundição apresenta condições físicoquímicas adequadas para receber a aplicação da cerâmica. Dos resultados de MEV, observouse que todos os sistemas apresentaram integridade nas interfaces titânio/bonder, livre de fendas ou poros, com um bom contato entre a cerâmica e o metal, confirmado pelas imagens do mapeamento elementar, sugerindo adequada interação entre esses materiais. Os coeficientes de expansão térmica do titânio comercialmente puro e das três cerâmicas utilizadas apresentaram compatibilidade, confirmando suas associações em restaurações metalocerâmicas.

Devido à elevada oxidação natural do titânio em altas temperaturas, e a formação de elevada espessura da camada de óxido em sua superfície, que prejudica a adesividade da porcelana ao titânio, Al Hussaini et al. (2005) desenvolveram um trabalho sobre o efeito do agente de união metalocerâmico. Os autores variaram os tratamentos de superfície do titânio comercialmente puro utilizando jateamento com partículas abrasivas e acido hidroclorídrico, objetivando avaliar a força de adesão da cerâmica de ultra-baixa fusão com o titânio comercialmente puro. Amostras em titânio cp. $(25 \mathrm{x} 3 \mathrm{x} \quad 0,5 \mathrm{~mm})$ foram confeccionadas e divididas em grupos, sendo que o primeiro grupo não recebeu nenhum tratamento superficial, o segundo foi submetido ao jateamento com partículas abrasivas e o terceiro grupo foi tratado com ácido hidroclorídrico. Metade das amostras recebeu tratamento com agente de união previamente à aplicação da cerâmica Noritake Ti22 e metade não. Os corpos-de-prova foram submetidos ao ensaio de flexão de três pontos em uma máquina universal de ensaios e a interface titânio/porcelana foi submetida à análise em microscopia 
eletrônica de varredura. O resultado do teste de flexão demonstrou que o grupo que recebeu tratamento superficial com jateamento de partículas abrasivas seguido da aplicação do agente de união obtive os maiores valores de força de adesão, seguido pelo grupo que recebeu apenas tratamento superficial com jateamento de partículas abrasivas, seguido pelo grupo que apenas recebeu aplicação do agente de união. As superfícies que foram tratadas com ácido hidroclorídrico obtiveram os piores valores, demonstrando que não beneficiaram a adesão entre cerâmica/titânio. As fotomicrografias das superfícies do substrato metálico após a fratura da cerâmica, demonstraram porcelana residual na superfície do metal em todos os grupos. Os pesquisadores concluíram que os tratamentos de superfície utilizando apenas jateamento com partículas abrasivas ou apenas agente de união, promovem adequada força de união entre o titânio comercialmente puro e a porcelana de ultra-baixa fusão. Ressaltam ainda que as superfícies tratadas com a combinação de jateamento com partículas abrasivas seguido de aplicação do agente de união, mostraram aumento nos valores de força de adesão entre o titânio e a cerâmica.

\subsection{Titânio comercialmente puro}

Na década de 70 o custo do ouro começou a aumentar e os profissionais, que utilizavam esse elemento como principal para as ligas odontológicas, se preocuparam. Este fato marcou o início do incremento das pesquisas sobre as ligas não-áureas ou semi-nobres para restaurações dentais. Provavelmente as primeiras substituições tenham ocorrido justamente para os trabalhos com cerâmica aplicada sobre ligas metálicas, devido ao custo das ligas à base de ouro para esse fim serem maiores do que o das ligas áureas para outros tipos de restaurações. 
Segundo Gegel e Hoch (1973), o titânio foi descoberto em 1795 por Klaproth, um químico alemão. Entretanto o processo metalúrgico para a produção comercial do titânio puro foi desenvolvido por Wilhelm Kroll. Primeiro o dióxido de titânio era aquecido à temperatura de $500^{\circ} \mathrm{C}$, em presença de gás clorídrico, obtendo o tetracloreto de titânio mais cloro, cloridrato de ferro e outras impurezas. Adicionava-se cobre a esta mistura obtendo somente o tetracloreto de titânio, que posteriormente era adicionado ao magnésio e ao titânio metálico. A produção em grande escala do Ti c.p. com finalidade de construir estruturas mais leves e resistentes para a indústria aeroespacial só foi possível graças a este método idealizado por Kroll.

Em 1980, Ida et al. descreveram dificuldades no uso do titânio com finalidade protética. Em altas temperaturas o titânio apresentava alta reatividade, combinando-se com elementos gasosos presentes ao seu redor durante a fundição, o que tornava impossível sua fundição pelos métodos tradicionais. Outro problema era o baixo peso específico da massa fundida, fato que inabilitava a injeção do mesmo no molde de revestimento pelas técnicas convencionais de centrifugação. Na tentativa de solucionar esses inconvenientes os autores desenvolveram uma máquina de fundição denominada "Castmatic", que apresentava duas câmaras: uma superior, onde se realizava a fundição do titânio através de um sistema de arco voltaico, e outra inferior, onde era posicionado o molde de revestimento, sendo que as duas câmaras se comunicavam por meio de uma abertura. No momento da fundição, a câmara superior era preenchida com um gás inerte (argônio) para prevenir a contaminação da liga, ao passo que na câmara inferior criava-se vácuo, com a intenção de sugar a massa fundida para o interior do molde de revestimento.

Segundo Adell et al. (1981), o titânio era conhecido como material biocompatível desde a década de 1940, em estudos realizados com ossos de animais para verificar a reação desencadeada por diversos tipos de implantes metálicos. Em meados da 
década de 60 foi percebido um grande sucesso dos implantes osseointegrados confeccionados em titânio, que se confirmou com estudos de longo prazo. O titânio tornou-se uma opção na substituição de ligas à base de berílio e níquel devido a sua biocompatibilidade, sendo desenvolvidas a partir daí técnicas de fundição para a obtenção de artefatos protéticos.

Em 1982, Ida et al. relataram que o titânio durante sua injeção no molde de revestimento também reagia com a superfície do mesmo, formando uma grossa camada de oxidação denominada "alfa-case". Pretendendo diminuir a formação desta camada, os autores desenvolveram um novo revestimento para uso com titânio e suas ligas, à base de óxido de magnésio, tornando possíveis as aplicações clínicas do metal para a confecção de próteses fixas e removíveis.

Kasemo, em 1983, comentando sobre a biocompatibilidade do titânio relatou que a maioria dos metais quando expostos a atmosfera forma uma camada de óxidos. $\mathrm{O}$ titânio puro teoricamente poderia formar vários óxidos: $\mathrm{TiO}, \mathrm{TiO}_{2}$ e $\mathrm{TiO}_{3}$. Destes o $\mathrm{TiO}_{2}$ era o mais estável e mais comumente formado. Esses óxidos formavam-se espontaneamente em contato com o ar, sendo que em um milésimo de segundo podia-se encontrar uma camada de cerca de 10 ângstrons de espessura. Esta camada de óxidos, denominada passivadora é que conferiria ao titânio grande biocompatibilidade e ótima resistência à corrosão.

Donachie em 1988 afirmou que o titânio apresenta uma camada de oxidação extremamente aderida ao corpo do metal, e comentou sobre os procedimentos mais freqüentes para a remoção dessa camada de óxidos. Segundo o autor, tratamentos superficiais do titânio comercialmente puro como o jateamento com óxido de alumínio, seguido de aplicações de soluções ácidas, são bastante utilizados. Soluções aquosas de ácido nítrico também se mostraram efetivas na finalização do tratamento superficial do titânio comercialmente puro, demonstrando elevada habilidade na remoção do excesso da camada de óxidos. 
Wolf et al., em 1998, compararam a qualidade das margens de coroas inlays $e$ onlyas em titânio e em ligas de ouro. Cinqüenta e cinco pacientes receberam noventa e nove coroas de titânio confeccionadas em máquina de fundição por vácuo-pressão, e cinqüenta e seis pacientes receberam noventa e seis coroas de liga áurea. Duas semanas após a inserção das coroas, a integridade marginal foi avaliada pela técnica da réplica. As fendas marginais foram examinadas sob microscopia eletrônica de varredura. Os resultados demonstraram que a adaptação foi melhor nas coroas de ligas áureas do que nas de titânio; entretanto, o desajuste marginal das coroas de titânio está dentro do padrão clinicamente aceitável. As medidas encontradas foram $62 \pm 18 \mu \mathrm{m}$ para as ligas áureas e $72 \pm 18 \mu \mathrm{m}$ para as de titânio.

Em 2005, Liu et al. estudaram a interface titânio fundido/porcelana após diferentes tratamentos de superfície. O estudo foi feito para observar a topografia e difusão dos elementos titânio e silício, entre outros, na região da interface titânio/porcelana, tratada por diferentes métodos. A porcelana Ti Bond foi aplicada sobre titânio comercialmente puro fundido com diferentes métodos de pré-tratamento. A topografia e a difusão iônica dos elementos na interface titânio/porcelana foi analisada em microscopia eletrônica de varredura e microanálise em sonda eletrônica. Os resultados demonstraram rachaduras e descamações nos grupos de pré-oxidação de $500^{\circ} \mathrm{C}$ e $600^{\circ} \mathrm{C}$. Nas imagens geradas pela microanálise em sonda eletrônica, a distribuição do titânio pela interface decresceu da superfície do titânio para a porcelana, enquanto que a distribuição do silício foi oposta. Os autores concluíram que as rachaduras e descamações sugerem uma região de fragilidade na camada $\alpha$-titânio.

\subsection{Rugosidade Superficial de Cerâmicas Odontológicas}

Em 1994, Jagger e Harrison avaliaram a abrasão de amostras cerâmicas glazeadas, polidas, e não glazeadas contra a superfície antagonista de esmalte humano, 
utilizando uma máquina que simulava o ciclo mastigatório. Após análise dos dados, os autores concluíram que a quantidade de abrasão sofrida pelas amostras em esmalte foi menor quando os corpos-de-prova antagonistas eram de cerâmica glazeada e polida, e maior quanto à amostra antagonista era de cerâmica não glazeada, revelando que a lisura superficial das amostras influencia consideravelmente a abrasão.

Wright et al. (2004) compararam a rugosidade superficial de uma cerâmica odontológica de ultra-baixa fusão (Finesse), confeccionada em forma de discos, submetida a 3 diferentes sistemas de polimento. Uma superfície dos discos foi autoglazeada e considerada como controle. A outra superfície foi polida utilizando 1 dos 3 kits para polimento de porcelana (Axis Dental, Jelenko e Brasseler). A superfície de cada disco cerâmico foi avaliada quantitativamente por um rugosímetro e qualitativamente utilizando microscopia eletrônica de varredura (MEV). A diferença da Ra (rugosidade superficial média) de cada espécime foi determinada pela subtração dos valores encontrados na superfície polida e na superfície autoglazeada, e submetida à análise estatística. Ao final do estudo os autores concluíram que as superfícies que receberam os três sistemas de polimento se mostraram mais lisas que aquelas autoglazeadas, e o sistema Axis proporcionou superfícies mais lisas que os sistemas Brasseler e Jelenko.

Em 2005, Demirel et al. avaliaram a rugosidade superficial de uma cerâmica prensável (IPS Empress). Os autores variaram o glaze, de maneira que as amostras recebiam um ou dois glazes. Ainda, foi aplicado fluorfosfato acidulado $(1,23 \%)$ na superfície dos discos cerâmicos por 32 minutos, simulando dois anos de terapia em pacientes com alto risco de cárie. A superfície desses discos foi avaliada por microscopia de força atômica e após análise estatística os autores encontraram que após aplicação de fluorfosfato acidulado a 1,23\% houve aumento significativo de rugosidade superficial, tanto para os discos com autoglaze, quanto para aqueles que receberam glaze extrínseco. 
A fim de avaliar a rugosidade superficial das cerâmicas odontológicas IPS Empress 2 e In-Ceram, Al-Wahadni (2006) confeccionou amostras livres de metal que foram submetidas a diferentes tratamentos: glazeamento, acabamento e polimento com pontas e discos apropriados, e não glazeamento. $\mathrm{O}$ autor tomou as medidas de rugosidade superficial em rugosímetro, submetendo os valores encontrados à análise estatística. Independente da cerâmica analisada, o autor ressalta que todo ajuste clínico de restaurações em cerâmica deve ser seguido de novo glazeamento da peça ou acabamento com discos apropriados, seguido de polimento com pasta diamantada.

Ainda em 2006, Bottino et al. avaliaram a hipótese de que o acabamento e polimento da superfície cerâmica produzem rugosidade superficial semelhante à superfície cerâmica glazeada. Para tanto, foram confeccionados corpos-de-prova da cerâmica Vitadur Alpha, sendo todos glazeados e divididos em grupos, recebendo diferentes tratamentos superficiais: apenas glazeamento; glazeamento seguido de abrasão com ponta diamantada; glazeamento, abrasão com ponta diamantada e em seguida com borracha abrasiva; glazeamento, abrasão com ponta diamantada, polimento com borracha abrasiva e em seguida polimento com disco de feltro e pasta diamantada; glazeamento, abrasão com ponta diamantada, polimento com borracha abrasiva e em seguida polimento com disco de feltro e pasta diamantada de baixa granulação. Foi feita microscopia eletrônica de varredura (MEV) na superfície das amostras e a leitura de rugosidade superficial (Ra) foi realizada em rugosímetro. Os valores de Ra obtidos foram submetidos à análise estatística, que permitiu aos autores concluir que apenas o último método de polimento proporcionou à cerâmica lisura superficial semelhante estatisticamente àquela obtida quando do glazeamento. Os pesquisadores ressaltam a necessidade de sempre, após um ajuste clínico de uma restauração cerâmica, se realizar o polimento superficial, garantindo assim que sua superfície esteja suficientemente lisa. 
Recentemente, Prakki et al. (2007) estudaram resistência à abrasão de cimentos resinosos e materiais restauradores indiretos, incluindo uma cerâmica odontológica (Duceram). Os autores submeteram os diferentes materiais odontológicos à escovação simulada, avaliando a rugosidade superficial (obtida através de mensuração em rugosímetro, como resultado da diferença de valores entre a rugosidade superficial inicial - antes da escovação, e a rugosidade superficial final - após a escovação) e a perda de massa (obtida através da diferença de valores entre a massa inicial, antes da escovação, e a massa final, após a escovação). Após análise estatística dos valores observados foi possível concluir que a cerâmica avaliada apresentou a menor perda de massa, revelando superfície mais lisa após a escovação.

\subsection{Alteração de Cor em Cerâmicas Odontológicas}

Em 1985, Brewer et al. realizaram um estudo comparando a cor de uma cerâmica feldspática (Vita) aplicada sobre diferentes ligas (liga áurea, liga de prata-paládio e níquel-cromo), em diferentes momentos (preparação da superfície do metal, oxidação, primeira camada de opaco, segunda camada de opaco, primeira camada de dentina, segunda camada de dentina e glazeamento). Os pesquisadores utilizaram espectrofotômetro (sistema CIE Lab) para mensuração quantitativa da cor, após a conclusão de cada etapa de confecção das amostras citadas anteriormente, comparando as colorações obtidas a cada etapa. Após análise estatística dos dados, foi possível concluir que a maior diferença foi encontrada entre a liga de prata-paládio e as demais, após a aplicação da primeira camada de dentina e as etapas subseqüentes, possibilitando dizer que o metal influenciou a coloração final das amostras.

O’Neal et al., em 1987, objetivaram em seu estudo avaliar a influência da rugosidade superficial do metal subjacente (liga rica em ouro e liga em níquel-cromo) na 
coloração de amostras metalocerâmicas (cerâmica Ceramco). Os autores utilizaram diferentes polimentos da superfície metálica, diferentes momentos de tomadas de cor (após aplicação do opaco e cerâmica de corpo), e diferentes métodos de aferição de cor: instrumentação tricolor, espectrometria, avaliação visual. Os dados obtidos foram submetidos à análise estatística, sendo possível concluir que houve concordância de resultados quando comparados os diferentes tipos de leitura de cor, sendo que a espectrometria mostrou-se mais sensível às alterações de cor das amostras. Independente do tipo de tratamento superficial, a subestrutura metálica em liga de níquel-cromo afetou a coloração final dos corpos-de-prova apenas quando somente a camada de opaco era aplicada, sendo que após a condensação da cerâmica de corpo, a diferença de cor com a liga áurea desaparecia. Os pesquisadores atribuem esses resultados à formação de óxidos na superfície da cerâmica opaca, que posteriormente era mascarada pela adição da cerâmica de corpo.

Em 2000, Al Mutawa et al. estudaram os efeitos de diferentes agentes de união, diferentes rugosidades superficiais e aplicações de ácidos na superfície do metal, sobre a resistência de união metalocerâmica e sua influência na cor de uma cerâmica de ultra-baixa fusão (Golden Gate) aplicada sobre uma liga áurea. Os autores utilizaram uma cerâmica de baixa fusão como controle (Vita VMK). A leitura de cor foi realizada em colorímetro pelo sistema CIE $\mathrm{L}^{*} \mathrm{a}^{*} \mathrm{~b}^{*}$, sendo que os pesquisadores compararam os valores das amostras do grupo teste com o grupo controle $(\Delta \mathrm{E})$. Após análise estatística do $\Delta \mathrm{E}$, os autores concluíram que independente do agente de união, rugosidade superficial e tratamento da superfície do metal não houve diferença na cor da cerâmica de ultra-baixa fusão, que apresentou melhor reprodutibilidade que a porcelana convencional de baixa fusão.

Em 2004, estudando a coloração final de corpos-de-prova metalocerâmicos, Kourtis et al. realizaram um estudo em que utilizaram 4 ligas metálicas (níquel-cromo, cobalto-cromo, liga rica em paládio, liga rica em ouro) e duas cerâmicas (Vita-Omega e 
Ceramco Silver). As subestruturas metálicas das amostras, fundidas nas 4 ligas utilizadas, possuíam $10 \mathrm{~mm}$ de diâmetro e $1 \mathrm{~mm}$ de espessura. Para cada amostra, 2 camadas de opaco e 2 de dentina foram aplicadas sobre o metal. A espessura da camada de opaco e de dentina foram respectivamente $0,2 \mathrm{~mm} \pm 0,05 \mathrm{~mm}$ e $1 \mathrm{~mm} \pm 0,05 \mathrm{~mm}$, somando um total de espessura cerâmica de 1,2 mm. As amostras foram avaliadas com espectrofotômetro (sistema CIE $\left.\mathrm{L}^{*} \mathrm{a}^{*} \mathrm{~b}^{*}\right)$, considerando que a partir da diferença de cor entre os vários grupos, os autores obtiveram o valor de $\Delta \mathrm{E}$, que foi submetido à análise estatística. Os autores concluíram que a liga áurea e a liga de cobalto-cromo proporcionaram amostras mais claras que aquelas obtidas a partir das ligas de níquel-cromo e liga com alto teor de paládio. Quanto às cerâmicas estudadas, Ceramco se mostrou mais vermelha com todos os metais como subestrutura. As ligas ricas em ouro e em paládio foram responsáveis por amostras metalocerâmicas mais amarelas quando comparadas às ligas de cobalto-cromo e níquel-cromo. Assim sendo, foi possível constatar que a coloração final das amostras metalocerâmicas foi influenciada pelo metal subjacente.

Stavridakis et al. (2004) avaliaram a influência de ligas com alto teor de paládio (paládio-cobre-gálio, paládio-gálio e prata-paládio) na coloração final da camada de dentina de uma cerâmica odontológica (Vita-Omega), e também da camada de opaco após simulação dos ciclos de queima da dentina e do glazeamento. Os autores padronizaram a espessura de opaco dividida em duas aplicações $(0,1 \mathrm{~mm})$, e de dentina $(0,9 \mathrm{~mm})$, também dividida em duas aplicações, sendo que o grupo controle era representado por uma liga de ouro-paládio. Foram tomadas medidas de cor em espectrofotômetro em diversos momentos: após a segunda aplicação do opaco, segunda aplicação de dentina, e glaze. Os autores utilizaram o $\Delta \mathrm{E}$ como valor a ser submetido à análise estatística, de maneira que o mesmo foi obtido a partir da diferença dos valores entre o grupo controle e os grupos testes, em todos os momentos de tomada de cor. Após análise estatística dos dados obtidos, foi possível concluir 
que as ligas de paládio-cobre-gálio com apenas a camada de opaco aplicada, após simulação das queimas da dentina e glaze, exibiram alterações de cor inaceitáveis clinicamente. Para essas mesmas ligas, as amostras glazeadas após aplicação da camada de dentina, foram encontradas alterações de cor aceitáveis clinicamente. A aplicação da camada de dentina para a liga prata-paládio, após glazeamento, resultou em alterações de cor aceitáveis clinicamente. Diferentemente das ligas de paládio-cobre-gálio, as amostras da liga prata-paládio, com aplicação apenas da camada de opaco, simulando aplicação da dentina e glazeamento, revelaram valores aceitáveis clinicamente de alteração de cor. Já as ligas de paládio-gálio foram capazes de reproduzir a cor da cerâmica Vita-Omega, de maneira que as alterações de cor encontradas entre essas ligas e o grupo controle foram estatisticamente insignificantes, sendo clinicamente aceitáveis, tanto quando da aplicação da camada de opaco ou da camada de dentina, revelando que a subestrutura metálica influenciou a cor dessas restaurações metalocerâmicas.

Sarac et al. em 2006, desenvolveram um trabalho avaliando a influência de diferentes métodos de polimento na cor e rugosidade superficial de uma cerâmica feldspática (Vitadur Alpha). Os autores preparam discos em cerâmica pura $(10 \times 2 \mathrm{~mm})$, variando o polimento superficial: pasta polidora, disco diamantado, borracha polidora e um kit para polimento de cerâmica, de maneira que o grupo controle recebeu glazeamento extrínseco. A cor foi tomada em espectrofotômetro (sistema CIE L*a*b*), sendo que os autores utilizaram o $\Delta \mathrm{E}$ (diferença entre a cor do grupo controle e os grupos testes) para análise estatística; e a rugosidade superficial foi aferida em rugosímetro ( $\mathrm{Ra}$ - rugosidade média), sendo que os valores utilizados na análise estatística foram obtidos a partir da diferença da rugosidade do grupo controle e dos grupos testes. Ao final das análises, os autores concluíram que o tipo de polimento superficial influencia a rugosidade e a cor da cerâmica feldspática analisada. Para a Vitadur Alpha, a aplicação da pasta polidora e do disco diamantado resultou nos maiores 
valores de $\Delta \mathrm{E}$ e $\mathrm{Ra}$. $\mathrm{O}$ uso do kit para ajuste de cerâmica, precedido ou não do uso da pasta polidora, proporcionou às amostras superfície mais lisa que dos corpos-de-prova glazeados. As alterações de cor, contudo, foram mínimas, apresentando valores clinicamente aceitáveis.

Recentemente, Uludag et al. (2007) estudaram a influência da espessura da camada de dentina e do número de queimas, na coloração final de amostras cerâmicas livres de metal. Variando a espessura da camada de dentina dos espécimes $(0.5,1$, e $1.5 \mathrm{~mm})$ e o número de queimas $(3,5$ e 7), os autores utilizaram corpos-de-prova obtidos de uma cerâmica infiltrada de óxido de alumínio (In-Ceram) e uma reforçada por leucita (IPS Empress). A leitura de cor das amostras foi realizada em espectrofotômetro (sistema CIE L*a*b*), variando as espessuras e as queimas, sendo que os valores obtidos do $\Delta \mathrm{L}^{*}, \Delta \mathrm{a}^{*}$ e $\Delta \mathrm{b}^{*}$ foram submetidos à análise estatística. Ao final do estudo, os autores concluíram que houve diferença estatística dependente da espessura da camada de dentina, do número de queimas e do tipo de cerâmica. Com o aumento do número de queimas, ambas as cerâmicas apresentaram diminuição do $L^{*}$, resultando em espécimes mais escuros. Contudo, houve aumento para $\mathrm{a}^{*} \mathrm{e} \mathrm{b}^{*}$ depois de repetidas queimas, resultando em amostras mais vermelhas e amarelas. Com o aumento da espessura da camada de dentina, a cerâmica In-Ceram se mostrou mais escura, vermelha e amarela; a cerâmica IPS Empress apresentou coloração mais escura e verde. Além disso, o tipo de cerâmica influenciou a cor das amostras. A cerâmica reforçada por leucita IPS Empress é translúcida e a cerâmica In-Ceram é opaca, sendo que quando comparado com o In-Ceram, o IPS Empress apresenta menor quantidade de cristal na matriz, refletindo mais luz.

Al Wazzan e Al Hussaini, em 2007 estudaram a influência do titânio comercialmente puro (cp.) e liga de titânio (Ti-6Al-4V) na coloração final de uma cerâmica de ultra-baixa fusão (Noritake Ti22). O grupo controle era formado por amostras metalocerâmicas de liga áurea, liga de paládio e níquel-cromo com uma cerâmica feldspática 
convencional (VMK 95, Vita). A coloração final das amostras metalocerâmicas (25 x 3 x $0,5 \mathrm{~mm}$ de metal e $8 \times 3 \times 1 \mathrm{~mm}$ de cerâmica aplicada na porção central de cada subestrutura metálica) foi obtida utilizando-se espectrofotômetro (sistema CIE L* a* $b^{*}$ de coordenadas), sendo que o $\Delta \mathrm{E}$ (diferença entre os valores de cor entre os grupos testes e os controles) foi utilizado para análise estatística. Ao final da pesquisa os autores concluíram que a coloração das restaurações metalocerâmicas pode ser prejudicada pelo metal subjacente. Quando comparados todos os metais, as amostras com titânio comercialmente apresentaram a maior diferença de coloração, enquanto que para as amostras com a liga de titânio (Ti-6Al-4V) foi observada a menor alteração de cor. Os autores ressaltaram que dentre os metais utilizados o titânio comercialmente puro afetou mais a coloração final de cerâmicas de baixa fusão que a liga de titânio utilizada.

Em um estudo recente, Lakatos et al. (2007) analisaram a alteração de cor de cerâmicas odontológicas de ultra-baixa fusão (Noritake Ti22 - Noritake, Triceram Dentaurum e Vitatitankeramik - Vita). Foram confeccionadas para as 3 cerâmicas amostras livres de metal $(8 \times 5 \times 1,5 \mathrm{~mm}$ de espessura) e metalocerâmicas $(8 \times 5 \times 0,4 \mathrm{~mm}$ de espessura do titânio comercialmente puro, e $8 \times 5 \times 1,5 \mathrm{~mm}$ de espessura da camada cerâmica, sendo $0,5 \mathrm{~mm}$ de opaco). Nesse estudo foi utilizado o sistema CIE L* $a^{*} b^{*}$ para mensuração quantitativa da cor, sendo que para a análise estatística foi utilizado o valor do $\Delta \mathrm{E}$ (diferença dos valores de cor entre as amostras metalocerâmicas e as livres de metal). Ao final das análises, os autores concluíram que houve diferença entre as amostras em cerâmica pura e aquelas com subestrutura metálica, contudo as cerâmicas apresentaram valores de $\Delta \mathrm{E}$ semelhantes estatisticamente. Ainda, foi possível concluir que o titânio comercialmente puro induziu tendência ao verde para as 3 cerâmicas, e Triceram e Noritake Ti 22 apresentaram diminuição na luminosidade. 


\subsection{Envelhecimento Artificial Acelerado em Cerâmicas Odontológicas}

Em 1994, Razzog et al. submeteram ao envelhecimento artificial acelerado corpos-de-prova metalocerâmicos convencionais (Ceramco) e em titânio com cerâmica de baixa-fusão (Procera), utilizando quatro cores diferentes de cerâmicas. A cor das amostras foi tomada com espectrofotômetro pelo sistema CIE L*a*b* antes e após o envelhecimento. Ao fim da análise estatística foi possível concluir que embora tenha havido diferença estatisticamente significante entre Ceramco e Procera em três das quatro cores avaliadas, as modificações de cor foram clinicamente imperceptíveis.

Heydecke et al. em 2001 compararam a cor de discos cerâmicos em porcelana feldspática All-Ceram aplicada sobre a subestrutura em Procera que media 13,5 mm de diâmetro e 0,2 mm de espessura. Para a confecção das amostras, os autores aplicaram duas colorações diferentes da cerâmica feldspática $(0,4 \mathrm{~mm})$ sobre o Procera, e também utilizaramna sem aplicação de cerâmica feldspática. Em seguida foi aplicado sobre as amostras cimento resinoso (Nexus) de presa dual, de acordo com as especificações do fabricante. Posteriormente os autores submeteram as amostras ao envelhecimento artificial acelerado por 300 horas. A coloração dos corpos-de-prova foi medida em espectrofotômetro (sistema CIE $\left.\mathrm{L}^{*} \mathrm{a}^{*} \mathrm{~b}^{*}\right)$ e o $\Delta \mathrm{E}$ utilizado para a análise estatística resultou da diferença entre os valores de cor dos três grupos avaliados antes e após o envelhecimento artificial acelerado. Ao final da pesquisa foi possível concluir que as amostras ceramo-cerâmicas avaliadas apresentaram aceitável estabilidade de cor.

Em 2005, Ertan e Sahin submeteram ao envelhecimento artificial acelerado, diferentes cerâmicas de baixa-fusão e ultra-baixa fusão. Os autores confeccionaram amostras livres de metal (11 mm de diâmetro e 1,4 $\mathrm{mm}$ de espessura) que tiveram sua cor aferida por espectrofotômetro antes e após o envelhecimento artificial acelerado. Após análise estatística, 
os resultados revelaram que as cerâmicas de ultra-baixa fusão apresentaram maior alteração de cor que as de baixa-fusão, sendo, contudo, clinicamente aceitáveis.

\subsection{Fluorfosfato Acidulado e Cerâmicas Odontológicas}

Estudando os efeitos do flúor na superfície de vários tipos de cerâmicas odontológicas, Copps et al. (1984) confeccionaram amostras metalocerâmicas que receberam aplicação das soluções de fluoreto estanoso, fluorfosfato acidulado e neutro, pelo período de 20 minutos. A rugosidade superficial foi tomada antes e após a imersão dos espécimes nas soluções fluoretadas, e após os achados em microscopia eletrônica de varredura, os autores concluíram que o fluoreto estanoso e as soluções neutras de flúor não alteraram a superfície dos espécimes. Já as soluções de flúor fosfato acidulado foram responsáveis por um aumento significativo da rugosidade superficial dos corpos-de-prova.

Dois anos em seguida, Wunderlich e Yaman (1986) submeteram amostras metalocerâmicas à aplicação tópica de soluções fluoretadas por intervalos de tempo que variaram de 4 a 64 minutos, sendo metade das amostras mascarada para evitar o contato com o flúor. Os autores mediram a rugosidade superficial em rugosímetro antes e após a aplicação das soluções fluoretadas, examinando também a superfície em microscopia eletrônica de varredura. Ao final das análises estatísticas foi possível concluir que as amostras que receberam aplicação das soluções de fluorfosfato acidulado a $1,23 \%$ e fluoreto estanoso a $8 \%$ apresentaram estatisticamente os maiores valores de rugosidade superficial quando comparadas com as do grupo controle.

Em 1991, Wozniak et al. realizaram um estudo submetendo amostras de cinco diferentes cerâmicas odontológicas a quatro minutos de tratamento de superfície com cinco diferentes géis fluoretados. Em seguida, as amostras cerâmicas foram submetidas à 
armazenamento em chá, café e mistura de mucina por nove dias, alternando os três substratos. Os autores avaliaram em espectrofotômetro a cor das amostras antes e após o tratamento com flúor e o armazenamento em diferentes substratos, sendo possível concluir que após o ensaio houve diminuição considerável de luminosidade para todas as cerâmicas analisadas.

Butler et al., 2004 propuseram em seu estudo comparar a rugosidade de 3 diferentes porcelanas expostas a duas diferentes soluções de flúor, uma solução de peróxido de carbamida e água destilada. Para isso foram confeccionados discos cerâmicos para cada uma das seguintes cerâmicas: feldspática (Ceramco II), porcelana de ultra-baixa fusão (Finesse) e porcelana aluminizada (All-Ceram). Os discos foram imersos em fluorfosfato acidulado a $1,23 \%$, fluoreto estanoso a $0,4 \%$, peróxido de carbamida a $10 \%$ e água destilada. A superfície de cada disco foi avaliada em rugosímetro e a partir dos dados obtidos foi feita análise estatística. Os autores concluíram que o fluorfosfato acidulado a 1,23\% aumentou significativamente a rugosidade superficial dos 3 materiais analisados, não devendo ser usado sem critérios em pacientes com próteses cerâmicas. Ressaltaram que a cerâmica Finesse (ultra-baixa fusão) foi a menos suscetível às soluções utilizadas, apresentando os menores valores de rugosidade média (Ra). 
PROPOSIÇÃO 


\section{PROPOSIÇÃO}

Na busca de maiores informações científicas, o objetivo deste trabalho é avaliar a influência do envelhecimento artificial acelerado e do fluorfosfato acidulado a 1,23\% na rugosidade superficial e alteração de cor de cerâmicas odontológicas de ultra-baixa fusão para titânio comercialmente puro. 
MATERIAL E MÉTODO 


\section{MATERIAL E MÉTODO}

\subsection{Material}

Para realização deste trabalho foram utilizadas duas cerâmicas comerciais de ultrabaixa fusão na cor A3: Noritake Ti 22 (Noritake, Nagoya, Japão) e Triceram (Dentaurum, Pforzheim, Alemanha) específicas para o uso com titânio comercialmente puro (c.p.), e titânio c.p. (Tritan Ti - Dentaurum, Pforzheim, Alemanha), materiais que podem ser vistos na Figura 01.
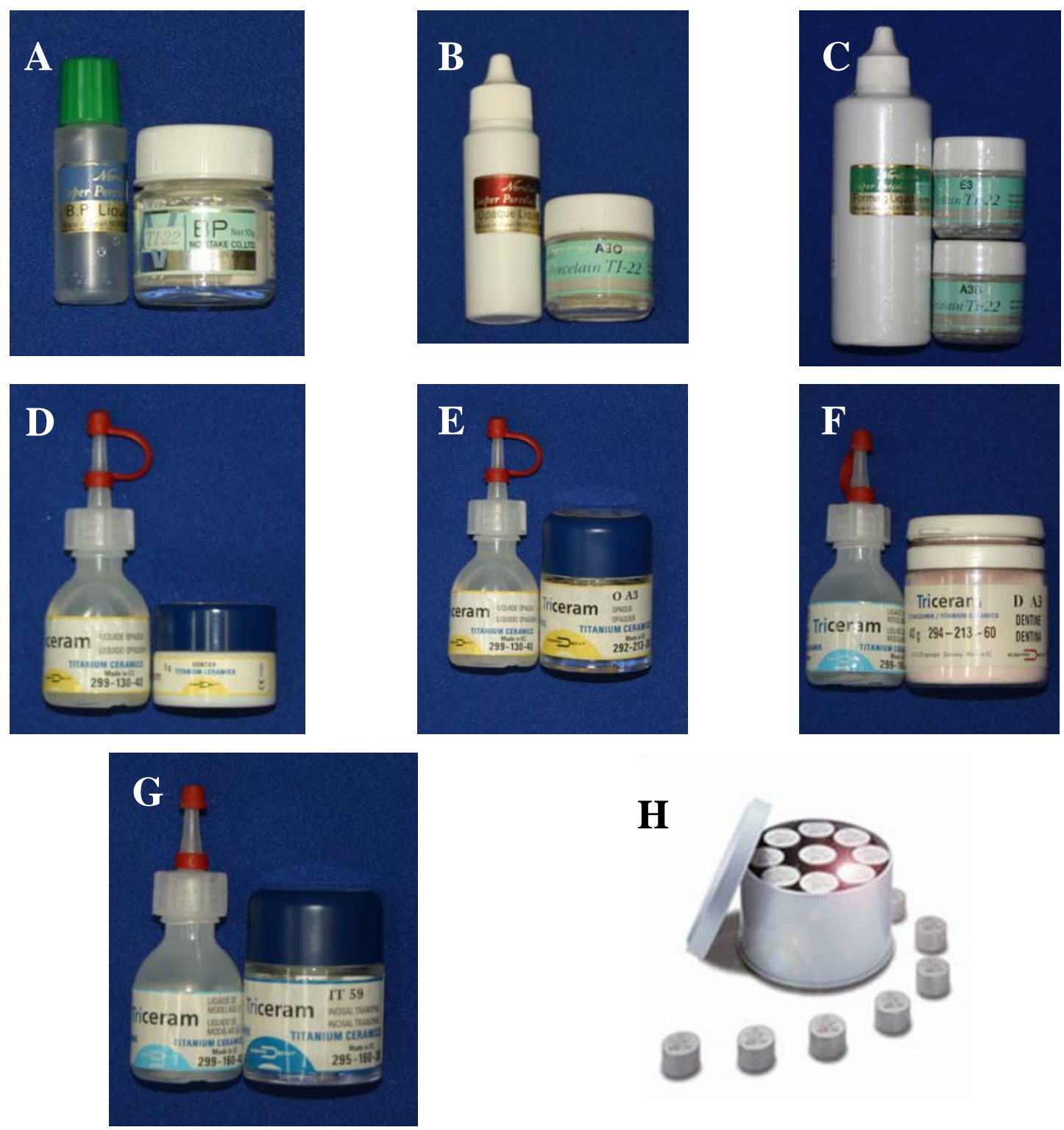

Figura 01. A- Adesivo da cerâmica Noritake Ti22; B- Cerâmica opaca da Noritake Ti22; C- Dentina e esmalte da cerâmica Noritake Ti22; D- Bonder da cerâmica Triceram; E- Opaco da cerâmica Triceram; F- Dentina da cerâmica Triceram; G- Cerâmica incisal da Triceram; H- Titânio comercialmente puro Tritan. 


\subsection{Método}

Para cada cerâmica foram confeccionadas 20 amostras livres de metal e 20 metalocerâmicas, sendo 10 espécimes submetidos ao envelhecimento artificial acelerado e 10 armazenados em fluorfosfato acidulado (1,23\%). Assim, foram obtidas 40 amostras para cada cerâmica, totalizando 80 corpos-de-prova.

\subsubsection{Confecção da Matriz}

Para a obtenção dos corpos-de-prova foi confeccionada uma matriz em teflon com o interior perfeitamente liso e diâmetro interno de $15 \mathrm{~mm}$. A matriz era formada por uma porção externa e outra interna em forma de êmbolo, sendo que as duas partes se encaixavam. Acompanhando a matriz havia três espaçadores, um com $2 \mathrm{~mm}$ de espessura, um com $1 \mathrm{~mm}$ e outro com $0,5 \mathrm{~mm}$ de espessura, que eram encaixados no êmbolo entre as porções interna e externa da matriz, de forma que a parte externa ficava mais alta que a interna proporcionando a espessura necessária do corpo-de-prova (Figura 02- A e B).
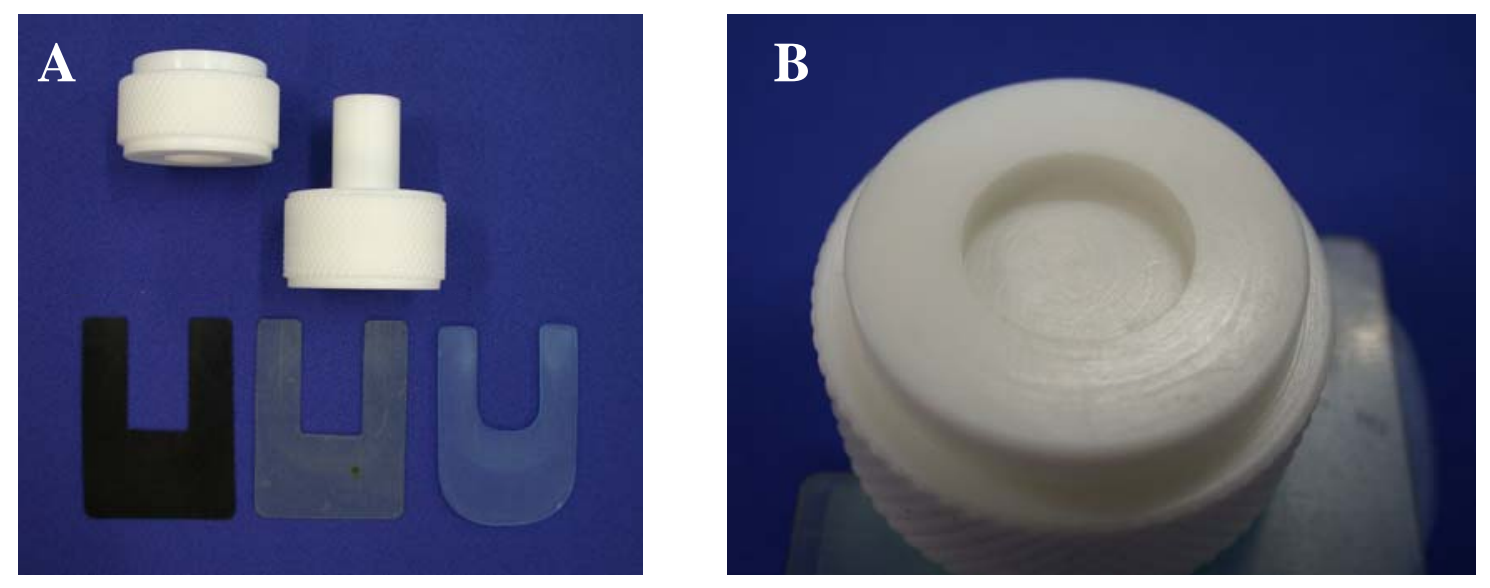

Figura 02. A- Matriz em teflon e espaçadores de 0,5, 1 e $2 \mathrm{~mm}$ respectivamente da esquerda para a direita; BVista aproximada da matriz devidamente montada com o auxílio dos 3 espaçadores. 


\subsubsection{Confecção dos corpos-de-prova livres de metal}

As cerâmicas foram aplicadas segundo as instruções de cada fabricante para preparo das massas, condensação, temperatura e tempo de cocção. Para a confecção dos corpos-de-prova livres de metal, a cerâmica foi inserida diretamente na matriz, respeitando a espessura determinada pelo espaçador utilizado. Para a formação das camadas utilizavam-se os espaçadores relativos à espessura da camada, ou seja, para elaborar a camada de dentina utilizava-se o espaçador de $2 \mathrm{~mm}$ de espessura (Figura 03- A e B) e para acrescentar sobre esta a camada de esmalte, acrescentava-se um espaçador de $1 \mathrm{~mm}$ (Figura 03- C), de modo que a amostra tinha cerca de $3 \mathrm{~mm}$ de espessura (Figura 03- D).

Após a inserção de cada camada de cerâmica na matriz previamente isolada com vaselina líquida, foi realizada a remoção do excesso de líquido através da colocação de papel absorvente sobre a massa cerâmica, exercendo leve pressão manual. Em seguida os corpos-de-prova foram levados ao forno (Jelfire UPF, Jelenko, San Diego, Estados Unidos) para cocção de acordo com cada programação especificada pelo fabricante (Tabelas 1 e 2).

Tabela 1- Tabela de queima da cerâmica Triceram

\begin{tabular}{|c|c|c|c|c|c|c|}
\hline & Adesivo & $\begin{array}{l}1^{\text {a }} \text { camada de } \\
\text { opaco }\end{array}$ & $\begin{array}{l}2^{\mathrm{a}} \text { camada de } \\
\text { opaco }\end{array}$ & $\begin{array}{l}\mathbf{1}^{\mathrm{a}} \text { camada de } \\
\text { dentina }\end{array}$ & $\begin{array}{l}1^{\text {a }} \text { camada de } \\
\text { esmalte }\end{array}$ & Glaze \\
\hline $\begin{array}{ll}\text { Tempo de } \\
\text { secagem }\end{array}$ & $2 \min$ & $2 \min$ & $2 \min$ & $6 \mathrm{~min}$ & $6 \mathrm{~min}$ & $2 \min$ \\
\hline $\begin{array}{l}\text { Temperatura } \\
\text { inicial }\end{array}$ & $600^{\circ} \mathrm{C}$ & $600^{\circ} \mathrm{C}$ & $600^{\circ} \mathrm{C}$ & $600^{\circ} \mathrm{C}$ & $600^{\circ} \mathrm{C}$ & $500^{\circ} \mathrm{C}$ \\
\hline $\begin{array}{l}\text { Início do } \\
\text { vácuo }\end{array}$ & $600^{\circ} \mathrm{C}$ & $600^{\circ} \mathrm{C}$ & $600^{\circ} \mathrm{C}$ & $600^{\circ} \mathrm{C}$ & $600^{\circ} \mathrm{C}$ & ------- \\
\hline $\begin{array}{l}\text { Taxa de } \\
\text { aquecimento }\end{array}$ & $65^{\circ} \mathrm{C} / \mathrm{min}$ & $65^{\circ} \mathrm{C} / \mathrm{min}$ & $65^{0} \mathrm{C} / \mathrm{min}$ & $55^{0} \mathrm{C} / \mathrm{min}$ & $55^{0} \mathrm{C} / \mathrm{min}$ & $55^{0} \mathrm{C} / \mathrm{min}$ \\
\hline $\begin{array}{l}\text { Nível de } \\
\text { vácuo }\end{array}$ & $72 \mathrm{~cm} / \mathrm{Hg}$ & $72 \mathrm{~cm} / \mathrm{Hg}$ & $72 \mathrm{~cm} / \mathrm{Hg}$ & $72 \mathrm{~cm} / \mathrm{Hg}$ & $72 \mathrm{~cm} / \mathrm{Hg}$ & -------- \\
\hline $\begin{array}{l}\text { Liberação de } \\
\text { vácuo }\end{array}$ & $795^{\circ} \mathrm{C}$ & $795^{\circ} \mathrm{C}$ & $795^{\circ} \mathrm{C}$ & $755^{\circ} \mathrm{C}$ & $755^{\circ} \mathrm{C}$ & -------- \\
\hline $\begin{array}{l}\text { Tempo de } \\
\text { permanência }\end{array}$ & $1 \mathrm{~min} \mathrm{~s} /$ vácuo & 1 min s/ vácuo & 1 min s/ vácuo & 1 min s/ vácuo & 1 min s/ vácuo & \\
\hline $\begin{array}{l}\text { Temperatura } \\
\text { final }\end{array}$ & $795^{\circ} \mathrm{C}$ & $795^{\circ} \mathrm{C}$ & $795^{\circ} \mathrm{C}$ & $755^{\circ} \mathrm{C}$ & $755^{\circ} \mathrm{C}$ & $755^{\circ} \mathrm{C}$ \\
\hline $\begin{array}{l}\text { Tempo de } \\
\text { resfriamento }\end{array}$ & 0 & 0 & 0 & 0 & 0 & 0 \\
\hline
\end{tabular}


Tabela 2- Tabela de queima da cerâmica Noritake Ti 22

\begin{tabular}{|c|c|c|c|c|c|c|c|}
\hline $\begin{array}{l}\text { Tempo de } \\
\text { secagem }\end{array}$ & $\begin{array}{l}\text { Desgaseificação } \\
3 \mathrm{~min}\end{array}$ & $\begin{array}{l}\text { Adesivo } \\
5 \mathrm{~min}\end{array}$ & $\begin{array}{l}\mathbf{1}^{\text {a }} \text { camada } \\
\text { de opaco } \\
5 \mathrm{~min}\end{array}$ & $\begin{array}{l}2^{\text {a }} \text { camada } \\
\text { de opaco } \\
5 \mathrm{~min}\end{array}$ & $\begin{array}{l}\mathbf{1}^{\text {a }} \text { camada } \\
\text { de dentina } \\
7 \mathrm{~min}\end{array}$ & $\begin{array}{l}\mathbf{1}^{\mathrm{a}} \text { camada } \\
\text { de esmalte } \\
7 \mathrm{~min}\end{array}$ & $\begin{array}{l}\text { Glaze } \\
5 \mathrm{~min}\end{array}$ \\
\hline $\begin{array}{l}\text { Temperatura } \\
\text { inicial }\end{array}$ & $500^{\circ} \mathrm{C}$ & $500^{\circ} \mathrm{C}$ & $500^{\circ} \mathrm{C}$ & $500^{\circ} \mathrm{C}$ & $500^{\circ} \mathrm{C}$ & $500^{\circ} \mathrm{C}$ & $500^{\circ} \mathrm{C}$ \\
\hline $\begin{array}{l}\text { Início do } \\
\text { vácuo }\end{array}$ & $500^{\circ} \mathrm{C}$ & $500^{\circ} \mathrm{C}$ & $500^{\circ} \mathrm{C}$ & $500^{\circ} \mathrm{C}$ & $500^{\circ} \mathrm{C}$ & $500^{\circ} \mathrm{C}$ & ------- \\
\hline $\begin{array}{l}\text { Taxa de } \\
\text { aquecimento }\end{array}$ & $50^{\circ} \mathrm{C} / \mathrm{min}$ & $50^{\circ} \mathrm{C} / \mathrm{min}$ & $50^{\circ} \mathrm{C} / \mathrm{min}$ & $50^{\circ} \mathrm{C} / \mathrm{min}$ & $40^{\circ} \mathrm{C} / \mathrm{min}$ & $40^{\circ} \mathrm{C} / \mathrm{min}$ & $50^{\circ} \mathrm{C} / \mathrm{min}$ \\
\hline Nível de vácuo & $74 \mathrm{~cm} / \mathrm{Hg}$ & $72 \mathrm{~cm} / \mathrm{Hg}$ & $72 \mathrm{~cm} / \mathrm{Hg}$ & $72 \mathrm{~cm} / \mathrm{Hg}$ & $72 \mathrm{~cm} / \mathrm{Hg}$ & $72 \mathrm{~cm} / \mathrm{Hg}$ & ------ \\
\hline $\begin{array}{l}\text { Liberação do } \\
\text { vácuo }\end{array}$ & $790^{\circ} \mathrm{C}$ & $790^{\circ} \mathrm{C}$ & $770^{\circ} \mathrm{C}$ & $770^{\circ} \mathrm{C}$ & $750^{\circ} \mathrm{C}$ & $750^{\circ} \mathrm{C}$ & ------- \\
\hline $\begin{array}{l}\text { Tempo de } \\
\text { permanência }\end{array}$ & 3 min. & - & - & - & - & - & \\
\hline $\begin{array}{l}\text { Temperatura } \\
\text { final }\end{array}$ & $800^{\circ} \mathrm{C}$ & $800^{\circ} \mathrm{C}$ & $780^{\circ} \mathrm{C}$ & $780^{\circ} \mathrm{C}$ & $760^{\circ} \mathrm{C}$ & $760^{\circ} \mathrm{C}$ & $760^{\circ} \mathrm{C}$ \\
\hline $\begin{array}{l}\text { Tempo de } \\
\text { resfriamento }\end{array}$ & 0 & 0 & 0 & 0 & 0 & 0 & 0 \\
\hline
\end{tabular}
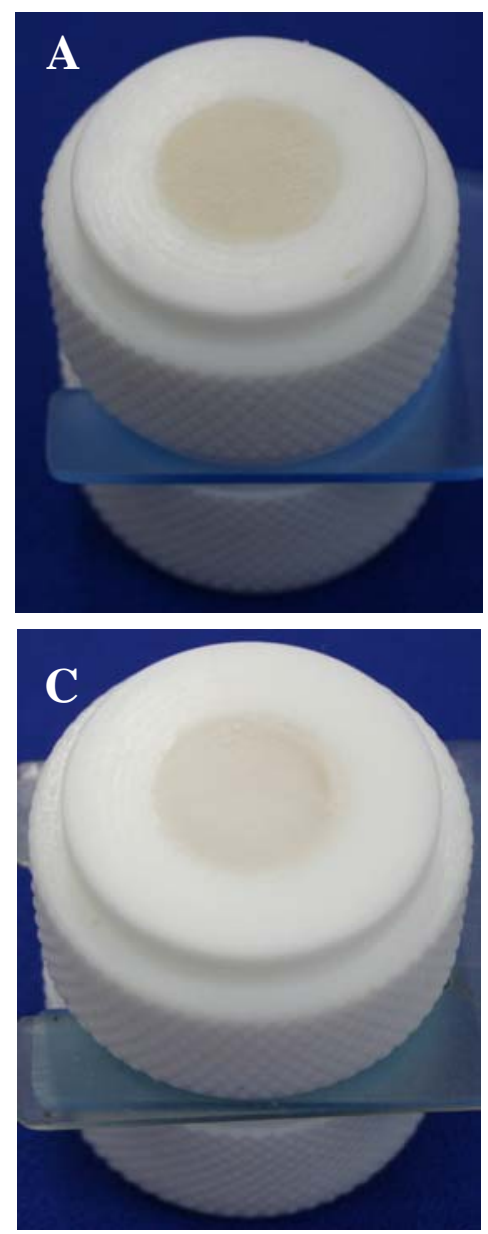
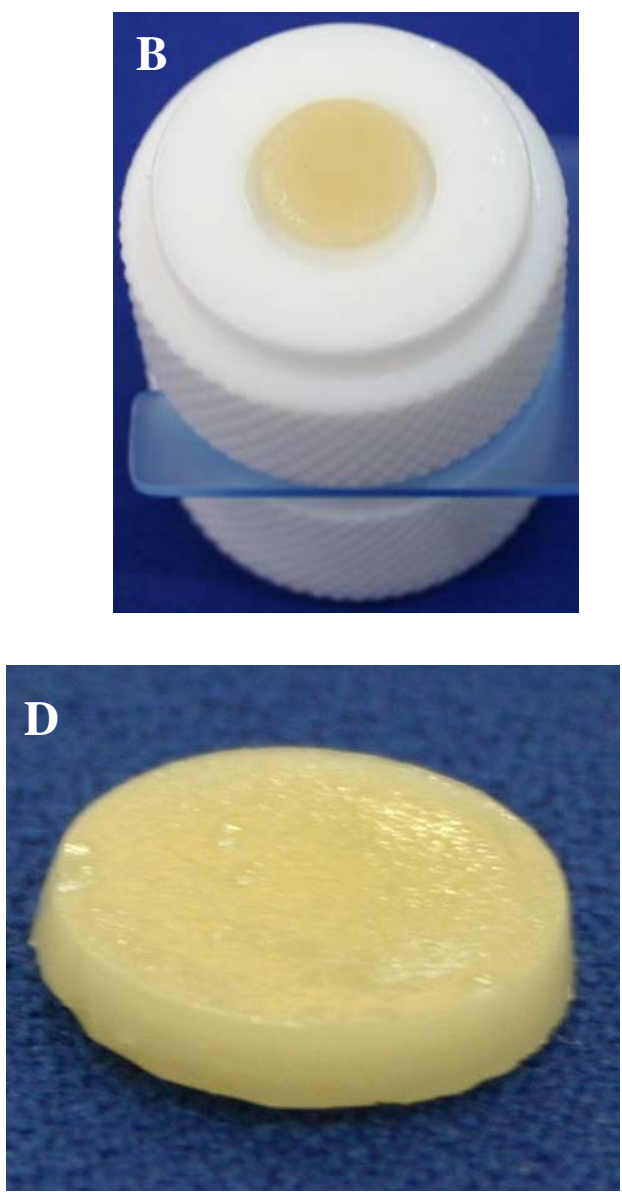

Figura 03. A- Matriz em teflon com espaçador de $2 \mathrm{~mm}$ e a camada de dentina condensada; B- Camada de dentina após a sinterização; C- Matriz em teflon com os espaçadores de 2 e $1 \mathrm{~mm}$ com a camada de esmalte aplicada; D- Amostra obtida após a sinterização da camada de esmalte. 


\subsubsection{Confecção das infra-estruturas metálicas}

A obtenção das infra-estruturas metálicas das restaurações metalocerâmicas se deu de acordo com a técnica da cera perdida (ANUSAVICE, 2003). Dessa maneira, sobre a matriz de teflon, previamente isolada com pequena quantidade de vaselina, e ajustada em 1 mm com o auxílio do espaçador, verteu-se cera fundida com um conta-gotas até o completo preenchimento da matriz. Aguardou-se o completo endurecimento da cera, retirou-se o excesso com uma espátula quente e removeu-se da matriz a partir da remoção do espaçador (Figura 04- A e B). Os padrões de cera obtidos foram fixados em uma base conformadora de cadinho com auxílio de cera azul em corda (Struers Miniton, Struers A/S Rodrove, Denmark, Alemanha). Em seguida, pincelou-se anti-bolhas (Excelsior, SS W, Rio de Janeiro, Brasil) em toda superfície dos padrões de cera, sendo depois incluídos em revestimento próprio para titânio (Rematitan Plus, Dentaurum JP, Pforzheim, Alemanha), sendo 5 padrões para cada anel de fundição (Figura 04- C e D), seguindo-se a orientação do fabricante quanto à relação pó/líquido (o líquido era diluído na proporção de $60 \%$ de líquido para $40 \%$ de água destilada) e tempo de mistura, empregando-se equipamento eletro mecânico a vácuo (EDG Ind. e Com. Ltda, São Carlos, Brasil). Terminada a mistura e utilizando-se de vibrador e espátula para gesso, o material foi vertido no interior do anel metálico, adaptado à base conformadora de cadinho. Em seguida, os anéis de fundição foram submetidos ao ciclo térmico preconizado pelo fabricante do revestimento e levados ao forno (EDG- 7000 3P- EDG Equipamentos e Controles Ltda, São Carlos, Brasil) por aproximadamente 12 horas, antes de ser realizada a fundição. A fusão do titânio foi realizada na máquina Discovery Plasma (EDG- Equipamentos e Controles Ltda, São Carlos, Brasil) por meio de arco voltaico e injeção por meio de pressão positiva de argônio na porção superior do cilindro e, negativa, pelo vácuo, na região inferior do cilindro (Figura 04- E). 
Após a fundição, os discos metálicos foram submetidos à jateamento (Jato de areia Multjet III - EDG Equipamentos e Controles Ltda., São Carlos, Brasil) com partícula de óxido de alumínio de 100 mesh com pressão de 42 psi para eliminação do revestimento aderido aos discos de titânio. Os discos obtidos tiveram suas extremidades convenientemente cortadas da sobra da fundição e foram ajustadas para perfeita adaptação na matriz de teflon (Figura 04- F). Em seguida os discos foram novamente jateados para remoção dos óxidos superficiais, durante 20 segundos, ou na granulação de 100 mesh ou de 60 mesh (dependendo do tipo de cerâmica que seria aplicada sobre os discos) e limpos somente com jato de ar isento de óleo, sob pressão de 30-40 psi distante de 3 a $5 \mathrm{~cm}$ da superfície plana do disco. Depois os discos foram submetidos ao tratamento do metal determinado para cada grupo, previamente à aplicação da cerâmica:

- Tratamento 1 - jateamento com óxido de alumínio (100 mesh), limpeza em ultra-som por 10 minutos em álcool isopropílico, sem desgaseificação. [grupo segundo recomendação do fabricante da cerâmica Triceram].

- Tratamento 2 - jateamento com óxido de alumínio (60 mesh), limpeza em ultra-som por 10 minutos em álcool isopropílico, desgaseificação (temp. $500^{0} \mathrm{C}-800^{\circ} \mathrm{C}$ ). [grupo segundo recomendação do fabricante da cerâmica Noritake Ti22].

A desgaseificação seguindo a recomendação do fabricante da cerâmica Noritake Ti 22 foi feita entre $500^{\circ} \mathrm{C}$ e $800^{\circ} \mathrm{C}$ por 3 minutos sem vácuo. Os corpos-de-prova da cerâmica Triceram eram representados pelo grupo 1 e os corpos-de-prova da cerâmica Noritake Ti 22 eram representados pelo grupo 2. 

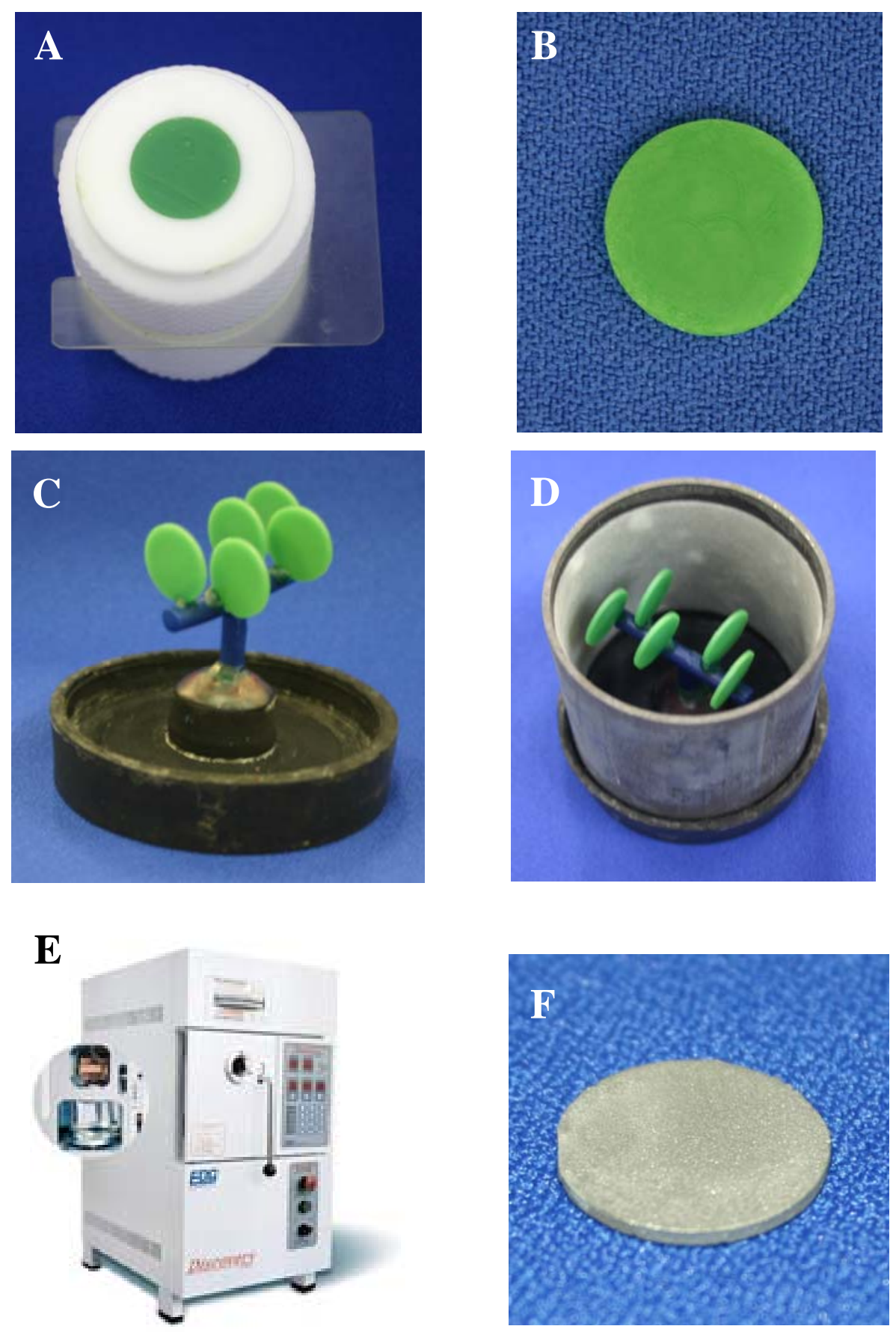

Figura 04. A- Matriz em teflon com espaçador de $1 \mathrm{~mm}$ e enceramento do disco; B- Disco encerado; C e DDiscos em cera adaptados no anel de fundição; E- Máquina para fundição do Titânio c.p. Discovery Plasma/ EDG; F- Pastilha em Titânio c.p. obtida após ser recortada da sobra da fundição. 


\subsubsection{Confecção dos corpos-de-prova metalocerâmicos}

As cerâmicas foram aplicadas segundo as instruções de cada fabricante para preparo das massas, condensação, temperatura e tempo de cocção. Primeiramente uma fina camada de adesivo era aplicada de forma a molhar a superfície do metal com cerâmica sendo em seguida levado ao forno para a queima (Jelfire UPF, Jelenko, San Diego, Estados Unidos), garantindo união entre esta e o metal (Figura 05- A). Após o resfriamento uma fina camada de opaco era aplicada, da mesma maneira que a de adesivo, sendo em seguida submetido à queima. Após o resfriamento, uma segunda camada de opaco era aplicada, com o objetivo de mascarar o metal semelhantemente aos procedimentos de laboratório (Figura 05- B). Para a aplicação da cerâmica de corpo, os padrões metálicos foram posicionados dentro da matriz de teflon, utilizando o espaçador de $2 \mathrm{~mm}$, assim essa camada de cerâmica possuía cerca de 1 $\mathrm{mm}$, uma vez que a subestrutura metálica acondicionada na matriz media $1 \mathrm{~mm}$ de espessura (Figura 05- C). Para a aplicação da cerâmica incisal era adicionado a este conjunto o espaçador de 0,5 mm. As massas cerâmicas foram aplicadas com auxílio de espátula no interior da matriz, realizando-se vibração manual para condensação da cerâmica e então o excesso de líquido era removido por meio de papel absorvente. Em seguida à aplicação da camada de corpo, os espécimes foram removidos cuidadosamente e levados ao forno para a queima da cerâmica. Após o resfriamento, os corpos-de-prova eram novamente colocados na matriz e a camada de cerâmica incisal era aplicada (Figura 05- D). 

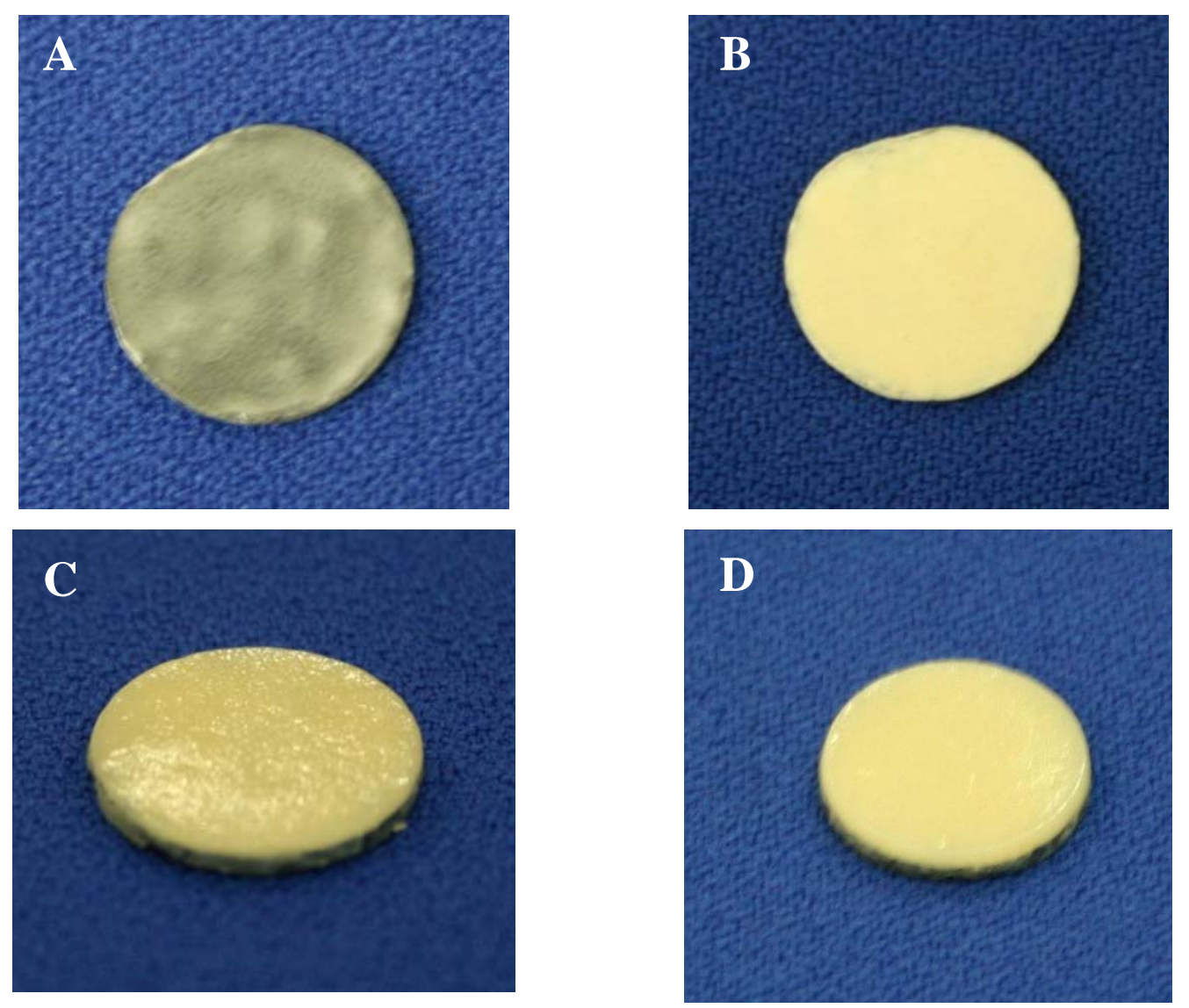

Figura 05. A- Pastilha em Titânio c.p. com a camada de adesivo aplicada e sinterizada; B- Pastilha em Titânio c.p. com as duas camadas de opaco aplicadas e sinterizadas; C- Pastilha em Titânio c.p. com a camada de dentina aplicada e sinterizadas; D- Pastilha em Titânio c.p. com a camada de esmalte aplicada e sinterizada.

\subsubsection{Acabamento dos corpos-de-prova}

Todas as amostras, após sua confecção, receberam o acabamento da superfície em equipamento para polimento (Lixadeira e Politriz, modelo PFL, FORTEL Ind. Com. Ltda., São Paulo, Brasil) para aplainamento da sua superfície, por meio de lixas nas granulações 100, 320, 600, 800 e 1200. Era nessa fase que, com paquímetro digital (Mitutoyo - Tokyo - Japão), a espessura dos espécimes era padronizada em 2,5 mm, que é aquela preconizada para a face oclusal de restaurações metalocerâmicas. 


\subsubsection{Glazeamento dos corpos-de-prova}

Após a obtenção de superfícies planas e lisas, os 80 espécimes receberam glazeamento (Tabelas 1 e 2), estando prontas para as leituras de rugosidade superficial e cor (Figura 06 A e B).
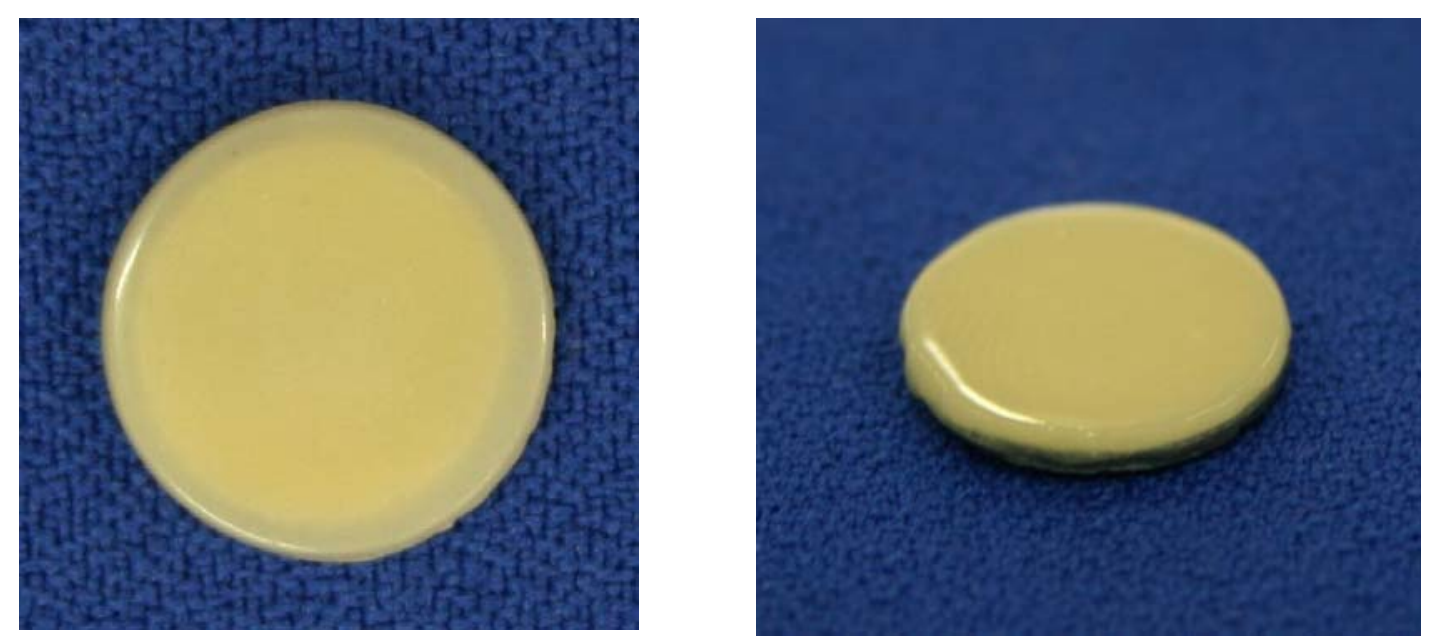

Figura 06. A- Corpo-de-prova livre de metal glazeado; B- Corpo-de-prova metalocerâmico glazeado.

\subsubsection{Leitura da Rugosidade Superficial}

A leitura da rugosidade superficial foi realizada em dois momentos durante o experimento. A rugosidade superficial inicial (R1) foi aquela mensurada logo após obtidos os corpos-de-prova e a rugosidade superficial final (R2) aquela obtida após o envelhecimento artificial acelerado ou armazenamento em fluorfosfato acidulado (1,23\%). Os valores utilizados na análise estatística foram R1 e R2.

Para tanto, utilizou-se o rugosímetro SJ - 201P (Mitutoyo, Tokyo, Japão) (Figura 07 A e B). Este equipamento é composto de duas partes principais: 
- Unidade Programadora de Controle e Registro da Leitura - encontra-se nessa unidade os comandos para o acionamento do aparelho e também o seletor do programa a ser utilizado. A leitura obtida de determinada superfície é exposta no display do controle. No controle, através do $\lambda \mathrm{c}$ (meter cut-off), foi programada a distância a ser percorrida pelo pick-up de $0,8 \times 5 \mu \mathrm{m}$.

- Unidade Transversal Motorizada Percursora de Leitura - Compõe-se de um motor e uma agulha. Esta, ao ser movimentada, fará a sondagem da superfície selecionada de acordo com o programa pré-estabelecido. A unidade motora é fixa a uma haste vertical que, por sua vez se prende a uma base sólida de granito, oferecendo estabilidade ao conjunto. Ao ser acionado o aparelho, a agulha é movimentada em uma única direção e detecta as irregularidades da superfície. Estas irregularidades correspondem aos picos, vales e ondas. Este valor é definido como a média dos afastamentos do pick-up tanto para cima como para baixo, em relação a uma linha central (Rugosidade Média - Ra).

Para cada corpo-de-prova foram tomadas três medidas de rugosidade, sendo que o valor utilizado foi a média aritmética desses valores.
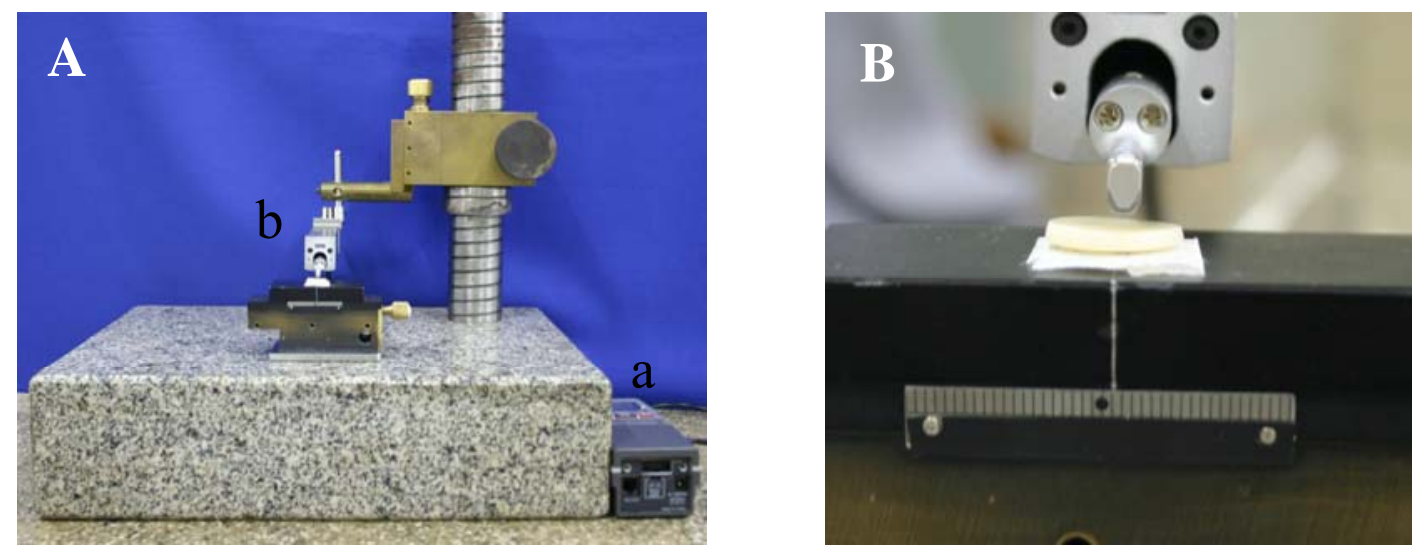

Figura 07. A- Rugosímetro com unidade programadora (a) e unidade de leitura (b); B- Visão aproximada da unidade de leitura. 


\subsubsection{Análise espectrofotométrica da cor}

Para verificar as alterações de cor ocorridas nas cerâmicas odontológicas utilizou-se o Espectrofotômetro PCB 6807 BYK GARDNER (Columbia, Estados Unidos) (Figura 08- A). Foram feitas leituras antes e após as etapas de envelhecimento artificial acelerado e armazenamento em fluorfosfato acidulado $(1,23 \%)$.

Para isso as amostras foram colocadas em um bloco de fundo padrão branco (Standard For $45^{\circ}, 0^{\circ}$, Reflectance and Color Gardner Laboratory Inc. Bethesda, Maryland 20014), e o espectrocolorímetro foi colocado sobre a amostra. Uma vez acionado, pela pressão sobre o conjunto, o equipamento emite luzes de componentes LED- 30 lâmpadas LED, com 10 cores diferentes, dispostas de forma circular, que acendem e incidem o feixe de luz em $45^{\circ}$ com a superfície do material. Esse feixe é refletido em $0^{\circ}$ de volta para o aparelho, e assim se torna possível medir quantitativamente a cor do material (Figura 08- B).

A CIE (Comission Internationale de I'Eclairage) padronizou fontes de luz pela quantidade de energia emitida a cada comprimento de onda. O padrão de observação simulado pelo Colorímetro Espectrofotométrico segue o sistema CIE Lab, recomendado pela CIE (Commission Internationale de l'Eclairage) e amplamente usado atualmente, funcionando como ferramenta para comunicar e documentar a cor e as diferenças de cores. Este consiste de eixos $a^{*}$ e $b^{*}$, que possuem ângulos retos e representam a dimensão da tonalidade ou cor. $\mathrm{O}$ terceiro eixo é o brilho $\mathrm{L}^{*}$, sendo perpendicular ao plano $\mathrm{a}^{*} \mathrm{~b}^{*}$. Com este sistema qualquer cor pode ser especificada matematicamente com as coordenadas L* (luminosidade), a* (eixo vermelho-verde), b* (eixo amarelo-azul).

Os corpos-de-prova foram então submetidos ao processo de envelhecimento artificial acelerado ou armazenamento em fluorfosfato acidulado (1,23\%). 

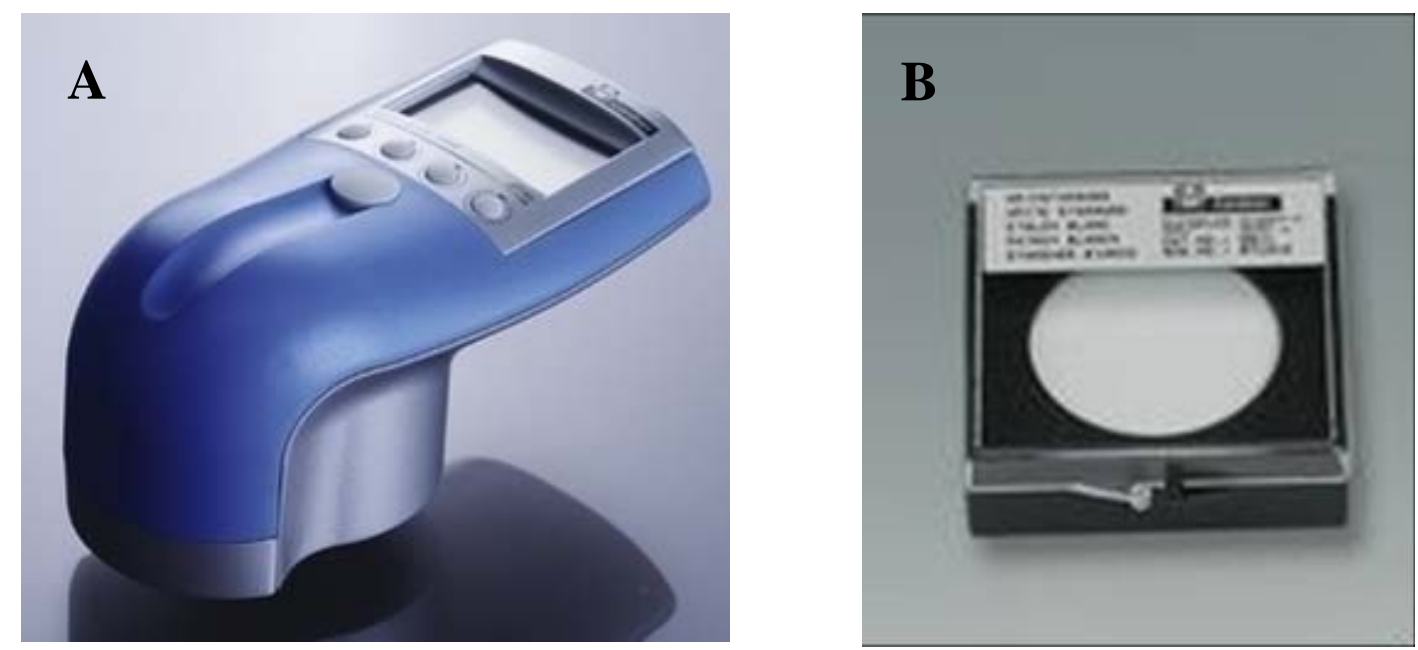

Figura 08. A- Espectrofotômetro PVB 6897 BYK GARDNER; B- Fundo padrão branco.

\subsubsection{Envelhecimento artificial acelerado}

O sistema de envelhecimento artificial acelerado simula as forças da natureza predizendo a durabilidade relativa dos materiais expostos às intempéries. A chuva e a neblina são simuladas por processo de condensação de água destilada, saturada e o oxigênio auto gerado pelo sistema. Os efeitos da luz do sol, onde apenas $1 \%$ da radiação provoca degradação, são simulados por uma rede de 8 fontes de luz UV-B composta por tubos fluorescentes de 40 watts com emissão concentrada na região ultravioleta $\mathrm{B}$, com radiação concentrada em 280/320 nm como na natureza. A temperatura de exposição é automaticamente controlada de acordo com os programas estabelecidos para ciclos UV / condensação.

As amostras foram colocadas no aparelho de Sistema Acelerado de Envelhecimento para não-metálicos C-UV (Comexim Matérias Primas Ltda, São Paulo, Brasil) (Figura 09) sob ação da luz UV e a condensação realizada em ciclos separados que se repetiam sucessiva e automaticamente. Nesse equipamento a fonte de luz UV-B compõe-se de tubos fluorescentes com emissão concentrada na região ultravioleta B. O processo de condensação foi produzido com a exposição de uma das superfícies dos corpos-de-prova a 
uma mistura aquecida de vapor de água saturada de ar, enquanto que o lado oposto da amostra era utilizado para sua aderência às placas metálicas que as sustentam. Esse aparelho possui um sistema de controle que oferece possibilidades de programas diários intercalando-se ciclos de condensação e de radiação UV-B. Um aparelho temporizador fornece o tempo total da operação e de exposição à luz UV-B. A medida da temperatura era fornecida por um termômetro com bulbo remoto. Este equipamento apresenta precisão de mais ou menos $1^{\circ} \mathrm{C} \mathrm{e}$ opera na faixa de $30^{\circ}$ a $80^{\circ} \mathrm{C}$.

Dessa forma, em poucos dias ou semanas, o C-UV pode produzir degradações que ocorreriam em meses ou anos. Estas degradações podem ser observadas como descoloração, perda de brilho, aparecimento de trincas, bolhas, etc.

Os corpos-de-prova eram então aderidos às placas fixadoras do aparelho utilizando-se silicone especificamente indicado para tal, e levados à câmara de condensação frente à fonte de luz, numa distância de $50 \mathrm{~mm}$ desta. $\mathrm{O}$ programa de funcionamento fixado foi de 4 horas de exposição ao UV-B a $50^{\circ} \mathrm{C}$ e 4 horas de condensação a $50^{\circ} \mathrm{C}$, o tempo máximo de envelhecimento foi de 384 horas, tempo que corresponde ao uso clínico de 10 anos.

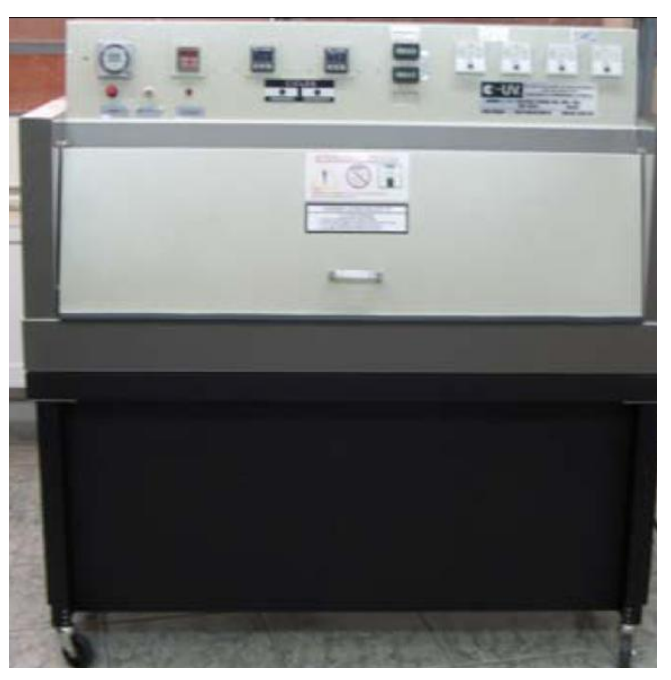

Figura 09. Sistema Acelerado de Envelhecimento para não-metálicos C-UV. 


\subsubsection{Armazenamento em fluorfosfato acidulado (1,23\%)}

Os espécimes foram imersos em $20 \mathrm{~mL}$ de gel incolor de fluorfosfato acidulado a 1,23\% (Farmácia Ensino, Ribeirão Preto, Brasil), por 12 horas e 47 minutos (aproximadamente 10 anos de uso clínico de flúor), de modo que a cada 50 minutos o substrato era trocado (BUTLER et. al, 2004). Após esse período os discos foram lavados em água corrente e secos com jato de ar isento de óleo, sendo em seguida realizadas novamente as leituras de cor e de rugosidade superficial.

Após o término do processo de envelhecimento artificial acelerado e armazenamento em fluorfosfato acidulado os corpos-de-prova foram novamente submetidos à análise de cor para a verificação da mudança total de cor $(\Delta \mathrm{E})$.

$\mathrm{O} \Delta \mathrm{E}$ pode ser calculado pela fórmula:

$\Delta \mathrm{E}=\sqrt{\left(\Delta \mathrm{L}^{*}\right)+\left(\Delta \mathrm{a}^{*}\right)+\left(\Delta \mathrm{b}^{*}\right)}$

Onde: $\Delta \mathrm{L}=$ variação de $\mathrm{L}$ (antes e após o envelhecimento)

$\Delta \mathrm{a}=$ variação de a (antes e após o envelhecimento)

$\Delta \mathrm{b}=$ variação de $\mathrm{b}$ (antes e após o envelhecimento)

Após a segunda leitura de cor, a rugosidade superficial também foi novamente mensurada. Os valores das rugosidades iniciais e finais, e os valores do $\Delta \mathrm{E}$ foram submetidos à análise estatística segundo a verificação da normalidade. 
RESULTADOS 


\section{RESULTADOS}

\subsection{Envelhecimento Artificial Acelerado}

Os resultados obtidos antes e após as leituras de rugosidade superficial e cor das amostras livres de metal submetidas ao envelhecimento artificial acelerado estão descritos nas Tabelas 03 a 05.

Tabela 03. Resultados de rugosidade superficial $(\mu \mathrm{m})$ para as amostras livres de metal das cerâmicas Triceram e Noritake Ti22 submetidas ao envelhecimento artificial acelerado.

\begin{tabular}{ccccc}
\hline & \multicolumn{2}{c}{ ANTES } & \multicolumn{2}{c}{ DEPOIS } \\
\hline & Triceram & Noritake Ti22 & Triceram & Noritake Ti22 \\
\hline $\mathbf{1}$ & 0,463 & 0,326 & 0,516 & 0,380 \\
$\mathbf{2}$ & 0,543 & 0,360 & 0,570 & 0,370 \\
$\mathbf{3}$ & 0,483 & 0,336 & 0,580 & 0,340 \\
$\mathbf{4}$ & 0,240 & 0,290 & 0,303 & 0,290 \\
$\mathbf{5}$ & 0,403 & 0,276 & 0,416 & 0,283 \\
$\mathbf{6}$ & 0,343 & 0,423 & 0,426 & 0,430 \\
$\mathbf{7}$ & 0,286 & 0,346 & 0,353 & 0,346 \\
$\mathbf{8}$ & 0,300 & 0,256 & 0,300 & 0,260 \\
$\mathbf{9}$ & 0,450 & 0,166 & 0,461 & 0,166 \\
$\mathbf{1 0}$ & 0,386 & 0,216 & 0,390 & 0,260 \\
$\mathbf{X}$ & $\mathbf{0 , 3 9 0}$ & $\mathbf{0 , 2 9 9}$ & $\mathbf{0 , 4 3 1}$ & $\mathbf{0 , 3 1 2}$ \\
$\mathbf{s}$ & $\mathbf{0 , 0 9 7}$ & $\mathbf{0 , 0 7 5}$ & $\mathbf{0 , 1 0 0}$ & $\mathbf{0 , 0 7 6}$ \\
\hline
\end{tabular}


Tabela 04. Resultados de cor para as amostras livres de metal da cerâmica Triceram submetidas ao envelhecimento artificial acelerado.

\begin{tabular}{|c|c|c|c|c|c|c|c|c|c|c|}
\hline & \multicolumn{3}{|c|}{ ANTES } & \multicolumn{3}{|c|}{ APÓS } & \multicolumn{4}{|c|}{ VARIAÇÃO } \\
\hline & $\mathbf{L}^{*}$ & $a^{*}$ & $\mathbf{b}^{*}$ & $L^{*}$ & $A^{*}$ & $\mathbf{b}^{*}$ & $\Delta \mathbf{L}^{*}$ & $\Delta \mathbf{a}^{*}$ & $\Delta \mathbf{b}^{*}$ & $\Delta \mathbf{E}$ \\
\hline 1 & 64,57 & 3,96 & 17,06 & 64,4 & 4,06 & 17,2 & $-0,20$ & 0,10 & 0,09 & 0,24 \\
\hline 2 & 63,63 & 3.60 & 15,22 & 64,4 & 3,74 & 15,2 & $-0,13$ & 0,14 & 0,02 & 0,19 \\
\hline 3 & 64,38 & 3,88 & 16,02 & 63,5 & 3,92 & 15,9 & $-0,42$ & 0,03 & $-0,16$ & 0,45 \\
\hline 4 & 65,80 & 3,58 & 14,33 & 64,0 & 3,62 & 14,2 & $-0,25$ & 0,04 & $-0,10$ & 0,27 \\
\hline 5 & 65,84 & 4,21 & 17,69 & 65,5 & 4,32 & 17,7 & $-0,13$ & 0,11 & $-0,04$ & 0,17 \\
\hline 6 & 63,75 & 3,76 & 15,93 & 65,7 & 3,87 & 16,2 & 0,12 & 0,11 & 0,25 & 0,29 \\
\hline 7 & 65,20 & 4,24 & 17,56 & 63,9 & 4,40 & 17,7 & $-0,03$ & 0,16 & 0,12 & 0,20 \\
\hline 8 & 63,95 & 3,79 & 16,17 & 65,2 & 3,87 & 16,1 & $-0,33$ & 0,08 & $-0,05$ & 0,34 \\
\hline 9 & 65,77 & 4,12 & 16,45 & 63,6 & 4,34 & 16,5 & $-0,21$ & 0,22 & 0,05 & 0,30 \\
\hline 10 & 64,45 & 3,94 & 16,32 & 65,6 & 4,32 & 16,9 & 0,10 & 0,38 & 0,53 & 0,65 \\
\hline $\mathbf{X}$ & 64,51 & 3,94 & 16,25 & 64,40 & 3,99 & 16,35 & $-0,17$ & $\mathbf{0 , 1 1}$ & 0,04 & 0,28 \\
\hline $\mathbf{s}$ & 0,86 & 0,22 & 1,02 & $\mathbf{0 , 8 5}$ & 0,28 & 1,10 & $\mathbf{0 , 1 7}$ & $\mathbf{0 , 1 0}$ & $\mathbf{0 , 2 0}$ & 0,14 \\
\hline
\end{tabular}

Tabela 05. Resultados de cor para as amostras livres de metal da cerâmica Noritake Ti 22 submetidas ao envelhecimento artificial acelerado.

\begin{tabular}{|c|c|c|c|c|c|c|c|c|c|c|}
\hline & \multicolumn{3}{|c|}{ ANTES } & \multicolumn{3}{|c|}{ APÓS } & \multicolumn{4}{|c|}{ VARIAÇÃO } \\
\hline & $\mathbf{L}^{*}$ & $a^{*}$ & $\mathrm{~B}^{*}$ & $\mathbf{L}^{*}$ & $\mathbf{A}^{*}$ & $\mathbf{b}^{*}$ & $\Delta \mathbf{L}^{*}$ & $\Delta \mathbf{a}^{*}$ & $\Delta \mathbf{b}^{*}$ & $\Delta \mathbf{E}$ \\
\hline 1 & 67,33 & 4,89 & 17,81 & 67,3 & 67,3 & 18,1 & $-0,04$ & $-0,07$ & 0,31 & 0,32 \\
\hline 2 & 67,05 & 4,99 & 19,06 & 67,1 & 67,1 & 19,2 & 0,03 & $-0,03$ & 0,11 & 0,11 \\
\hline 3 & 67,40 & 4,86 & 18,85 & 67,6 & 67,6 & 19,1 & 0,21 & 0 & 0,26 & 0,33 \\
\hline 4 & 67,09 & 4,49 & 18,60 & 67,0 & 67,0 & 19,3 & $-0,07$ & 0,06 & 0,68 & 0,68 \\
\hline 5 & 68,04 & 4,90 & 21,32 & 67,7 & 67,7 & 21,0 & $-0,34$ & $-0,21$ & $-0,31$ & 0,50 \\
\hline 6 & 67,44 & 4,93 & 19,74 & 67,3 & 67,3 & 19,7 & $-0,11$ & $-0,09$ & $-0,07$ & 0,15 \\
\hline 7 & 66,67 & 4,75 & 18,81 & 66,7 & 66,7 & 18,8 & 0,01 & $-0,01$ & $-0,01$ & 0,01 \\
\hline 8 & 68,59 & 5,36 & 24,55 & 68,2 & 68,2 & 24,3 & $-0,39$ & $-0,23$ & $-0,24$ & 0,51 \\
\hline 9 & 67,78 & 4,80 & 20,44 & 67,6 & 67,6 & 19,9 & $-0,22$ & $-0,08$ & $-0,53$ & 0,57 \\
\hline 10 & 68,29 & 4,60 & 20,61 & 68,3 & 68,3 & 20,8 & 0 & 0,02 & 0,17 & 0,17 \\
\hline $\mathbf{X}$ & 67,42 & 4,88 & 19,40 & 67,45 & 67,45 & 19,50 & $-0,06$ & $-0,05$ & 0,05 & $\mathbf{0 , 3 3}$ \\
\hline $\mathbf{s}$ & 0,60 & 0,23 & 1,93 & $\mathbf{0 , 5 1}$ & $\mathbf{0 , 5 1}$ & 1,74 & 0,18 & $\mathbf{0 , 0 9}$ & $\mathbf{0 , 3 5}$ & 0,22 \\
\hline
\end{tabular}

Os resultados obtidos antes e após as leituras de rugosidade superficial e cor das amostras metalocerâmicas das cerâmicas Triceram e Noritake Ti 22 submetidas ao envelhecimento artificial acelerado estão descritos nas Tabelas 06 a 08. 
Tabela 06. Resultados de rugosidade superficial $(\mu \mathrm{m})$ para as amostras metalocerâmicas das cerâmicas Triceram e Noritake Ti22 submetidas ao envelhecimento artificial acelerado.

\begin{tabular}{ccccc}
\hline & \multicolumn{2}{c}{ ANTES } & \multicolumn{2}{c}{ DEPOIS } \\
\hline $\mathbf{1}$ & Triceram & Noritake Ti22 & Triceram & Noritake Ti22 \\
$\mathbf{2}$ & 0,240 & 0,213 & 0,240 & 0,220 \\
$\mathbf{3}$ & 0,270 & 0,330 & 0,323 & 0,330 \\
$\mathbf{4}$ & 0,295 & 0,300 & 0,300 & 0,380 \\
$\mathbf{5}$ & 0,372 & 0,366 & 0,420 & 0,426 \\
$\mathbf{6}$ & 0,376 & 0,233 & 0,512 & 0,233 \\
$\mathbf{7}$ & 0,170 & 0,303 & 0,170 & 0,303 \\
$\mathbf{8}$ & 0,334 & 0,303 & 0,339 & 0,320 \\
$\mathbf{9}$ & 0,232 & 0,213 & 0,267 & 0,226 \\
$\mathbf{1 0}$ & 0,230 & 0,260 & 0,280 & 0,266 \\
$\mathbf{X}$ & 0,300 & 0,166 & 0,300 & 0,200 \\
$\mathbf{S}$ & $\mathbf{0 , 2 8 2}$ & $\mathbf{0 , 2 6 9}$ & $\mathbf{0 , 3 1 5}$ & $\mathbf{0 , 2 9 0}$ \\
\hline
\end{tabular}

Tabela 07. Resultados de cor para as amostras metalocerâmicas da cerâmica Triceram submetidas ao envelhecimento artificial acelerado.

\begin{tabular}{ccccccccccc}
\hline & \multicolumn{3}{c}{ ANTES } & \multicolumn{3}{c}{ APÓS } & \multicolumn{3}{c}{ VARIAÇÃO } \\
\hline & $\mathbf{L}^{*}$ & $\mathbf{A}^{*}$ & $\mathbf{B}^{*}$ & $\mathbf{L}^{*}$ & $\mathbf{a}^{*}$ & $\mathbf{b}^{*}$ & $\Delta \mathbf{L}^{*}$ & $\Delta \mathbf{a}^{*}$ & $\Delta \mathbf{b}^{*}$ & $\Delta \mathbf{E}$ \\
\hline $\mathbf{1}$ & 68,29 & 4,77 & 20,45 & 67,9 & 4,74 & 20,6 & $-0,44$ & $-0,02$ & 0,19 & 0,47 \\
$\mathbf{2}$ & 68,77 & 5,03 & 20,76 & 68,3 & 4,85 & 20,8 & $-0,52$ & $-0,18$ & 0,05 & 0,55 \\
$\mathbf{3}$ & 68,19 & 5,07 & 20,47 & 67,6 & 4,89 & 20,1 & $-0,61$ & $-0,18$ & $-0,34$ & 0,72 \\
$\mathbf{4}$ & 69,10 & 5,23 & 21,11 & 68,4 & 5,10 & 20,7 & $-0,66$ & $-0,13$ & $-0,42$ & 0,79 \\
$\mathbf{5}$ & 68,44 & 4,75 & 20,01 & 68,3 & 4,91 & 20,6 & $-0,16$ & 0,15 & 0,55 & 0,59 \\
$\mathbf{6}$ & 67,79 & 5,09 & 20,51 & 67,1 & 4,87 & 20,7 & $-0,72$ & $-0,21$ & 0,16 & 0,76 \\
$\mathbf{7}$ & 68,29 & 5,07 & 20,22 & 67,8 & 5,04 & 20,0 & $-0,54$ & $-0,03$ & $-0,18$ & 0,56 \\
$\mathbf{8}$ & 68,51 & 4,81 & 20,64 & 68,0 & 4,83 & 20,5 & $-0,50$ & 0,01 & $-0,13$ & 0,51 \\
$\mathbf{9}$ & 68,73 & 4,63 & 20,27 & 68,2 & 4,61 & 20,0 & $-0,54$ & $-0,01$ & $-0,23$ & 0,58 \\
$\mathbf{1 0}$ & 68,97 & 5,17 & 21,20 & 68,4 & 5,15 & 21,0 & $-0,52$ & $-0,02$ & $-0,15$ & 0,54 \\
\hline $\mathbf{X}$ & $\mathbf{6 8 , 4 8}$ & $\mathbf{5 , 0 5}$ & $\mathbf{2 0 , 4 9}$ & $\mathbf{6 8 , 1 0}$ & $\mathbf{4 , 8 8}$ & $\mathbf{2 0 , 6 0}$ & $\mathbf{- 0 , 5 3}$ & $\mathbf{- 0 , 0 3}$ & $\mathbf{- 0 , 1 4}$ & $\mathbf{0 , 5 7}$ \\
$\mathbf{s}$ & $\mathbf{0 , 3 9}$ & $\mathbf{0 , 2 0}$ & $\mathbf{0 , 3 8}$ & $\mathbf{0 , 4 2}$ & $\mathbf{0 , 1 6}$ & $\mathbf{0 , 3 5}$ & $\mathbf{0 , 1 5}$ & $\mathbf{0 , 1 1}$ & $\mathbf{0 , 2 9}$ & $\mathbf{0 , 1 1}$ \\
\hline
\end{tabular}


Tabela 08. Resultados de cor para as amostras metalocerâmicas da cerâmica Noritake Ti 22 submetidas ao envelhecimento artificial acelerado.

\begin{tabular}{|c|c|c|c|c|c|c|c|c|c|c|}
\hline & \multicolumn{3}{|c|}{ ANTES } & \multicolumn{3}{|c|}{ APÓS } & \multicolumn{4}{|c|}{ VARIAÇÃO } \\
\hline & $\mathbf{L}^{*}$ & $A^{*}$ & $\mathbf{B}^{*}$ & $\mathbf{L}^{*}$ & $\mathbf{a}^{*}$ & B* $^{*}$ & $\Delta \mathbf{L}^{*}$ & $\Delta \mathbf{a}^{*}$ & $\Delta \mathbf{b}^{*}$ & $\Delta \mathbf{E}$ \\
\hline 1 & 70,61 & 4,63 & 18,52 & 70,2 & 4,54 & 18,5 & $-0,45$ & $-0,09$ & $-0,02$ & 0,45 \\
\hline 2 & 69,95 & 4,82 & 20,02 & 69,5 & 4,78 & 19,9 & $-0,42$ & $-0,03$ & $-0,13$ & 0,44 \\
\hline 3 & 69,21 & 3,64 & 17,19 & 68,8 & 3,64 & 17,2 & $-0,40$ & 0 & 0 & 0,39 \\
\hline 4 & 70,21 & 4,51 & 19,11 & 69,9 & 4,44 & 19,1 & $-0,34$ & $-0,06$ & $-0,02$ & 0,34 \\
\hline 5 & 69,32 & 4,63 & 18,56 & 68,9 & 4,53 & 18,6 & $-0,44$ & $-0,10$ & 0 & 0,45 \\
\hline 6 & 69,28 & 4,95 & 19,49 & 68,9 & 4,99 & 19,4 & $-0,33$ & 0,03 & $-0,11$ & 0,34 \\
\hline 7 & 70,70 & 4,94 & 19,81 & 70,3 & 4,91 & 19,7 & $-0,42$ & $-0,03$ & $-0,08$ & 0,42 \\
\hline 8 & 70,41 & 4,80 & 19,02 & 70,1 & 4,76 & 18,9 & $-0,28$ & $-0,04$ & $-0,08$ & 0,29 \\
\hline 9 & 69,70 & 4,58 & 19,73 & 69,4 & 4,53 & 19,8 & $-0,27$ & $-0,04$ & 0,06 & 0,27 \\
\hline 10 & 67,98 & 3,07 & 17,00 & 67,4 & 3,01 & 16,9 & $-0,54$ & $-0,05$ & $-0,08$ & 0,54 \\
\hline $\mathbf{X}$ & 69,83 & 4,63 & 19,07 & 69,45 & 4,54 & 19,00 & $-0,41$ & $\begin{array}{l}-0,04 \\
\end{array}$ & $-0,05$ & 0,41 \\
\hline $\mathbf{s}$ & $\mathbf{0 , 8 3}$ & 0,61 & 1,05 & $\mathbf{0 , 8 8}$ & 0,62 & 1,04 & 0,08 & 0,04 & 0,06 & 0,08 \\
\hline
\end{tabular}

Na Figura 10 estão expressas as representações gráficas das médias e desvio padrão dos resultados obtidos das análises de rugosidade superficial, antes e após o envelhecimento artificial acelerado.

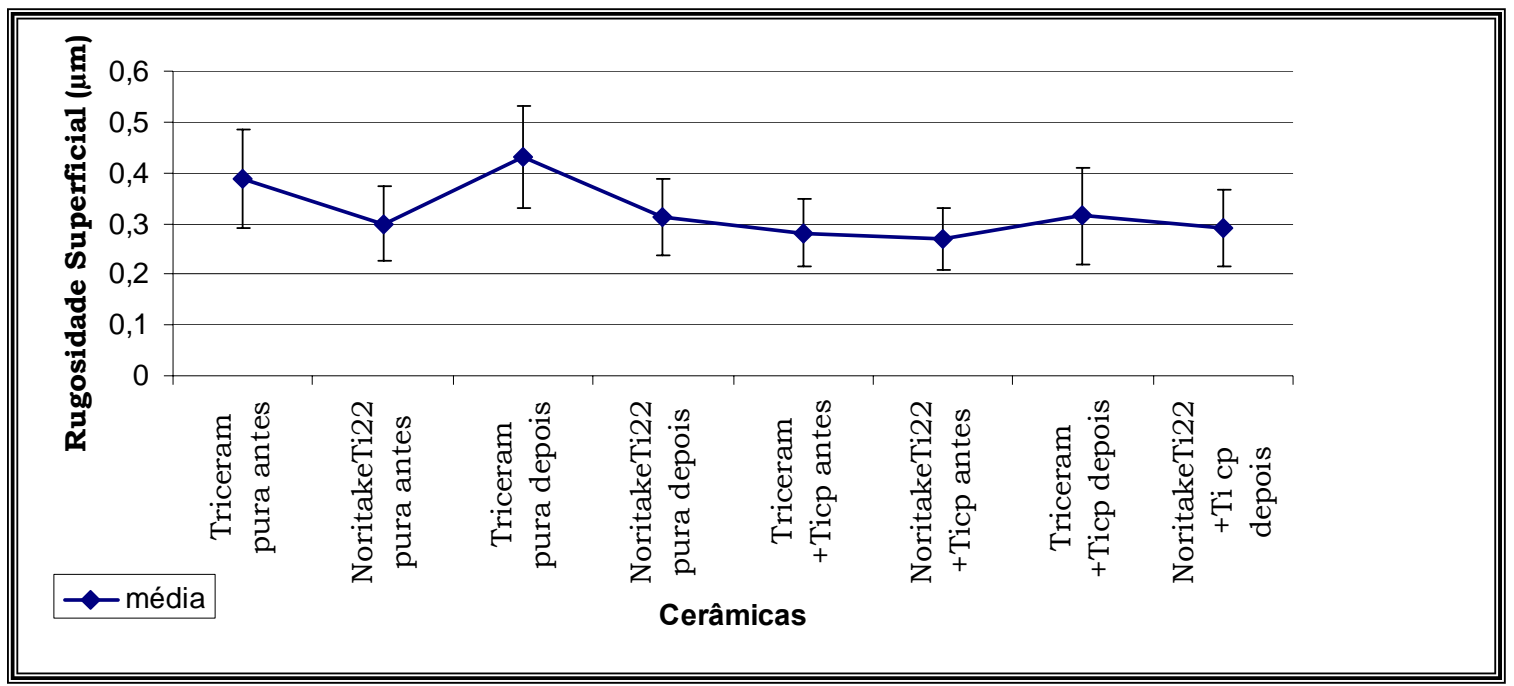

Figura 10. Valores médios e desvio padrão dos valores de rugosidade superficial ( $\mu \mathrm{m})$ para as cerâmicas Triceram e Noritake Ti 22 puras ou aplicadas ao metal, antes e após o envelhecimento artificial acelerado. 
Para análise estatística dos valores obtidos, os dados observados foram submetidos à Análise de Variância (Tabela 09) e Teste Complementar de Duncan para $\alpha=0,05$ (Tabela 10) utilizando-se programa estatístico (SPSS - LEAD Technologies, Inc.).

Tabela 09. Análise de Variância da rugosidade superficial para os grupos livres de metal e metalocerâmicos submetidos ao envelhecimento artificial acelerado.

\begin{tabular}{|c|c|c|c|c|c|}
\hline & \multirow{2}{*}{$\begin{array}{l}\text { Soma dos } \\
\text { quadrados }\end{array}$} & \multicolumn{3}{|c|}{ Quadrado } & \multirow[b]{2}{*}{ Sig. } \\
\hline & & Df & Médio & $\mathrm{F}$ & \\
\hline Grupos & 0,226 & 7 & 0,032 & 4,811 & 0,0002 \\
\hline Erro & 0,484 & 72 & 0,007 & & \\
\hline Total & 0,711 & 79 & & & \\
\hline
\end{tabular}

Tabela 10. Teste complementar de Duncan da rugosidade superficial para os grupos livres de metal e metalocerâmicos submetidos ao envelhecimento artificial acelerado.

\begin{tabular}{lccc}
\hline VAR00002 & \multicolumn{3}{c}{$\mathrm{P}=0.05$} \\
\hline Noritake Ti22/ Ti cp. antes & 10 & 0,2687 & 2 \\
Triceram/Ti cp. antes & 10 & 0,2819 & \\
Noritake Ti22/ Ticp depois & 10 & 0,2904 & \\
Noritake Ti22 pura antes & 10 & 0,2995 & \\
Noritake Ti22 pura depois & 10 & 0,3125 & \\
Triceram/ Ti cp depois & 10 & 0,3151 & \\
Triceram pura antes & 10 & & 0,3897 \\
Triceram pura depois & 10 & & 0,4315 \\
\hline Significância & & 0,277 & 0,258 \\
\hline
\end{tabular}

Os valores de rugosidade superficial para a cerâmica Triceram livre de metal tanto antes quanto após o envelhecimento artificial acelerado foram estatisticamente semelhantes. No entanto, esses valores apresentaram-se maiores e estatisticamente diferentes dos demais [Triceram pura: antes $(0,39 \pm 0,09)$ e depois $(0,43 \pm 0,1)$; Noritake Ti 22 pura: antes $(0,30 \pm 0,07)$ e depois $(0,31 \pm 0,07)$; Triceram com Titânio cp.: antes $(0,29 \pm 0,07)$ e depois $(0,32 \pm 0,09)$; Noritake Ti 22 com Titânio cp.: antes $(0,27 \pm 0,06)$ e depois $(0,30 \pm$ $0,07)]$. 
Para a cerâmica Noritake Ti 22 livre de metal a análise estatística mostrou que não houve diferença entre os valores obtidos antes ou após o envelhecimento artificial acelerado. O mesmo foi observado para as cerâmicas Triceram e Noritake Ti 22 aplicadas ao Titânio comercialmente puro (cp). Esses grupos apresentaram valores de rugosidade superficial, estatisticamente semelhantes entre si, tanto antes quanto após o envelhecimento artificial acelerado.

Para rugosidade superficial $(\mathrm{Ra})$ a cerâmica Triceram livre de metal, tanto antes quanto após o envelhecimento artificial acelerado apresentou os maiores valores de rugosidade superficial, diferindo dos demais grupos.

Na Figura 11 estão expressas as representações gráficas das médias e desvio padrão dos resultados obtidos das análises de cor, antes e após o envelhecimento artificial acelerado.

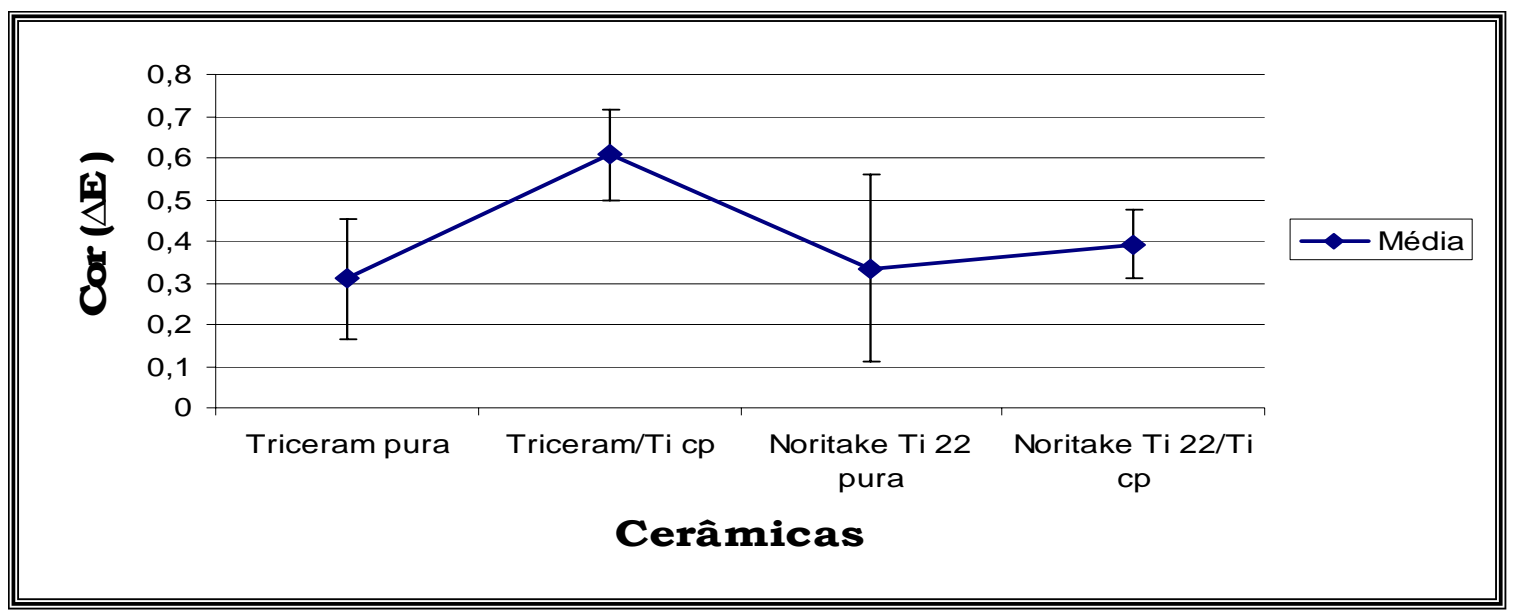

Figura 11. Valores médios da alteração de cor $(\Delta \mathrm{E})$ para as cerâmicas Triceram e Noritake Ti 22 puras ou aplicadas ao metal.

Para a análise estatística foram utilizados os valores que expressam a mudança total de cor ( $\Delta$ E) que foram submetidos à Análise de Variância (Tabela 11) e Teste Complementar de Duncan para $\alpha=0,05$ (Tabela 12) utilizando-se software estatístico (SPSS - LEAD Technologies, Inc.). 
Tabela 11. Análise de Variância da alteração de cor $(\Delta \mathrm{E})$ para os grupos livres de metal e metalocerâmicos submetidos ao envelhecimento artificial acelerado.

\begin{tabular}{|c|c|c|c|c|c|}
\hline & Soma dos & \multicolumn{3}{|c|}{ Soma dos } & \multirow[b]{2}{*}{ Sig. } \\
\hline & Quadrados & $\mathrm{df}$ & Quadrados & $\mathrm{F}$ & \\
\hline Grupos & 0,547 & 3 & 0,182 & 8,101 & 0,0003 \\
\hline Erro & 0,810 & 36 & 0,023 & & \\
\hline Total & 1,358 & 39 & & & \\
\hline
\end{tabular}

Tabela 12. Teste complementar de Duncan da alteração de cor $(\Delta \mathrm{E})$ para os grupos livres de metal e metalocerâmicos submetidos ao envelhecimento artificial acelerado.

\begin{tabular}{lccr}
\hline VAR00002 & $\mathrm{N}$ & \multicolumn{2}{c}{$\mathrm{P}=0.05$} \\
\hline Triceram & & 1 & 2 \\
Ti 22 & 10 & 0,3100 & \\
Ti 22/ Ti cp & 10 & 0,3350 & \\
Triceram / Ti cp & 10 & 0,3930 & \\
\hline Significância & 10 & & 0,6070 \\
\hline
\end{tabular}

Quando analisado o $\Delta \mathrm{E}\left[\sqrt{ }\left(\Delta \mathrm{L}^{*}\right)+\left(\Delta \mathrm{a}^{*}\right)+\left(\Delta \mathrm{b}^{*}\right)\right]$ o grupo representado pela cerâmica Triceram com Titânio cp. foi o único que se apresentou estatisticamente diferentes dos demais, possuindo os maiores valores para $\Delta \mathrm{E}$. Os demais grupos não diferiram estatisticamente entre si (Triceram pura: $0,31 \pm 0,14$; Noritake Ti22 pura: 0,34 $\pm 0,22$; Triceram com Titânio cp.: 0,61 \pm 0,11; Noritake Ti 22 com Titânio cp.: 0,39 $\pm 0,08$ ).

\subsection{Fluorfosfato Acidulado 1,23\%}

Os resultados obtidos antes e após as leituras de rugosidade superficial e cor das amostras livres de metal das cerâmicas Triceram e Noritake Ti 22 submetidas ao armazenamento em fluorfosfato acidulado estão descritos nas Tabelas 13 a 15. 
Tabela 13. Resultados de rugosidade superficial $(\mu \mathrm{m})$ para as amostras livres de metal das cerâmicas Triceram e Noritake Ti22 submetidas ao armazenamento em fluorfosfato acidulado.

\begin{tabular}{ccccc}
\hline & \multicolumn{2}{c}{ ANTES } & \multicolumn{2}{c}{ DEPOIS } \\
\hline $\mathbf{1}$ & Triceram & Noritake Ti22 & Triceram & Noritake Ti22 \\
$\mathbf{2}$ & 0,313 & 0,267 & 1,053 & 3,587 \\
$\mathbf{3}$ & 0,357 & 0,517 & 1,413 & 1,797 \\
$\mathbf{4}$ & 0,370 & 0,173 & 2,293 & 2,330 \\
$\mathbf{5}$ & 0,340 & 0,227 & 3,913 & 4,133 \\
$\mathbf{6}$ & 0,380 & 0,300 & 2,586 & 1,977 \\
$\mathbf{7}$ & 0,263 & 0,357 & 3,210 & 3,747 \\
$\mathbf{8}$ & 0,300 & 0,300 & 1,993 & 2,103 \\
$\mathbf{9}$ & 0,310 & 0,397 & 2,427 & 2,990 \\
$\mathbf{1 0}$ & 0,307 & 0,333 & 1,813 & 2,873 \\
$\mathbf{X}$ & 0,313 & 0,303 & 1,290 & 2,063 \\
$\mathbf{S}$ & $\mathbf{0 , 3 2 5}$ & $\mathbf{0 , 3 1 7}$ & $\mathbf{2 , 1 9 9}$ & $\mathbf{2 , 7 6 0}$ \\
\hline
\end{tabular}

Tabela 14. Resultados de cor para as amostras livres de metal da cerâmica Triceram submetidas ao armazenamento em fluorfosfato acidulado.

\begin{tabular}{ccccccccccc}
\hline & \multicolumn{3}{c}{ ANTES } & \multicolumn{4}{c}{ APÓS } & \multicolumn{4}{c}{ VARIAÇÃO } \\
\hline & $\mathbf{L}^{*}$ & $\mathbf{A}^{*}$ & $\mathbf{B}^{*}$ & $\mathbf{L}^{*}$ & $\mathbf{A}^{*}$ & $\mathbf{B}^{*}$ & $\Delta \mathbf{L}^{*}$ & $\Delta \mathbf{a}^{*}$ & $\Delta \mathbf{b}^{*}$ & $\Delta \mathbf{E}$ \\
\hline $\mathbf{1}$ & 65,00 & 3,99 & 17,40 & 67,9 & 3,45 & 13,20 & 2,91 & $-0,54$ & $-4,20$ & 5,13 \\
$\mathbf{2}$ & 64,86 & 3,82 & 18,33 & 66,6 & 4,06 & 16,60 & 1,77 & 0,24 & $-1,71$ & 2,47 \\
$\mathbf{3}$ & 65,89 & 3,60 & 15,96 & 69,2 & 3,12 & 12,10 & 3,26 & $-0,47$ & $-3,82$ & 5,04 \\
$\mathbf{4}$ & 65,47 & 4,05 & 17,86 & 68,7 & 3,51 & 12,70 & 3,23 & $-0,54$ & $-5,12$ & 6,07 \\
$\mathbf{5}$ & 66,73 & 4,36 & 18,47 & 71,2 & 3,66 & 11,60 & 4,46 & $-0,69$ & $-6,83$ & 8,18 \\
$\mathbf{6}$ & 64,81 & 3,98 & 18,00 & 68,2 & 3,53 & 13,90 & 3,41 & $-0,44$ & $-4,10$ & 5,35 \\
$\mathbf{7}$ & 66,43 & 3,12 & 13,49 & 70,7 & 2,54 & 8,38 & 4,21 & $-0,58$ & $-5,11$ & 6,64 \\
$\mathbf{8}$ & 65,55 & 4,10 & 18,08 & 68,9 & 3,69 & 13,80 & 3,36 & $-0,40$ & $-4,24$ & 5,42 \\
$\mathbf{9}$ & 63,86 & 3,73 & 16,70 & 68,7 & 3,11 & 10,50 & 4,81 & $-0,61$ & $-6,22$ & 7,88 \\
$\mathbf{1 0}$ & 64,81 & 4,03 & 18,48 & 68,3 & 3,73 & 14,50 & 3,50 & $-0,30$ & $-3,98$ & 5,30 \\
\hline $\mathbf{X}$ & $\mathbf{6 5 , 2 4}$ & $\mathbf{3 , 9 9}$ & $\mathbf{1 7 , 9 3}$ & $\mathbf{6 8 , 7 0}$ & $\mathbf{3 , 5 2}$ & $\mathbf{1 2 , 9 5}$ & $\mathbf{3 , 3 9}$ & $\mathbf{- 0 , 5 1}$ & $\mathbf{- 4 , 2 2}$ & $\mathbf{5 , 3 9}$ \\
$\mathbf{S}$ & $\mathbf{0 , 8 6}$ & $\mathbf{0 , 3 4}$ & $\mathbf{1 , 5 6}$ & $\mathbf{1 , 3 3}$ & $\mathbf{0 , 4 2}$ & $\mathbf{2 , 2 7}$ & $\mathbf{0 , 8 6}$ & $\mathbf{0 , 2 6}$ & $\mathbf{1 , 4 1}$ & $\mathbf{1 , 6 1}$ \\
\hline
\end{tabular}


Tabela 15. Resultados de cor para as amostras livres de metal da cerâmica Noritake Ti 22 submetidas ao armazenamento em fluorfosfato acidulado.

\begin{tabular}{ccccccccccc}
\hline & \multicolumn{3}{c}{ ANTES } & \multicolumn{3}{c}{ APÓS } & \multicolumn{4}{c}{ VARIAÇ̃̃O } \\
\hline & $\mathbf{L}^{*}$ & $\mathbf{A}^{*}$ & \multicolumn{1}{c}{$\mathbf{b}^{*}$} & \multicolumn{1}{c}{$\mathbf{L}^{*}$} & $\mathbf{A}^{*}$ & \multicolumn{1}{c}{$\mathbf{B}^{*}$} & $\Delta \mathbf{L}^{*}$ & $\Delta \mathbf{a}^{*}$ & $\Delta \mathbf{b}^{*}$ & $\Delta \mathbf{E}$ \\
\hline $\mathbf{1}$ & 66,36 & 4,11 & 16,98 & 70,7 & 3,63 & 11,40 & 4,30 & $-0,48$ & $-5,57$ & 7,05 \\
$\mathbf{2}$ & 65,87 & 4,49 & 16,90 & 70,4 & 3,84 & 11,50 & 4,47 & $-0,65$ & $-5,44$ & 7,07 \\
$\mathbf{3}$ & 66,03 & 4,53 & 16,62 & 70,1 & 3,86 & 11,20 & 4,09 & $-0,67$ & $-5,38$ & 6,79 \\
$\mathbf{4}$ & 65,91 & 4,69 & 17,73 & 70,6 & 3,86 & 11,50 & 4,65 & $-0,83$ & $-6,18$ & 7,77 \\
$\mathbf{5}$ & 63,78 & 3,24 & 12,94 & 69,1 & 2,64 & 8,84 & 5,34 & $-0,59$ & $-4,10$ & 6,75 \\
$\mathbf{6}$ & 66,20 & 4,54 & 19,86 & 71,2 & 3,95 & 12,50 & 5,03 & $-0,58$ & $-7,32$ & 8,90 \\
$\mathbf{7}$ & 66,03 & 4,86 & 19,15 & 70,5 & 4,27 & 13,60 & 4,47 & $-0,58$ & $-5,54$ & 7,14 \\
$\mathbf{8}$ & 66,29 & 4,25 & 17,67 & 70,7 & 3,42 & 11,70 & 4,39 & $-0,82$ & $-5,99$ & 7,47 \\
$\mathbf{9}$ & 65,88 & 4,69 & 21,60 & 70,2 & 4,08 & 14,50 & 4,30 & $-0,60$ & $-7,15$ & 8,36 \\
$\mathbf{1 0}$ & 66,17 & 4,59 & 18,38 & 70,7 & 3,93 & 11,90 & 4,51 & $-0,65$ & $-6,51$ & 7,94 \\
\hline $\mathbf{X}$ & $\mathbf{6 6 , 0 3}$ & $\mathbf{4 , 5 4}$ & $\mathbf{1 7 , 7 0}$ & $\mathbf{7 0 , 5 5}$ & $\mathbf{3 , 8 6}$ & $\mathbf{1 1 , 6 0}$ & $\mathbf{4 , 4 7}$ & $\mathbf{- 0 , 6 3}$ & $\mathbf{- 5 , 7 8}$ & $\mathbf{7 , 3 1}$ \\
$\mathbf{s}$ & $\mathbf{0 , 7 5}$ & $\mathbf{0 , 4 6}$ & $\mathbf{2 , 2 9}$ & $\mathbf{0 , 5 6}$ & $\mathbf{0 , 4 5}$ & $\mathbf{1 , 5 1}$ & $\mathbf{0 , 3 7}$ & $\mathbf{0 , 1 1}$ & $\mathbf{0 , 9 4}$ & $\mathbf{0 , 7 1}$ \\
\hline
\end{tabular}

Os resultados obtidos antes e após as leituras de rugosidade superficial e cor das amostras metalocerâmicas das cerâmicas Triceram e Noritake Ti 22 submetidas ao armazenamento em fluorfosfato acidulado estão descritos nas Tabelas 16 a 18 .

Tabela 16. Resultados de rugosidade superficial $(\mu \mathrm{m})$ para as amostras metalocerâmicas das cerâmicas Triceram e Noritake Ti22 submetidas ao armazenamento em fluorfosfato acidulado.

\begin{tabular}{ccccc}
\hline & \multicolumn{2}{c}{ ANTES } & \multicolumn{2}{c}{ DEPOIS } \\
\hline & Triceram & Noritake Ti22 & Triceram & Noritake Ti22 \\
\hline $\mathbf{1}$ & 0,163 & 0,100 & 2,500 & 3,037 \\
$\mathbf{2}$ & 0,133 & 0,193 & 2,953 & 3,670 \\
$\mathbf{3}$ & 0,130 & 0,087 & 2,620 & 2,740 \\
$\mathbf{4}$ & 0,123 & 0,090 & 3,257 & 2,977 \\
$\mathbf{5}$ & 0,087 & 0,123 & 2,140 & 3,367 \\
$\mathbf{6}$ & 0,160 & 0,137 & 2,020 & 2,923 \\
$\mathbf{7}$ & 0,137 & 0,167 & 2,397 & 3,533 \\
$\mathbf{8}$ & 0,153 & 0,100 & 2,837 & 2,673 \\
$\mathbf{9}$ & 0,090 & 0,130 & 2,313 & 3,650 \\
$\mathbf{1 0}$ & 0,131 & 0,125 & 2,560 & 3,174 \\
\hline $\mathbf{X}$ & $\mathbf{0 , 1 3 7}$ & $\mathbf{0 , 1 2 5}$ & $\mathbf{2 , 5 6 0}$ & $\mathbf{3 , 1 7 4}$ \\
$\mathbf{S}$ & $\mathbf{0 , 0 2 6}$ & $\mathbf{0 , 0 3 4}$ & $\mathbf{0 , 3 7 7}$ & $\mathbf{0 , 3 6 5}$ \\
\hline
\end{tabular}


Tabela 17. Resultados de cor para as amostras metalocerâmicas da cerâmica Triceram submetidas ao armazenamento em fluorfosfato acidulado.

\begin{tabular}{ccccccccccc}
\hline & \multicolumn{3}{c}{ ANTES } & \multicolumn{3}{c}{ APÓS } & \multicolumn{4}{c}{ VARIAÇÃO } \\
\hline & $\mathbf{L}^{*}$ & $\mathbf{a}^{*}$ & $\mathbf{B}^{*}$ & $\mathbf{L}^{*}$ & $\mathbf{a}^{*}$ & $\mathbf{b}^{*}$ & $\Delta \mathbf{L}^{*}$ & $\Delta \mathbf{a}^{*}$ & $\Delta \mathbf{b}^{*}$ & $\Delta \mathbf{E}$ \\
\hline $\mathbf{1}$ & 66,25 & 4,36 & 18,78 & 70,90 & 3,37 & 11,10 & 4,65 & $-0,98$ & $-7,71$ & 9,05 \\
$\mathbf{2}$ & 67,87 & 5,09 & 21,01 & 71,70 & 4,47 & 13,80 & 3,78 & $-0,61$ & $-7,19$ & 8,14 \\
$\mathbf{3}$ & 66,91 & 4,54 & 19,49 & 70,60 & 4,22 & 14,80 & 3,64 & $-0,32$ & $-4,67$ & 5,92 \\
$\mathbf{4}$ & 67,29 & 4,40 & 19,49 & 71,20 & 3,53 & 11,90 & 3,93 & $-0,87$ & $-7,58$ & 8,58 \\
$\mathbf{5}$ & 66,98 & 4,36 & 19,66 & 71,00 & 4,05 & 14,20 & 3,97 & $-0,31$ & $-5,45$ & 6,74 \\
$\mathbf{6}$ & 68,46 & 4,68 & 20,98 & 71,80 & 4,62 & 16,70 & 3,33 & $-0,05$ & $-4,27$ & 5,41 \\
$\mathbf{7}$ & 67,12 & 4,63 & 19,91 & 70,70 & 4,26 & 15,00 & 3,59 & $-0,36$ & $-4,92$ & 6,10 \\
$\mathbf{8}$ & 67,26 & 3,85 & 19,16 & 71,40 & 3,32 & 12,40 & 4,09 & $-0,52$ & $-6,72$ & 7,88 \\
$\mathbf{9}$ & 67,82 & 4,15 & 19,88 & 71,70 & 3,45 & 13,10 & 3,91 & $-0,69$ & $-6,76$ & 7,83 \\
$\mathbf{1 0}$ & 67,33 & 4,45 & 19,82 & 71,22 & 3,92 & 13,67 & 3,88 & $-0,52$ & $-6,14$ & 7,29 \\
\hline & $\mathbf{6 7 , 2 8}$ & $\mathbf{4 , 4 3}$ & $\mathbf{1 9 , 7 4}$ & $\mathbf{7 1 , 2 1}$ & $\mathbf{3 , 9 9}$ & $\mathbf{1 3 , 7 4}$ & $\mathbf{3 , 9 0}$ & $\mathbf{- 0 , 5 2}$ & $\mathbf{- 6 , 4 3}$ & $\mathbf{7 , 5 6}$ \\
& $\mathbf{0 , 6 1}$ & $\mathbf{0 , 3 3}$ & $\mathbf{0 , 7 1}$ & $\mathbf{0 , 4 3}$ & $\mathbf{0 , 4 8}$ & $\mathbf{1 , 6 4}$ & $\mathbf{0 , 3 5}$ & $\mathbf{0 , 2 8}$ & $\mathbf{1 , 2 5}$ & $\mathbf{1 , 2 1}$ \\
\hline
\end{tabular}

Tabela 18. Resultados de cor para as amostras metalocerâmicas da cerâmica Noritake Ti22 submetidas ao armazenamento em fluorfosfato acidulado.

\begin{tabular}{ccccccccccc}
\hline & \multicolumn{3}{c}{ ANTES } & \multicolumn{3}{c}{ APÓS } & \multicolumn{4}{c}{ VARIAÇ̃̃O } \\
\hline & $\mathbf{L}^{*}$ & $\mathbf{a}^{*}$ & $\mathbf{B}^{*}$ & $\mathbf{L}^{*}$ & $\mathbf{a}^{*}$ & $\mathbf{b}^{*}$ & $\Delta \mathbf{L}^{*}$ & $\Delta \mathbf{a}^{*}$ & $\Delta \mathbf{b}^{*}$ & \multicolumn{1}{c}{$\mathbf{E}$} \\
\hline $\mathbf{1}$ & 69,87 & 3,63 & 19,65 & 73,9 & 3,11 & 11,5 & 4,04 & $-0,51$ & $-8,17$ & 9,12 \\
$\mathbf{2}$ & 68,71 & 2,87 & 18,42 & 72,0 & 2,65 & 13,1 & 3,26 & $-0,21$ & $-5,32$ & 6,24 \\
$\mathbf{3}$ & 68,62 & 2,60 & 18,47 & 72,4 & 2,57 & 12,0 & 3,72 & $-0,03$ & $-6,46$ & 7,45 \\
$\mathbf{4}$ & 69,19 & 3,28 & 18,49 & 72,4 & 2,95 & 12,9 & 3,23 & $-0,32$ & $-5,56$ & 6,43 \\
$\mathbf{5}$ & 69,17 & 4,08 & 21,50 & 73,4 & 3,30 & 12,4 & 4,22 & $-0,77$ & $-9,07$ & 10,03 \\
$\mathbf{6}$ & 68,50 & 3,35 & 20,73 & 72,6 & 2,88 & 12,8 & 4,07 & $-0,47$ & $-7,91$ & 8,9 \\
$\mathbf{7}$ & 70,45 & 3,38 & 19,12 & 73,2 & 3,01 & 12,9 & 2,76 & $-0,37$ & $-6,27$ & 6,86 \\
$\mathbf{8}$ & 68,66 & 3,60 & 19,41 & 72,3 & 3,15 & 13,0 & 3,65 & $-0,44$ & $-6,44$ & 7,41 \\
$\mathbf{9}$ & 68,12 & 4,09 & 18,99 & 72,8 & 3,46 & 11,5 & 4,68 & $-0,62$ & $-7,46$ & 8,82 \\
$\mathbf{1 0}$ & 69,03 & 3,43 & 19,42 & 72,8 & 3,01 & 12,5 & 3,74 & $-0,42$ & $-6,96$ & 7,92 \\
\hline $\mathbf{X}$ & $\mathbf{6 8 , 8 7}$ & $\mathbf{3 , 4 1}$ & $\mathbf{1 9 , 2 7}$ & $\mathbf{7 2 , 7 0}$ & $\mathbf{3 , 0 1}$ & $\mathbf{1 2 , 6 5}$ & $\mathbf{3 , 7 3}$ & $\mathbf{- 0 , 4 3}$ & $\mathbf{- 6 , 7 1}$ & $\mathbf{7 , 6 9}$ \\
$\mathbf{s}$ & $\mathbf{0 , 6 9}$ & $\mathbf{0 , 4 7}$ & $\mathbf{1 , 0 1}$ & $\mathbf{0 , 5 8}$ & $\mathbf{0 , 2 7}$ & $\mathbf{0 , 6 0}$ & $\mathbf{0 , 5 5}$ & $\mathbf{0 , 2 1}$ & $\mathbf{1 , 1 9}$ & $\mathbf{1 , 2 6}$ \\
\hline
\end{tabular}

Na Figura 12 está expressa a representação gráfica das médias e desvio padrão dos resultados obtidos da análise de rugosidade superficial, antes e após armazenamento em fluorfosfato acidulado $1,23 \%$. 


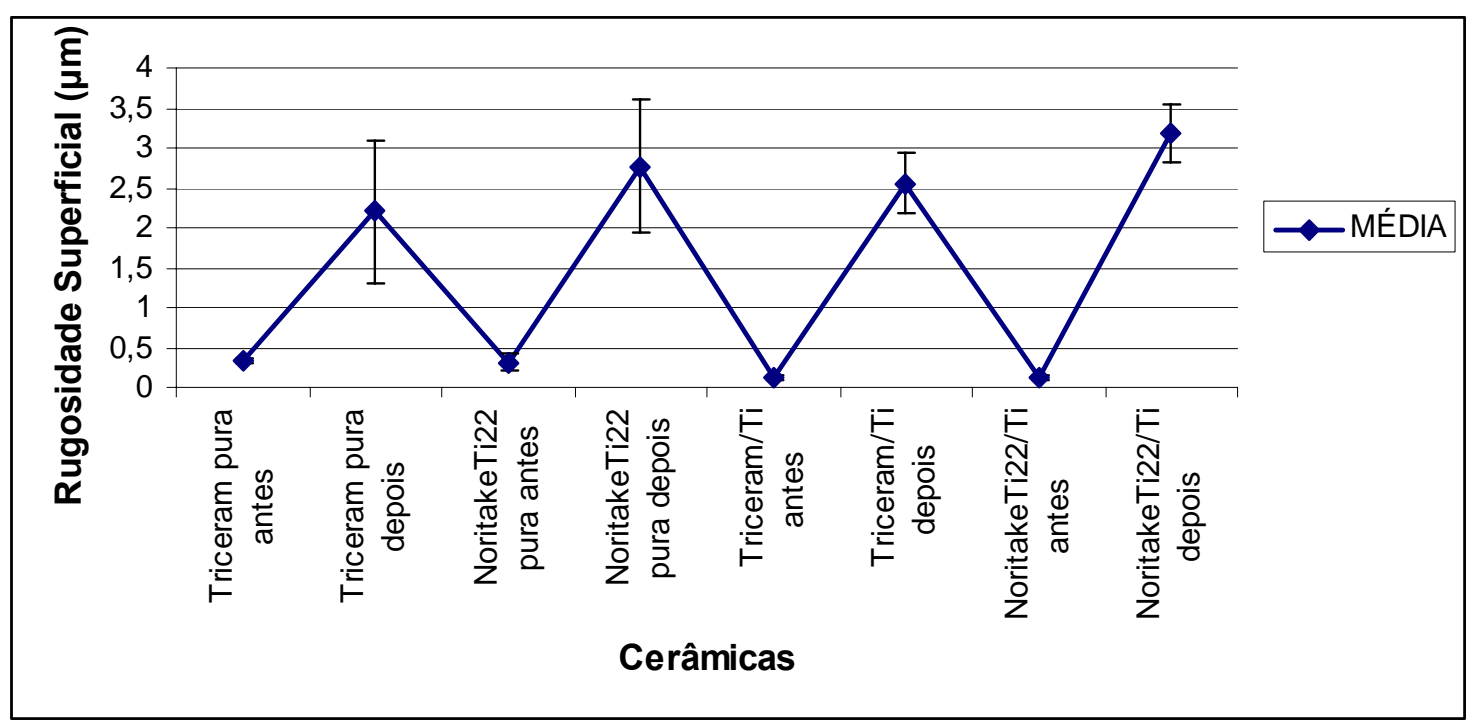

Figura 12. Valores médios de rugosidade superficial $(\mu \mathrm{m})$ para as cerâmicas Triceram e Noritake Ti22 puras ou aplicadas ao metal, antes e após o armazenamento em fluorfosfato acidulado.

Para a análise estatística foram utilizados os valores que expressam a mudança total de cor $(\Delta \mathrm{E})$ que foram submetidos à Análise de Variância (Tabela 19) e Teste Complementar de Duncan para $\alpha=0,05$ (Tabela 20) utilizando-se software estatístico (SPSS - LEAD Technologies, Inc.).

Tabela 19. Análise de Variância da rugosidade superficial para os grupos livres de metal e metalocerâmicos submetidos ao armazenamento em fluorfosfato acidulado (1,23\%).

\begin{tabular}{lrrrrr}
\hline & $\begin{array}{c}\text { Soma dos } \\
\text { quadrados }\end{array}$ & df & médios & F & Sig. \\
\hline Grupos & 125,256 & 7 & 17,894 & 80,734 & 0,000 \\
Erro & 15,958 & 72 & 0,222 & & \\
\hline Total & 141,214 & 79 & & & \\
\hline
\end{tabular}


Tabela 20. Teste complementar de Duncan da rugosidade superficial para os grupos livres de metal e metalocerâmicos submetidos ao armazenamento em fluorfosfato acidulado (1,23\%).

\begin{tabular}{lccccc}
\hline VAR00002 & $\mathrm{N}$ & \multicolumn{5}{c}{$\mathrm{P}=0.05$} \\
\hline & & 1 & 2 & 3 & 4 \\
\hline Noritake Ti22/ Ti cp. antes & 10 & 0,1252 & & & \\
Triceram/Ti cp. antes & 10 & 0,1307 & & & \\
Noritake Ti22 pura antes & 10 & 0,3174 & & & \\
Triceram pura antes & 10 & 0,3253 & & & \\
Triceram pura depois & 10 & & 2,1991 & & \\
Triceram/ Ti cp. depois & 10 & & 2,5597 & 2,5597 & \\
Noritake Ti22 pura depois & 10 & & & 2,7600 & 2,7600 \\
Noritake Ti22/ Ti cp. depois & 10 & & & & 3,1744 \\
\hline Significância & & 0,394 & 0,091 & 0,345 & 0,053 \\
\hline
\end{tabular}

Após análise estatística foi possível observar que para rugosidade superficial não houve diferença estatisticamente significante entre as duas cerâmicas, Triceram e Noritake Ti22, em amostras livres de metal e metalocerâmicas, antes do armazenamento em fluorfosfato acidulado.

Para a Triceram pôde-se verificar que após o armazenamento em fluorfosfato acidulado não houve diferença estatística entre o espécime livre de metal ou metalocerâmico. Resultado semelhante foi encontrado para a cerâmica Noritake Ti22 após o armazenamento em fluorfosfato acidulado, ou seja, não foi encontrada diferença estatisticamente significante entre as amostras livres de metal ou com titânio comercialmente puro como subestrutura metálica.

Na Figura 13 está expressa a representação gráfica das médias e desvio padrão dos resultados obtidos da análise de alteração de cor, antes e após armazenamento em fluorfosfato acidulado $1,23 \%$. 


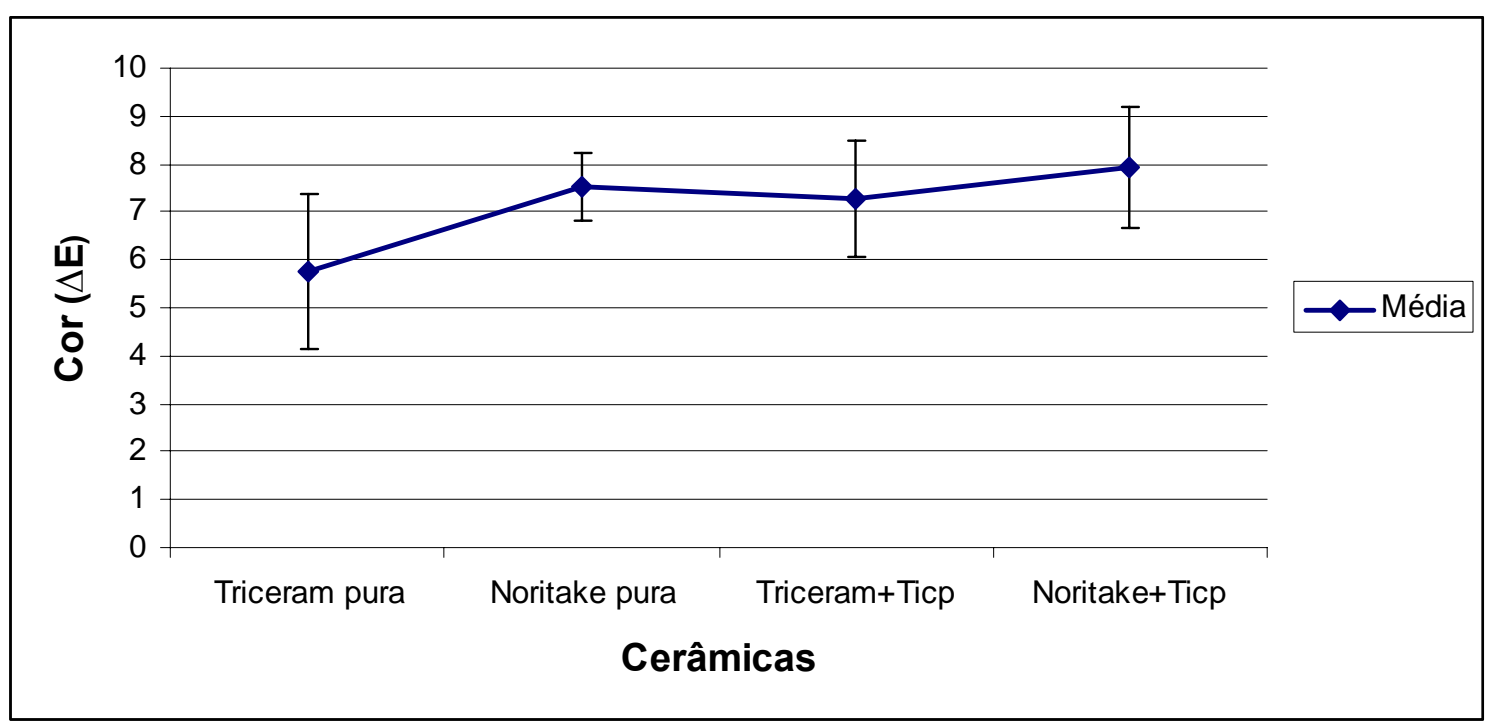

Figura 13. Valores médios da alteração de cor $(\Delta \mathrm{E})$ para as cerâmicas Triceram e Noritake Ti 22 puras ou aplicadas ao metal, após armazenamento em fluorfosfato acidulado.

Para a análise estatística foram utilizados os valores que expressam a mudança total de cor ( $\Delta$ E) que foram submetidos à Análise de Variância (Tabela 21) e Teste Complementar de Duncan para $\alpha=0,05$ (Tabela 22) utilizando-se software estatístico (SPSS - LEAD Technologies, Inc.).

Tabela 22. Análise de Variância da alteração de cor $(\Delta \mathrm{E})$ para os grupos livres de metal e metalocerâmicos submetidos ao armazenamento em fluorfosfato acidulado (1,23\%).

\begin{tabular}{|c|c|c|c|c|c|}
\hline & \multirow{2}{*}{$\begin{array}{l}\text { Soma dos } \\
\text { quadrados }\end{array}$} & \multicolumn{3}{|c|}{ Quadrado } & \multirow[b]{2}{*}{ Sig. } \\
\hline & & $\mathrm{df}$ & Médio & $\mathrm{F}$ & \\
\hline Grupos & 27,127 & 3 & 9,042 & 5,859 & 0,002 \\
\hline Erro & 55,563 & 36 & 1,543 & & \\
\hline Total & 82,689 & 39 & & & \\
\hline
\end{tabular}


Tabela 14. Teste complementar de Duncan da alteração de cor $(\Delta \mathrm{E})$ para os grupos livres de metal e metalocerâmicos submetidos ao armazenamento em fluorfosfato acidulado $(1,23 \%)$.

\begin{tabular}{|c|c|c|c|}
\hline VAR00002 & $\mathrm{N}$ & $\mathrm{P}=$ & \\
\hline & & 1 & 2 \\
\hline Triceram & 10 & 5,7480 & \\
\hline Ti 22 & 10 & & 7,2940 \\
\hline Ti 22/ Ti cp & 10 & & 7,5240 \\
\hline $\begin{array}{l}\text { Triceram / Ti } \\
\mathrm{cp}\end{array}$ & 10 & & 7,9180 \\
\hline Significância & & 1,000 & 0,297 \\
\hline
\end{tabular}

Quando analisado o $\Delta \mathrm{E}\left[\sqrt{ }\left(\Delta \mathrm{L}^{*}\right)+\left(\Delta \mathrm{a}^{*}\right)+\left(\Delta \mathrm{b}^{*}\right)\right]$, o grupo da cerâmica Triceram livre de metal foi o único que se apresentou estatisticamente diferente dos demais, possuindo os menores valores de $\Delta \mathrm{E}(5,748 \pm 1,6143)$. Já os grupos representados pelas cerâmicas Triceram metalocerâmica $(7,294 \pm 1,2135)$, Noritake Ti22 livre de metal $(7,524 \pm$ 0,7106) ou aplicada ao titânio comercialmente puro $(7,918 \pm 1,2609)$ apresentaram valores estatisticamente semelhantes entre si. 
DISCUSSÃO 


\section{DISCUSSÃO}

Com o grande aumento da valorização da estética na sociedade atual, a estabilidade de cor de materiais restauradores assume papel de grande importância para a Odontologia estética reabilitadora. É necessário que os materiais restauradores odontológicos apresentem tanto durabilidade mecânica quanto excelente aparência estética, sendo a cerâmica odontológica um material que atende muito bem a esses dois quesitos. Novas tecnologias, contudo, buscam aprimorar as propriedades das cerâmicas, visando expandir tanto seu uso, quanto sua durabilidade na cavidade oral. Parte deste aprimoramento resultou no desenvolvimento de cerâmicas odontológicas com ponto de fusão inferior a $800^{\circ} \mathrm{C}$, ou seja, as cerâmicas de ultra-baixa fusão (ANUSAVICE, 2003).

As cerâmicas odontológicas com ponto de fusão ultra-baixo são especialmente indicadas para a confecção de restaurações metalocerâmicas com o titânio como subestrutura metálica. O titânio, por características como alta biocompatibilidade, baixa densidade, alta resistência à corrosão e baixa condutibilidade térmica se mostra altamente atrativo à odontologia. Entretanto, quando fundido em temperaturas acima de $800^{\circ} \mathrm{C}$, o titânio apresenta alguns inconvenientes como alta reação com gases e formação de espessa camada de óxidos superficiais, interação química com o material de revestimento e em restaurações metalocerâmicas, dificuldade de adesão ao substrato cerâmico adjacente. Dessa maneira, foi necessário o desenvolvimento de sistemas cerâmicos que se apresentassem compatíveis com o titânio, suprindo a dificuldade de adesão entre a cerâmica e esse metal, e também oferecendo estabilidade estética a essa restauração.

Diversos trabalhos são encontrados na literatura científica a cerca da união cerâmica/titânio (TOGAYA et al.,1983; MENIS et al.; 1986; WHITE et al., 1996; CAI et al., 2001; REYES et al., 2001; CONTI, 2002; AL HUSSAINI et al., 2005). Contudo, a literatura é 
escassa quanto a estudos que avaliam a alteração de cor e a rugosidade superficial dessas cerâmicas de ultra-baixa fusão. Assim, neste trabalho, a fim de conhecer melhor essas propriedades pouco discutidas cientificamente, utilizamos as cerâmicas Triceram e Noritake Ti22, que apresentam ponto ultra-baixo de fusão, submetendo suas amostras ao envelhecimento artificial acelerado e armazenamento em fluorfosfato acidulado.

\subsection{Envelhecimento Artificial Acelerado - Rugosidade Superficial e Alteração de Cor}

$\mathrm{O}$ processo de envelhecimento artificial acelerado tem sido utilizado na odontologia como artifício para estudar os efeitos do tempo sobre diferentes propriedades físicas de diversos tipos de materiais, sendo a alteração de cor uma delas (RAZZOG et al., 1994; HEYDECKE et al., 2001).

O polimento e a lisura superficial (WRIGHT et al., 2004; DEMIREL et. al, 2005) bem como sua rugosidade, alteram a coloração final e a durabilidade de restaurações metalocerâmicas. Irregularidades presentes na superfície de uma restauração alteram a quantidade de luz refletida pelo material, modificando a percepção de sua cor. Além disso, a rugosidade superficial também altera a propagação de trincas pela restauração metalocerâmica, sendo que quanto mais rugosa a superfície, maior é a facilidade de propagação do defeito superficial para o interior da prótese, ocorrendo muitas vezes fratura do elemento protético ou descolamento total do revestimento estético da restauração, expondo o metal subjacente (ANUSAVICE, 2003).

Neste trabalho, a fim de avaliar a influência do envelhecimento artificial acelerado na rugosidade superficial e alteração de cor de duas cerâmicas de ultra-baixa fusão, amostras livres de metal e metalocerâmicas com o titânio comercialmente puro como 
subestrutura foram confeccionadas e submetidas a 384 horas de envelhecimento acelerado, o que equivale a aproximadamente 10 anos de uso clínico da restauração (FONSECA, 2005).

Quando do envelhecimento artificial acelerado, para a cerâmica Noritake Ti22, foi possível perceber que não houve diferença estatística entre a rugosidade superficial inicial (antes do envelhecimento) e final (depois do envelhecimento) de todas as amostras, ou seja, tanto os corpos-de-prova livres de metal quanto os metalocerâmicos apresentaram semelhante rugosidade superficial.

Já para a cerâmica Triceram foram encontrados resultados diferentes dos anteriores. Para essa cerâmica, as amostras livres de metal, tanto antes quanto após o envelhecimento apresentaram-se estatisticamente mais rugosas que as metalocerâmicas. Assim, foram obtidos melhores resultados de rugosidade para as amostras com titânio comercialmente puro como subestrutura.

As cerâmicas de ultra-baixa fusão, segundo Al Mutawa (2000), são compostas de finos cristais de leucita dispersos na matriz vítrea. Esses pequenos cristais podem produzir uma topografia superficial mais lisa devido à presença de partículas de carga menores quando comparadas às cerâmicas tradicionais de baixa fusão. O tamanho da partícula que constitui a cerâmica influencia a percepção da cor por afetar a dispersão, sendo que partículas menores dispersam menos luz que partículas maiores. Essas duas propriedades, a lisura superficial e o tamanho reduzido das partículas das cerâmicas de ultra-baixa fusão, são responsabilizadas por conferir a essas cerâmicas, melhor qualidade e reprodutibilidade de cor quando comparadas às cerâmicas convencionais de baixa fusão.

Neste estudo, com relação à análise de cor, foi observado que para ambas as cerâmicas Triceram e Noritake Ti22, livres de metal ou com titânio comercialmente puro como subestrutura, o $\Delta \mathrm{L}$ foi negativo para todas as situações. $\mathrm{O} \Delta \mathrm{L}(+)$ mostra que o espécime ficou mais claro, e (-) mostra que o espécime ficou mais escuro. Então, após o 
envelhecimento artificial acelerado, todas as amostras se mostraram mais escuras que o inicial. Nossos resultados foram contrários aos encontrados por Heydecke et al. em 2001, que submeteram ao envelhecimento artificial acelerado, amostras ceramo/cerâmicas.

Para a cerâmica Triceram livre de metal foi observado que após o envelhecimento artificial acelerado as amostras estavam mais vermelhas e amarelas $(\Delta \mathrm{a}$ e $\Delta \mathrm{b}$ positivos, respectivamente). Já para o grupo em que a Triceram foi aplicada sobre titânio comercialmente puro, após o envelhecimento artificial acelerado foi observado que as amostras ficaram mais verdes e azuis ( $\Delta \mathrm{a}$ e $\Delta \mathrm{b}$ negativos, respectivamente).

Para a cerâmica Noritake Ti22 livre de metal foi observado que após o envelhecimento artificial acelerado as amostras estavam mais verdes e amarelas ( $\Delta$ a negativo e $\Delta$ b positivo, respectivamente). Já para o grupo da Noritake Ti22 que possuía subestrutura em titânio comercialmente puro, após o envelhecimento artificial acelerado, as amostras se mostraram mais verdes e azuis ( $\Delta \mathrm{a}$ e $\Delta \mathrm{b}$ negativos, respectivamente), à semelhança do que foi encontrado para a cerâmica Triceram aplicada ao metal.

Para análise da alteração de cor no sistema CIE L*a*b*, avaliamos os valores obtidos para alteração de cor $(\Delta \mathrm{E})$, onde: $\Delta \mathrm{E}<1$ considera-se que a alteração de cor não é detectável clinicamente; $3,3>\Delta \mathrm{E}<1$ considera-se que a alteração de cor é clinicamente aceitável; e $\Delta \mathrm{E}>3,3$ considera-se alteração de cor clinicamente inaceitável (INOKOSHI et al., 1996; KIM \& HUM, 1996).

Com relação à alteração total de cor $(\Delta \mathrm{E})$, a cerâmica Noritake Ti22 apresentou resultados semelhantes estatisticamente tanto para as amostras livres de metal quanto para as metalocerâmicas, quando submetidas ao envelhecimento artificial acelerado. Assim, de posse dessa semelhança estatística, pode-se dizer que quando do envelhecimento artificial acelerado a subestrutura em titânio comercialmente puro não influenciou a coloração final dessa cerâmica. 
Já para a cerâmica Triceram foram encontrados resultados estatisticamente diferentes dos anteriores. As amostras metalocerâmicas desse material revelaram alteração de cor estatisticamente maior que as correspondentes livres de metal, quando simulado o uso clínico de dez anos da restauração. Para a Triceram, pode-se dizer que frente ao envelhecimento artificial acelerado, a subestrutura metálica em titânio comercialmente puro interferiu na coloração da restauração.

Recentemente, Lakatos et. al (2007) desenvolveram um trabalho em que utilizaram essas mesmas cerâmicas, comparando a cor de amostras metalocerâmicas com as correspondentes livres de metal. Os autores não encontraram diferença estatística entre os grupos, diferentemente do que ocorreu no presente trabalho. Assim, uma das justificativas para a diferença estatística das alterações de cor encontradas no presente trabalho seria justificá-la pela ação do envelhecimento artificial acelerado.

Uma possível explicação para as diferenças observadas é a possibilidade de que alguns elementos do metal possam ter reagido com a porcelana opaca adjacente, ao longo da interface cerâmica/metal, influenciando a percepção final da cor da restauração. Ainda, poderia ter ocorrido difusão de óxidos da superfície exposta do metal e subsequentemente para a superfície da cerâmica. Uma terceira possibilidade seria a deposição de vapor, onde algum elemento químico seria depositado na superfície da cerâmica (TUCCILLO, 1977; AL WAZZAN; AL HUSSAINI, 2007). Contudo, as amostras foram confeccionadas pelo mesmo operador, da mesma maneira e sob as mesmas condições, sendo ainda, submetidas ao envelhecimento artificial da mesma forma. Assim, pode-se dizer que a diferença observada na cor da cerâmica Triceram foi inerente ao material, uma vez a cerâmica Noritake Ti22 não apresentou resultado semelhante.

Sabe-se que óxidos metálicos são constituintes importantíssimos na composição de cerâmicas odontológicas, especialmente sendo responsáveis por conferir 
estética a esse material. Contudo, alguns desses óxidos são facilmente desestruturados quimicamente pela ação da radiação ultravioleta (ERTAN e SAHIN, 2005). Assim, outra possível justificativa para a alteração de cor encontrada nas amostras da cerâmica Triceram seria que seus óxidos metálicos fossem afetados por essa radiação, presente no sistema de envelhecimento artificial acelerado.

Somada à justificativa anterior, outra possível causa da alteração de cor para a cerâmica Triceram seria que o fabricante da cerâmica Noritake Ti22 pede uma etapa de desgaseificação da superfície do titânio comercialmente puro previamente à aplicação do adesivo, para remoção da espessa camada de óxidos; e o fabricante da Triceram não. Contudo, estudos subseqüentes devem ser desenvolvidos a fim de analisar essa interface cerâmica/titânio, buscando maiores explicações que endossem a diferença estatística encontrada.

Entretanto, é importante ressaltar que os valores para $\Delta \mathrm{E}$ encontrados foram, para todos os grupos, menores que 1, podendo-se dizer que as alterações de cor são consideradas indetectáveis clinicamente.

\section{2 Fluorfosfato Acidulado 1,23\% - Rugosidade Superficial e Alteração de Cor}

O uso de soluções fluoretadas na prática odontológica é comum. Tratamentos com aplicação de flúor tópico são indicados para pacientes com alta incidência de cárie (BHASKAR, 1976), xerostomia ou atividade salivar comprometida por irradiação, medicação, síndrome de Sjogren ou cirurgia (DREIZEN et al., 1977), sendo que seu uso diário tem revelado tanto diminuição no índice de cáries, quanto paralisando lesões existentes (DREIZEN, DALY, DRANE; 1997). 
Repetidas aplicações de soluções fluoretadas podem alterar a textura superficial da cerâmica dental, especialmente as soluções de fluorfosfato acidulado que atacam a sílica, que é o maior componente da cerâmica (WOZNIAK et al., 1991). O grau de ataque varia de acordo com o tipo da cerâmica, caracterização ou glaze utilizado (ANUSAVICE, 2003).

Aplicações tópicas de flúor a $1,23 \%$ têm mostrado afetar tanto superfícies cerâmicas autoglazeadas tanto com glaze extrínseco, sendo contra-indicadas a pacientes que possuem restaurações cerâmicas (COPPS et al., 1984; WUNDERLICH; YAMAN, 1986). Vários estudos científicos relatam que cerâmicas de ultra-baixa fusão apresentam menor susceptibilidade à ação do fluorfosfato acidulado, uma vez que esse tipo de cerâmica contém menor quantidade de cristais de leucita, quando comparada às cerâmicas tradicionais (DERAND; VEREBY, 1999; BUTLER et al., 2004).

No presente estudo, amostras metalocerâmicas e livres de metal foram submetidas à aplicação tópica de fluorfosfato acidulado a 1,23\% pelo período de 13 horas, sendo que a solução era renovada a cada 50 minutos, conforme descrito em Butler et al. (2004). A rugosidade superficial e a cor das amostras foram tomadas antes e após a aplicação, e os valores submetidos à análise estatística.

Antes do armazenamento em fluorfosfato acidulado $1,23 \%$, foi observada semelhança estatística para a rugosidade superficial entre as duas cerâmicas, Triceram e Noritake Ti22, em amostras livres de metal e metalocerâmicas.

Após o armazenamento em fluorfosfato acidulado, a cerâmica Triceram não mostrou diferença estatística entre seus espécimes livres de metal e metalocerâmicos. Contudo, esses valores foram estatisticamente maiores que aqueles obtidos antes da imersão no substrato fluoretado. 
Resultado semelhante foi encontrado para a cerâmica Noritake Ti22, ou seja, suas amostras, livres de metal e metalocerâmicas, apresentaram valores estatisticamente semelhantes de rugosidade superficial depois de submetidas ao armazenamento em fluorfosfato acidulado a 1,23\%. Entretanto, esses valores se mostraram estatisticamente maiores que aqueles obtidos antes da imersão no substrato fluoretado.

A diferença estatística apresentada, revelando que o fluorfosfato acidulado aumentou significantemente a rugosidade superficial das cerâmicas, tanto em amostras livres de metal quanto metalocerâmicas, é justificada por interações químicas, que podem ser visualizadas pela reação abaixo:

$$
12 \mathrm{HF}+3 \mathrm{SiO}_{2} \longrightarrow 2 \mathrm{H}_{2} \mathrm{SiF}_{6}+\mathrm{Si}(\mathrm{OH})_{4}+2 \mathrm{H}_{2} \mathrm{O}
$$

em que a degradação superficial da cerâmica quando da aplicação de fluorfosfato acidulado a 1,23\% ocorre pelo ataque dos íons fluoretos presentes na solução, sobre a sílica que compõe a cerâmica, resultando na formação do fluorsilicato, que é solúvel em água (COPPS, et al., 1984). Assim, a superfície cerâmica se torna irregular, apresentando aumento de rugosidade.

A lisura superficial de restaurações cerâmicas é necessária, uma vez que superfícies rugosas facilitam o acúmulo de placa bacteriana (RIMONDINI et al.; 1997) e podem aumentar sua propriedade de abrasionar o dente antagonista. Além disso, a lisura de superfície previne a descoloração e torna a restauração cerâmica com aparência mais próxima ao natural (JAGGER; HARRISON, 1994).

No desenvolvimento deste trabalho, quanto à alteração de cor, foi observado que ambas as cerâmicas, Triceram e Noritake Ti22, livres de metal e com titânio comercialmente puro como subestrutura, apresentaram o $\Delta \mathrm{L}$ positivo para todas as situações. O $\Delta \mathrm{L}(+)$ mostra que o espécime ficou mais claro, e (-) mostra que o espécime ficou mais escuro. Sendo assim, após o armazenamento em fluorfosfato acidulado, todas as amostras se 
mostraram mais claras que o inicial. Esse fato pode ser explicado por superfície sem brilho, opaca, esbranquiçada obtida após o armazenamento em flúor.

Tanto as amostras livres de metal quanto as metalocerâmicas, para Triceram e Noritake Ti22, apresentaram $\Delta \mathrm{a}$ e $\Delta \mathrm{b}$ negativos quando do armazenamento em fluorfosfato acidulado. $\Delta \mathrm{a}(+)$ e (-) mostram que as amostras ficaram, respectivamente, mais vermelhas e verdes. Já o $\Delta b(+)$ e (-) revelam respectivamente que os corpos-de-prova ficaram mais amarelos e azuis. Dessa forma, todas as amostras se mostraram mais verdes e azuis depois de submetidas ao armazenamento em fluorfosfato acidulado.

Quando considerada alteração total de cor, o grupo da cerâmica Triceram livre de metal apresentou valores estatisticamente menores de $\Delta \mathrm{E}$, quando comparado com os demais. Já os demais grupos, Triceram metalocerâmica, Noritake Ti22 livre de metal e metalocerâmica, apresentaram valores de alteração de cor semelhantes entre si, entretanto maiores que aquele revelado pelo grupo da Triceram livre de metal.

Contudo, todos os grupos analisados exibiram valores de $\Delta \mathrm{E}$ maiores que 3,3 , mostrando valores de alteração de cor inaceitáveis clinicamente. Isso se deve à elevada rugosidade superficial obtida após a imersão das amostras em fluorfosfato acidulado. 
CONCLUSÃO 


\section{CONCLUSÃO}

Considerando os dados obtidos e análises realizadas, dentro dessas condições experimentais é possível concluir que:

- O envelhecimento artificial acelerado simulando dez anos de uso clínico da restauração não afetou a rugosidade superficial de nenhuma das cerâmicas avaliadas, em nenhum grupo;

- Após o envelhecimento artificial acelerado, as amostras das duas cerâmicas estudadas, livres de metal e metalocerâmicas, revelaram $\Delta \mathrm{L}$ negativo, ou seja, todos os grupos apresentaram-se mais escuros que o inicial.

- Apenas o grupo da cerâmica Triceram com subestrutura em titânio comercialmente puro revelou valores de $\Delta \mathrm{E}$ estatisticamente maiores que os demais, revelando que o envelhecimento artificial acelerado influenciou a coloração desse grupo. Entretanto, a alteração de cor apresentou-se menor que um, sendo considerada clinicamente indetectável.

- Após o armazenamento em fluorfosfato acidulado foi observado aumento de rugosidade superficial semelhante estatisticamente para ambas as cerâmicas estudadas, tanto em amostras livres de metal quanto metalocerâmicas.

- Diferentemente do que foi encontrado após o envelhecimento artificial acelerado, as amostras das cerâmicas avaliadas exibiram $\Delta \mathrm{L}$ positivo após armazenamento em fluorfosfato acidulado.

- Quanto à alteração total de cor, após armazenamento em fluorfosfato acidulado, todos os grupos revelaram valores inaceitáveis clinicamente $(\Delta \mathrm{E}>3,3)$. 
REFERÊNCIAS BIBLIOGRÁFICAS 


\section{REFERÊNCIAS BIBLIOGRÁFICAS}

ADELL, R.; LEKHOLM, U.; ROCKLER, B.; BRANEMARK, P. I. A 15-year study of osseointegrated implants in the treatment of edentulous jaw. Int. J. Oral Surg. vol. 10, n. 6, p. 387-416, 1981.

AL HUSSAINI, I.; AL WAZZAN, K.A. Effect of surface treatment on bond strength of lowfusing porcelain to commercially pure titanium. J Prosthet Dent, v. 94, n. 4, p.350-6, 2005.

AL MUTAWA, N. J.; SATO, T.; SHIOZAWA, I.; HASEGAWA, S.; MIURA, H. A study of the bond strength and color of ultralow- fusing porcelain. Int. J. Prosthodont., v.13, p.15965, 2000.

AL WAHADNI, A. An in vitro investigation into the surface roughness of 2 glazed, unglazed, and refinished ceramic materials. Quintessence Int, v. 37, p. 311-7, 2006.

AL WAZZAN K. A., AL HUSSAINI I. S.. The influence of commercially pure titanium and titanium-aluminum-vanadium alloy on the final shade of low-fusing porcelain. J Comtemp Dent Pract; Feb., v. 8, n.2, p. 97-104, 2007.

ANUSAVICE, K. J.; SHEN, C.; HASHINGER, D.; TWIGGS, S. W. Interactive effect of stress and temperature on creep of PMF alloys. J. Dent. Res., v.64; n.8; p.1094-9; 1985.

ANUSAVICE, K. J. Phillips Materiais Dentários. Ed. Elsevier, 2003, $11^{\text {a }}$ ed.

ATSÜ, S.; BERKUN, S. Bond strength of three porcelains to two forms of titanium using two firing atmospheres. J. Prosthet. Dent., v.84, p.567-74, 2000.

BASSMAN, A. H. Baked porcelain fused to gold. Forth. Rev. Chicago Dent. Soc., v. 42, n. 1, p. 11-2, 1961.

BERGMAN, M. Cast titanium in dental constructions: manual DPNOVA AB. Malmo, 26 p., 1995.

BHASKAR, S. N. Patologia bucal. Ed. Artes Médicas, p. 615, 4ª ed, 1976.

BJÖRKNER, B.; BRUZE, M.; MÖLLER, H. High frequency of contact allergy to gold sodium thiosulfate. An indication of gold allergy? Contact Dermatitis., v. 30, n. 3; p. 144-51, 1994.

BOTTINO, M. C.; VALANDRO, L. F.; KANTORSKI, K. Z.; BRESSIANI, J. C.; BOTTINO, M. A. Polishing Methods of na Alumina-Reinforced Feldspar Ceramic. Braz Dent J, v. 17, n. 4, p. 285-9, 2006.

BRECKER, S. C. Porcelain baked to gold - a new medium in prosthodontics. J Prosthet Dent, v. 6, p. 801-10, Nov. 1956. 
BREWER, J. D.; AKERS, C. K.; GARLAPO, D. A. Spectrometric Analysis of the Influence of Metal Substrates on the Color of Metal-Ceramic Restorations. J Dent Res, v. 64, n. 01, p. 74-7, 1985.

BRUZE, M.; EDMAN, B.; BJÖRKNER, B.; MÖLLER, H. Clinical relevance of contact allergy to gold sodium thiosulfate. J Am Acad Dermatol., v. 31; n. 4, p. 579-83, 1994.

BUTLER, C. J.; MASRI, R.; DRISCOLL, C. F.; THOMPSON, G. A.; RRUNYAN, D. A.; VON FRAUNHOFER, J. A. Effect of fluoride and 10\% peroxide on the surface roughness of low-fusing and ultra low-fusing porcelain. J Prosthet Dent, v. 92, p. 179-83, 2004.

CAI, Z.; BUNCE, N.; NUNN, M. E.; OKABE, T. Porcelain adherence to dental cast cp titanium: effects of surface modifications. Biomaterials, v. 22, n.9, p. 979-86, 2001.

CLARK, E. B. Requeriments of the jacket crown. J Am Dent Assoc, v. 26, n. 3, p. 355-63, 1939.

CONTI, E. C. G. Estudo das interfaces titanio/porcelanas, com três porcelanas de ultrabaixa fusão, empregando-as microscopia eletrônica de varredura e dilatometria. Araraquara, 2002. 147p. Dissertaçao (Mestrado em Dentistica Restauradora) - Faculdade de Odontologia, Universidade Estadual Paulista Julio Mesquita Filho.

COPPS, D. P.; LACY, A. M.; CURTIS, T., CARMAN, J. E. Effect of topical fluorides on five low-fusing dental porcelains. J Prosthet Dent, v.52, n.3, sept, 1984.

CRAIG, R. G.; POWERS, J. M. Materiais Dentários Restauradores, 11ª edição. São Paulo: Livraria Santos, 2004.

DEMIREL, F.; YÜKSEL, G.; MUHTAROGULLARI, M.; ÇEKIÇ, C. Effect of Topical Fluoride and Citric Acid on Heat-Pressed All-Ceramic Material. Int J Periodontics Restorative Dent, 25:277-81; 2005.

DERAND, P.; VEREBY, P. Wear of low-fusing dental porcelain. J. Prosthet. Dent., v. 81, p. 460-3, 1999.

DONACHIE, M. J. Cleaning and finishing. In: Titanium: a technical guide. Manchester: ASM International, p. 87-103, 1988.

DREIZEN, S.; BROWN, L.R,; DALY, T.; DRANE, J.B. Prevencion of xerostomia-related dental caries in irradiated cancer patients. J Dent Res, v. 56, p. 99-104, 1977.

ERTAN A. A.; SAHIN E. Colour stability of low fusing porcelains: an in vitro study. J. Oral Rehabili. v. 32, p. 358-61, 2005.

ESQUIVEL, J. F.; CHAI, J.; WOZNIAK, W. T. Color Stability of Low-fusing porcelains for Titanium. Int J Prosthodont, v. 8, p. 479-85, 1995.

FELCHER, F. R. Dental Porcelains. J Am Dent Assoc, v. 19, p. 1021- 26, 1932. 
FRADEANI M. Six-year follow-up with Empress veeners. Int J Periodontics Restorative Dent, v. 18, p. 216-25, 1998.

GEGEL, H. L.; HOCK, M. Alloy processing. In: Titanium Science and Technology. New York: Plenum Press, 1973.

HEYDECKE, G.; ZAHNG, F.; RAZZOG, M. E. In vitro color stability of double-layer veneers after accelerated aging. J. Prosthet. Dent., n. 85, p. 551-7, 2001.

HODSON, J. T. Phase composition for crown and inlay porcelains. J Dent Res, v. 38, p. 48389, 1959.

IDA , K.; TOGAYA, T.; TSUTSUMI, S.; TOGAYA, T. Studies on the dental castings of titanium alloy. Party I. Casting of pure titanium. J. Res. Soc. Dent. Mater. Appl., v. 37, p. 45-52, 1980.

IDA, K.; TOGAYA, T.; TSUTSUMI, S.; TAKEUCHI, M. Effect of magnesia investments in dental casting of pure titanium and titanium alloys. Dent. Mater. J. v. 1, n. 1, p. 8-21, 1982.

INOKOSHI, S.M.; BURROW, M. F.; KATAUMI, M.; YAMADA, T.; TAKATSU, T. Opacity and color changes of tooth-colored restorative materials. Oper Dent, v. 21, p. 73-80, 1996.

JAGGER, D.C.; HARRISON, A. An in vitro investigation into the wear effects of unglazed, glazed, and polished porcelain on human enamel. J Prosthet Dent, v. 72, p. 320-3, 1994.

KASEMO, B. Biocompatibility of titanium implants: surface science aspects. J Prosthet Dent, v. 49, n. 6, p. 832-7, 1983.

KIM, H. S.; UM, C. M. Color differences between resin composites and shade guides. Quintenssence Int, v. 27, p. 559-67, 1996.

KOURTIS, S. G.; TRIPODAKIS, A. P.;DOUKOUDAKIS, A. A. Spectrophotometric evaluation of the optical influence of different metal alloys and porcelains in the metalceramic complex. J Prosthet Dent., v.92, p.477-85, 2004.

KNABE, C.; HOFFMEISTER, B. The use of implant-suported ceramometal titanium prosthesis following sinus lift and augmentarion procedures: a clinical reported. Int. J. Oral Maxilloface Implants. v. 13, n. 1, p. 102-8, Jan-Fev, 1998.

LAKATOS, S.; LAKATOS, C.; ROMINU, M.; FLORITA, Z. Chromatic behavior of porcelain fired on titanium. Quintenssence Int., v. 36, n. 7, 366-73, 2007.

LAND, C. H. Porcelain dental art. The Dental Cosmos, v. 45, n. 6, p.437-44, 1903.

LANG, B.R.; MORRIS, H.F.; RAZZOG, M. International Workshop on Biocompatibility, Toxicity and Hipersensitivity to alloy systems used in Dentistry. University of Michingan Press, p. 45-52, 1985. 
LAUTENSCHLAGER, E. P.; MONAGHAN, P. Titanium and titanium alloys as dental materials. Int. Dent. J., v. 43, p. 245-56, 1993.

LIU, Y.; CHAO, Y.L.; CHEN, X.D.; LI, D.PD.; FU, M.J.; CONG, L. Study on the interface of ti-porcelain fused under different surface treatment. Sichnuan da Xue Bao Yi Xue Ban, v. 36, n.4, p.571-3, 2005 (Abstract).

MC LEAN, J.M. Dental materials developments in the U.K.: a personal view. J Dent Res, v. 75, n. 11, p. 1816-19, 1996.

MENIS, D. L.; MOSER, J. B.; GREENER, E. H. Experimental porcelain compositions for application to cast titanium. J. Dent. Res., v.65, p. 343, 1986.

MEZZOMO, E.; MASSA, F.; SUZUKI, R. M. Fracture resistance of teeth restored with 2 different post-and-core designs fixed with 2 different luting cements: an in vitro study. Part II. Quintenssence Int., v. 37, n. 6, 477-84, 2006.

MEZZOMO, E.; SUZUKI, R. M. Reabilitação Oral Contemporânea. Ed. Santos, 2006, $1^{\mathrm{a}}$ edição.

O’NEIL, S. J.; LEINFELDER, K. F.; LEMONS, J. E.; JAMISON, H. C. Effect of metal surfacing on the color characteristics of porcelain veneer. Dent Mat., v. 3, n. 3, p. 97-101, 1987.

PEUMANS M.; VAN MEERBEEK B.; LAMBREECHTS P.; VANHERLE G. Porcelain veneers: a review of the literature. J Dent, v. 28, n. 16, p. 163-77, 2000.

PORTO, L.P.R.S. Estudo in vitro da estabilidade de cor e opacidade de cinco sistemas cerâmicos sob influência do envelhecimento artificial acelerado. Ribeirão Preto, 2007, 140f. Tese (Doutorado em Reabilitação Oral) - Faculdade de Odontologia, Universidade de São Paulo.

PRAKKI, A.; CILLI, R.; ARAÚJO, P. A.; NAVARRO, M. F. L.; MONDELLI, J.; MONDELLI, R. F. L. Effect of toothbrushing abrasion on weight and surface roughness of $\mathrm{pH}$-cycled resin cements and indirect restorative materials. Quintessence Int, v. 38, p. 54454, 2007.

RAPTIS, N. V.; MICHALAKIS, K. X.; HIRAYAMA, H. Optical Behavior of Current Ceramic Systems. Int J Periodontics Restorative Dent, v. 26, p. 31-41, 2006.

RAZZOG M. E., LANG B. R.; RUSSELL M. M., MAY K. B. A comparison of the color stability of conventional dental porcelain. J Prosthet Dent, v. 72, p. 453-6, 1994.

REYES, M. J. et al. Titanium porcelain system. Part. III: Effects of surface modification on bond strengths. Biomed Mater Eng, v. 11, n. 2, p.117-36, 2001.

RIMONDINI, L.; FARÈ, S.; BRAMBILLA, E.; FELLONI A.; CONSONNI, C.; BROSSA, F.; CARRASSI, A. The effect of surface roughness on early in vivo plaque colonization on titanium. J Periodontol, v. 68, p.556-62, 1997. 
SARAC, D.; SARAC, Y. S.; YUSBASIOGLU, E.; BAL, S. The effects of porcelain polishing systems on the color and surface texture of feldspathic porcelain. J Prosthet Dent, v. 96, p. 122-8, 2006.

SIMONPAOLI, Y. Le point de vue de clinician. Lês céramo-nickels. Rugosités de surface dês infrastructures métalliques ou mini-epaulements. Actualités Odontostomat., v. 109, p. 27-35, Mar. 1975.

STAVRIDAKIS, M. M.; PAPAZOGLOU, E.; SEGHI, R. R.; JOHNSTON, W. M.; BRANTLEY, W. A. Effect of different high-palladium metal-ceramic alloys on the coloro $f$ opaque and dentin porcelain. J Prosthet Dent, v. 92, p. 170-8, 2004.

TOGAYA, T.; SUZUKI, M.; TSUTSUMI, S.; IDA, K. An application of pure titanium to the metal porcelain system. Dent. Mater., v.2, n.2; p.210-9, 1983.

TUCCILLO, J. J. Composition and functional characteristics of precious metal alloys for dental restorations. In: Valega TM (ed). Alternatives to Gold Alloys in Dentristry. Washington DC: United States Department of Health, p. 62-62, 1977.

ULUDAG, B.; USUMEZ, A.; SAHIN, V.; ESER, K.; ERCOBAN, E. The effect of ceramic thickness and number of firing on the coloro f ceramic systems: An in vitro study. J Prosthet Dent, v. 97, p. 25-31, 2007.

VINES, R.F.; SEMMELMAN, J.O. Densification of Dental Porcelain. J Dent Res, v.36, n.6, p. 950-6, 1957.

YANG, J.; SHANBANG, A.; LILIEN, J.; BLACK, J. Human neutrofill response to shortterm exposure to F-75 cobalt-bases alloy. J Biomed Mater Res, v. 26, p. 1217-30, 1992.

WANG, R. R., BOYLE, A. M. A simple method for inspection of porosity in titanium casting. J Prosthet Dent, v.70, n.3, p. 275-6, 1993.

WHITE, S. N.; CAPUTO, A. A.; GOO, E. Strength of porcelain fused to titanium beams. J Prosthet Dent; v. 75, p. 640-8, 1996.

WOLF, B. H.; WALTER, M. H.; BOENING, K. W.; SCHIMITH, A. E. Marginal quality of titanium high-gold inlays and onlays - a clinical study. Dent. Mater. , v.14, p. 370-4, Sep. 1998.

WOZNIAK, W.T.; NALEWAY, C.A.; GONZALEZ, E., SCHEMEHORN, B.R.; STOOKEY, G.K. Use of an in vitro model to assess the effects of APF gel treatment on staining potencial of dental porcelain. Dent Mater, v. 7, p. 263-7, 1991.

WRIGHT, M. D.; MASRI, R.; DRISCOLL, C. F.; ROMBERG, E.; THOMPSON, G. A.; RUNYAN, D. A. Comparison of three systems for the polishing of an ultra-low fusing dental porcelain. J Prosthet Dent, v. 92, p. 486-90, 2004.

WUNDERLICH, R.C.; YAMAN, P. In vitro effect of topical fluoride on dental porcelain. J Prosthet Dent, v. 55, N. 03, p. 385-8, 1986.

ZINELIS S.; TSETSEKOU, A.; PAPADOPOULOS, T. Thermal expansion and microstructural analysis of experimental meta-ceramic titanium alloys. J Prosthet Dent, v. 90, p. 332-8, 2003. 